\title{
Supplementary Information \\ A systematical study on the influences of linkage length on phase behaviours and charge carrier mobilities of discotic dimers
}

Jianchuang Wang, Chunxiu Zhang*, Shuaifeng Zhang, Xingtian Hao,

Feng Hong, Ao Zhang, Yi-Fei Wang, Hao Wu, Wanying Zhang and

\section{Jia-Ling Pu}

Information Recording Materials Lab, Lab of Printing \& Packaging Material and Technology, Beijing Institute of Graphic Communication, 102600 Beijing, China .

*Corresponding author. E-mail: zhangchunxiu@bigc.edu.cn 


\section{Table of Contents}

1. Materials and Methods (P. 3)

2. Synthesis and Characterization (p. 4-11)

3. ${ }^{1} \mathrm{H}$ NMR and HRMS spectra (p. 12-34)

4. Mesomorphism (p. 35-41) 


\section{Materials and Methods}

\section{Materials}

All solvents employed were purchased from Aldrich and used without further purification unless stated otherwise. Column and thin layer chromatography were performed on silica gel (200-300 mesh ASTM) and Silica Gel 60 glass backed sheets, respectively.

\section{Methods}

${ }^{1} \mathrm{H}$ NMR spectra were measured in $\mathrm{CDCl}_{3}$ on Bruker NMR spectrometers (DMX 300 $\mathrm{MHz}$ ), chemical shifts are given in parts per million $(\delta)$ and are referenced from tetramethylsilane (TMS). Multiplicities of the peaks are given as $\mathrm{s}=$ singlet, $\mathrm{d}=$ doublet, $\mathrm{t}$ $=$ triplet and $\mathrm{m}=$ multiplet. Fourier transform infrared spectroscopy was carried out on a Shimadzu FTIR-8400 spectrometer using $\mathrm{KBr}$ pellets. High resolution mass spectrum was recorded on a Bruker Apex IV FTMS mass spectrometer. Elemental analysis (C, H) was performed on Elementar Vario EL CUBE elements analyser. Polarising optical microscopy was carried out on a lecia DM4500P microscope equipped with a linkam TMS94 hot stage. Differential scanning calorimetry was carried out on a Netzsch DSC 200. X-ray diffraction studies were conducted on a Bruker D8 advance diffractometer equipped with a variable temperature controller. All of the measurements were carried out

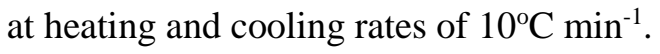

Compounds 1-3 and 5-7 were prepared according to literature procedures and characterised by ${ }^{1} \mathrm{H}$ NMR and FT-IR; compounds T3D3-T3D12 and T5D3-T5D12 were synthesised from 3 and appropriate $\alpha, \omega$-dibromoalkane according to our previous work dimers of HAT4.

Charge mobility was measured using a time-of-flight (TOF) devices. The LC cells with a thickness of $15 \mu \mathrm{m}$ were purchased from E.H.C. company with semi-transparent indium tin oxide (ITO) electrodes. The purified compounds were capillary-filled into the cell at the temperature $10^{\circ} \mathrm{C}$ higher than their clear point, and then slowly cooled to their mesophases at a rate of $0.1^{\circ} \mathrm{Cmin}^{-1}$ in order to obtain a well defined homeotropic alignment. The cell was placed on the hotstage and illuminated by light pulses from a $\mathrm{N}_{2}$ laser (USHO KEC 160, wavelength $337 \mathrm{~nm}$, and the pulse width is $600 \mathrm{ps}$ ). The transient photocurrent across the cell was amplified by using a NF low-noise current preamplifier (model 5307) and monitored using a digital phosphor oscilloscope (Tektronix TDS 3032c). The bias voltage was applied to the sample with a power supply unit (Kikusui PAN110-3A). Measurements were carried out under atmospheric conditions.

The products were purified by flash chromatography and recrystallised from ethanol and dichloromethane. 


\section{Synthesis and characterization}

(a)
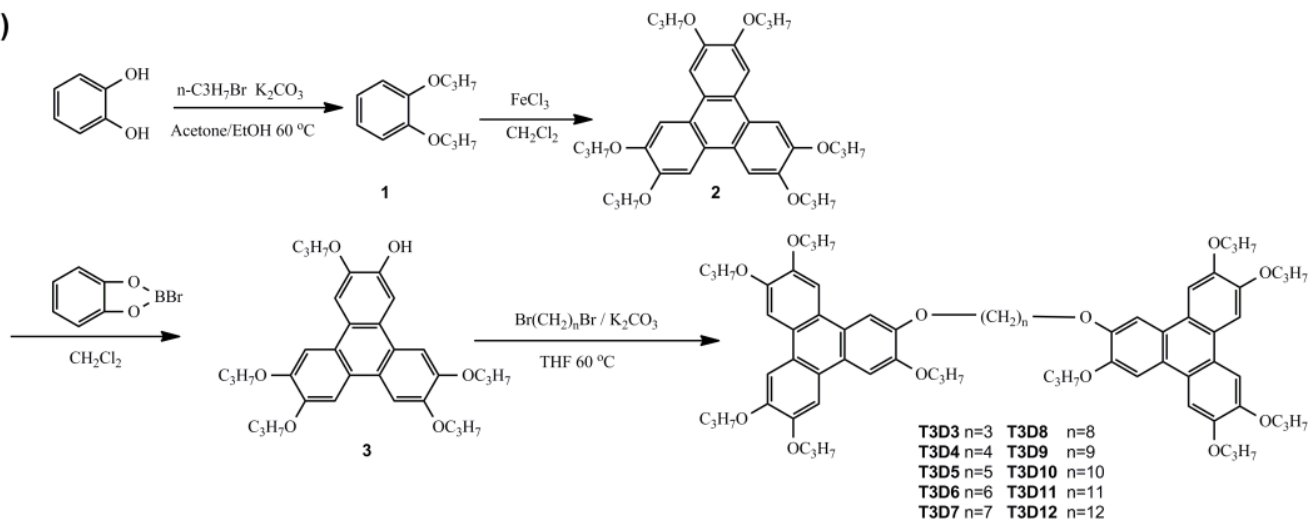

(b)

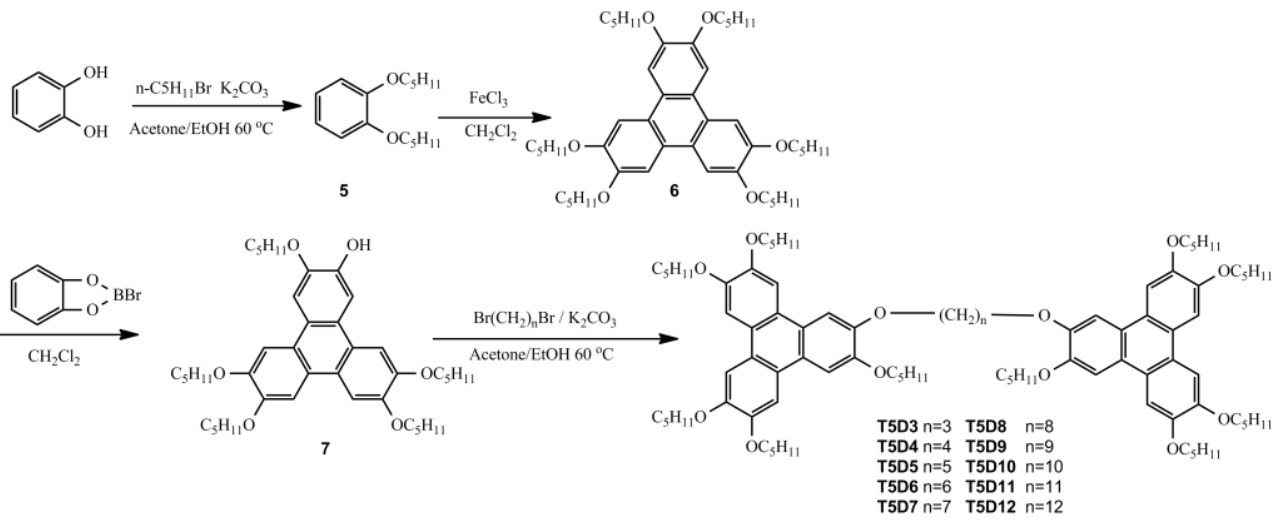

Scheme. 1s Syntheses of triphenylene dimers T3D3-T3D12 (a) and T5D3-T5D12 (b)

\section{1, 2-dipropoxybenzene (1)}

1-Bromoproane $(184.3 \mathrm{~g}, 1.5 \mathrm{~mol})$ was added to a vigorously stirred solution of catechol (44 $\mathrm{g}, 0.4 \mathrm{~mol})$ and potassium carbonate $(220.9 \mathrm{~g})$ in ethanol $(600 \mathrm{ml})$ under nitrogen. The reaction mixture was stirred under reflux for $24 \mathrm{~h}$ and filtered with copious washings of ethanol. The filtrate was concentrated in vacuo and subjected to a silica gel column chromatography on silica, eluting with 1:1 dichloromethane: light petroleum to give the product as pale yellow oil. (50 g, $95 \%$ ); TLC Rf: 0.6 (dichloromethane-hexane 1:1); IR (KBr): $\nu_{\max } / \mathrm{cm}^{-1} 1257$ (C-O-C); $\delta_{\mathrm{H}}\left(300 \mathrm{MHZ}, \mathrm{CDCl}_{3}\right) 6.90(4 \mathrm{H}, \mathrm{s}, \mathrm{ArH}), 4.0\left(4 \mathrm{H}, \mathrm{t}, \mathrm{OCH}_{2}\right), 1.91\left(4 \mathrm{H}, \mathrm{m}, \mathrm{OCH}_{2} \mathrm{CH}_{2}\right), 1.05(\mathrm{t}$, $\left.6 \mathrm{H}, \mathrm{CH}_{3}\right)$.

\section{2, 3, 6, 7, 10, 11-hexapropoxytriphenylene (2)}

Compound 1 (15g, 0.077mol) was added to a vigorously stirred suspension of Iron(III) chloride $(37.6 \mathrm{~g}, 0.232 \mathrm{~mol})$ in dichloromethane $(100 \mathrm{ml})$. The reaction occurred with vigorous evolution of gas and was quenched with methanol $(150 \mathrm{ml})$ after $70 \mathrm{~min}$. The reaction mixture was filtered and the filtrate concentrated in vacuo to give a pale yellow powder which was subjected to a silica gel column chromatography, eluting with 1: 1 dichloromethane: light petroleum to give 2 as pale yellow powder which was recrystallized from ethanol. (11.6g, 77\%); TLC Rf: 0.44 (ethyl acetate - hexane 1:6); IR (KBr): $v_{\max } / \mathrm{cm}^{-1} 1263$ (C-O-C); $\delta_{\mathrm{H}}$ (300MHZ, $\left.\mathrm{CDCl}_{3}\right) 7.85(6 \mathrm{H}, \mathrm{s}, \mathrm{ArH}), 4.22\left(12 \mathrm{H}, \mathrm{t}, \mathrm{OCH}_{2}\right), 2.0\left(12 \mathrm{H}, \mathrm{m}, \mathrm{OCH}_{2} \mathrm{CH}_{2}\right), 1.2$ $\left(18 \mathrm{H}, \mathrm{t}, \mathrm{CH}_{3}\right)$. 


\section{2-hydroxy -3, 6, 7, 10, 11-Pentapropoxytriphenylene (3)}

To a cooled suspension of catechol $(11 \mathrm{~g}, 0.1 \mathrm{~mol})$ in $\mathrm{CH}_{2} \mathrm{Cl}_{2}(50 \mathrm{~mL})$, a solution $\left(0{ }^{\circ} \mathrm{C}\right)$ of $\mathrm{BBr}_{3}(28.6 \mathrm{~g}, 0.11 \mathrm{~mol})$ in $\mathrm{CH}_{2} \mathrm{Cl}_{2}(10 \mathrm{ml})$ was added slowly with stirring $3 \mathrm{~h}$ under nitrogen. The mixture was brought to room temperature, the solvent removed and the product distilled under vacuum to give B-Bromocatecholboronane as white solid $(16 \mathrm{~g}, 80 \%)$. The solid was then used to make a $0.5 \mathrm{M}$ solution by mixing with $\mathrm{CH}_{2} \mathrm{Cl}_{2}(160 \mathrm{ml})$ and this was used for next ether cleavage reactions. A solution of $2(26.6 \mathrm{~g}, 0.0462 \mathrm{~mol})$ was dissolved in anhydrous $\mathrm{CH}_{2} \mathrm{Cl}_{2}(200 \mathrm{ml})$ and cooled to $0^{\circ} \mathrm{C}$. To this was added $(110.8 \mathrm{ml}, 0.055 \mathrm{~mol})$ of B-Bromocatecholboronane solution in $\mathrm{CH}_{2} \mathrm{Cl}_{2}$ under argon and the mixture was stirred at room temperature for $24 \mathrm{~h}$. After that it was poured over ice-water and extracted with $\mathrm{CH}_{2} \mathrm{Cl}_{2}$, the combined extract was dried with anhydrous $\mathrm{Na}_{2} \mathrm{SO}_{4}$ overnight, solvent was removed under vacuum and the crude product was purified by a silica gel column chromatography, eluting with 1: 30 ethyl acetate: light petroleum to give $\mathbf{3}$ as white powder which was recrystallized from ethanol. (7g, 33\%); TLC Rf: 0.22 (ethyl acetate- hexane 1:6); IR (KBr): $v_{\max } / \mathrm{cm}^{-1} 3483(\mathrm{O}-\mathrm{H}), 1261(\mathrm{C}-\mathrm{O}-\mathrm{C}) ; \delta_{\mathrm{H}}\left(300 \mathrm{MHZ}, \mathrm{CDCl}_{3}\right) 7.9(6 \mathrm{H}, \mathrm{m}, \mathrm{ArH}), 5.9(1 \mathrm{H}, \mathrm{s}, \mathrm{OH})$ $4.20\left(10 \mathrm{H}, \mathrm{t}, \mathrm{OCH}_{2}\right), 1.8\left(10 \mathrm{H}, \mathrm{m}, \mathrm{OCH}_{2} \mathrm{CH}_{2}\right), 1.0\left(10 \mathrm{H}, \mathrm{t}, \mathrm{CH}_{3}\right)$.

\section{1, 2-dipentyloxybenzene (5)}

1-Bromopentane $(181.2 \mathrm{~g}, 1.2 \mathrm{~mol})$ was added to a vigorously stirred solution of catechol (44 $\mathrm{g}, 0.4 \mathrm{~mol})$ and potassium carbonate $(110 \mathrm{~g})$ in ethanol $(600 \mathrm{ml})$ under nitrogen. The reaction mixture was stirred under reflux for $24 \mathrm{~h}$ and filtered with copious washings of ethanol. The filtrate was concentrated in vacuo and subjected to a silica gel column chromatography on silica, eluting with 1:1 dichloromethane: light petroleum to give the product as pale yellow oil. (96 g, $96 \%$ ); TLC Rf: 0.55 (dichloromethane-hexane 1:1); IR (KBr): $v_{\max } / \mathrm{cm}^{-1} 1263$ (C-O-C); $\delta \mathrm{H}\left(300 \mathrm{MHZ}, \mathrm{CDCl}_{3}\right) 6.90(4 \mathrm{H}, \mathrm{s}, \mathrm{ArH}), 4.0\left(4 \mathrm{H}, \mathrm{t}, \mathrm{OCH}_{2}\right), 1.80-1.87\left(4 \mathrm{H}, \mathrm{m}, \mathrm{OCH}_{2} \mathrm{CH}_{2}\right)$, 1.38-1.50 (8H, m, $\left.\mathrm{OCH}_{2} \mathrm{CH}_{2} \mathrm{CH}_{2} \mathrm{CH}_{2}\right), 0.97$ (t, 6H, $\left.\mathrm{CH}_{3}\right)$.

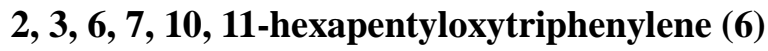

Compound 5 (15g, 0.06mol) was added to a vigorously stirred suspension of Iron(III) chloride $(31.1 \mathrm{~g}, 0.232 \mathrm{~mol})$ in dichloromethane $(100 \mathrm{ml})$. The reaction occurred with vigorous evolution of gas and was quenched with methanol $(150 \mathrm{ml})$ after $70 \mathrm{~min}$. The reaction mixture was filtered and the filtrate concentrated in vacuo to give a pale yellow powder which was subjected to a silica gel column chromatography, eluting with 1: 1 dichloromethane: light petroleum to give 6 as pale yellow powder which was recrystallized from ethanol. (11.6g, 77\%); TLC Rf: 0.44 (ethyl acetate - hexane 1:6); IR (KBr): $v_{\max } / \mathrm{cm}^{-1} 1253$ (C-O-C); $\delta_{\mathrm{H}}$ (300MHZ, $\left.\mathrm{CDCl}_{3}\right) 7.85(6 \mathrm{H}, \mathrm{s}, \mathrm{ArH}), 4.25\left(12 \mathrm{H}, \mathrm{t}, \mathrm{OCH}_{2}\right), 1.92-1.99\left(12 \mathrm{H}, \mathrm{m}, \mathrm{OCH}_{2} \mathrm{CH}_{2}\right)$, $2.0\left(12 \mathrm{H}, \mathrm{m}, \mathrm{OCH}_{2} \mathrm{CH}_{2}\right), 1.42-1.67\left(24 \mathrm{H}, \mathrm{m}, \mathrm{OCH}_{2} \mathrm{CH}_{2} \mathrm{CH}_{2} \mathrm{CH}_{2}\right), 0.99\left(18 \mathrm{H}, \mathrm{t}, \mathrm{CH}_{3}\right)$.

\section{2-hydroxy -3, 6, 7, 10, 11-Pentapentyloxytriphenylene (7)}

To a cooled suspension of catechol $(11 \mathrm{~g}, 0.15 \mathrm{~mol})$ in $\mathrm{CH}_{2} \mathrm{Cl}_{2}(50 \mathrm{~mL})$, a solution $\left(0{ }^{\circ} \mathrm{C}\right)$ of $\mathrm{BBr}_{3}(28.6 \mathrm{~g}, 0.11 \mathrm{~mol})$ in $\mathrm{CH}_{2} \mathrm{Cl}_{2}(10 \mathrm{ml})$ was added slowly with stirring $3 \mathrm{~h}$ under nitrogen. The mixture was brought to room temperature, the solvent removed and the product distilled under vacuum to give B-Bromocatecholboronane as white solid $(16 \mathrm{~g}, 80 \%)$. The solid was then used to make a $0.5 \mathrm{M}$ solution by mixing with $\mathrm{CH}_{2} \mathrm{Cl}_{2}(160 \mathrm{ml})$ and this was used for next ether cleavage reactions. A solution of $6(14.88 \mathrm{~g}, 0.0462 \mathrm{~mol})$ was dissolved in anhydrous $\mathrm{CH}_{2} \mathrm{Cl}_{2}(200 \mathrm{ml})$ and cooled to $0^{\circ} \mathrm{C}$. To this was added $(48 \mathrm{ml}, 0.024 \mathrm{~mol})$ of B-Bromocatecholboronane solution in $\mathrm{CH}_{2} \mathrm{Cl}_{2}$ under argon and the mixture was stirred at 
room temperature for $24 \mathrm{~h}$. After that it was poured over ice-water and extracted with $\mathrm{CH}_{2} \mathrm{Cl}_{2}$, the combined extract was dried with anhydrous $\mathrm{Na}_{2} \mathrm{SO}_{4}$ overnight, solvent was removed under vacuum and the crude product was purified by a silica gel column chromatography, eluting with 1: 30 ethyl acetate: light petroleum to give 7 as white powder which was recrystallized from ethanol. (6.2g, 46\%); TLC Rf: 0.22 (ethyl acetate- hexane 1:6); IR (KBr): $v_{\max } / \mathrm{cm}^{-1} 3456(\mathrm{O}-\mathrm{H}), 1255(\mathrm{C}-\mathrm{O}-\mathrm{C}) ; \delta_{\mathrm{H}}\left(300 \mathrm{MHZ}, \mathrm{CDCl}_{3}\right)$ 7.96-7.77 $(6 \mathrm{H}, \mathrm{m}, \mathrm{ArH}), 5.9(1 \mathrm{H}$, $\mathrm{s}, \mathrm{OH})$ 4.31-4.19 (10H, t, OCH$), 1.97-1.90\left(10 \mathrm{H}, \mathrm{m}, \mathrm{OCH}_{2} \mathrm{CH}_{2}\right), 1.58-1.39(20 \mathrm{H}, \mathrm{m}$, $\left.\mathrm{OCH}_{2} \mathrm{CH}_{2} \mathrm{CH}_{2} \mathrm{CH}_{2}\right), 1.0\left(10 \mathrm{H}, \mathrm{t}, \mathrm{CH}_{3}\right)$.

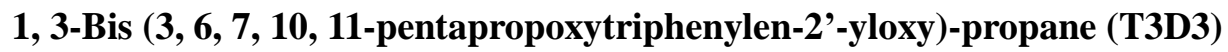

A mixture of 2-hydroxy-3, 6, 7, 10, 11-pentapropoxytriphenylene (500mg), 1,3-dibromoalkane (0.4 eq.) and anhydrous potassium carbonate $(1.0 \mathrm{~g})$ in THF (50ml) was heated under reflux for $72 \mathrm{~h}$. The mixture was cooled to room temperature, filtered, washed with dichloromethane. The solvent was removed in vacuo, and the residue was purified by column chromatography on silica eluting with dichloromethane and finally recrystallized from a mixture of ethanol and dichloromethane to give pure T3D3 $(0.19 \mathrm{~g}, 46 \%)$ : TLC Rf: 0.46 (dichloromethane-ethyl acetate 120:1); (found: $\mathrm{C} 74.4 ; \mathrm{H}$ 7.98. $\mathrm{C}_{69} \mathrm{H}_{88} \mathrm{O}_{12}$ requires: $\mathrm{C}$, 74.7; H, 7.99\%); IR (KBr): $v_{\max } / \mathrm{cm}^{-1} 1261(\mathrm{C}-\mathrm{O}-\mathrm{C}) ; \delta_{\mathrm{H}}\left(300 \mathrm{MHz}, \mathrm{CDCl}_{3}\right) 7.81-7.95(12 \mathrm{H}, \mathrm{s}$, $\mathrm{ArH}), 4.58\left(4 \mathrm{H}, \mathrm{t}, \mathrm{OCH}_{2}\right), 4.10-4.21\left(20 \mathrm{H}, \mathrm{t}, \mathrm{OCH}_{2}\right), 2.56\left(2 \mathrm{H}, \mathrm{m}, \mathrm{OCH}_{2} \mathrm{CH}_{2}\right), 1.84-1.98$ $\left(20 \mathrm{H}, \mathrm{m}, \mathrm{OCH}_{2} \mathrm{CH}_{2}\right), 1.10-1.20\left(30 \mathrm{H}, \mathrm{m}, \mathrm{CH}_{3}\right) ; \mathrm{HRMS}$ (ESI): calc. $\mathrm{m} / \mathrm{z} 1108.62703$ $\left(\mathrm{C}_{69} \mathrm{H}_{88} \mathrm{O}_{12}\right)$, found $\mathrm{m} / \mathrm{z} 1108.62915(\mathrm{M})^{+}$

\section{1, 4-Bis $(3,6,7,10,11$-pentapropoxytriphenylen-2'-yloxy)-butane (T3D4)}

A mixture of 2-hydroxy-3, 6, 7, 10, 11-pentapropoxytriphenylene (500mg), 1,4-dibromoalkane ( 0.4 eq.) and anhydrous potassium carbonate $(1.0 \mathrm{~g})$ in THF $(50 \mathrm{ml})$ was heated under reflux for $72 \mathrm{~h}$. The mixture was cooled to room temperature, filtered, washed with dichloromethane. The solvent was removed in vacuo, and the residue was purified by column chromatography on silica eluting with dichloromethane and finally recrystallized from a mixture of ethanol and dichloromethane to give pure T3D4 $(0.21 \mathrm{~g}, 50 \%)$ : TLC Rf: 0.49 (dichloromethane-ethyl acetate 120:1); (found: $\mathrm{C}, 74.24 ; \mathrm{H}, 8.08 . \mathrm{C}_{70} \mathrm{H}_{90} \mathrm{O}_{12}$ requires: $\mathrm{C}$, 74.84; H, 8.07\%); IR (KBr): $v_{\max } / \mathrm{cm}^{-1} 1263(\mathrm{C}-\mathrm{O}-\mathrm{C}) ; \delta_{\mathrm{H}}\left(300 \mathrm{MHz}, \mathrm{CDCl}_{3}\right) 7.81-7.89(12 \mathrm{H}$, $\mathrm{s}, \mathrm{ArH}), 4.41\left(4 \mathrm{H}, \mathrm{t}, \mathrm{OCH}_{2}\right), 4.15-4.21\left(20 \mathrm{H}, \mathrm{t}, \mathrm{OCH}_{2}\right), 2.26\left(4 \mathrm{H}, \mathrm{m}, \mathrm{OCH}_{2} \mathrm{CH}_{2}\right), 1.89-1.99$ $\left(2 \mathrm{H}, \mathrm{m}, \mathrm{OCH}_{2} \mathrm{CH}_{2}\right), 1.10-1.20\left(30 \mathrm{H}, \mathrm{m}, \mathrm{CH}_{3}\right) ; \mathrm{HRMS}$ (ESI): calc. $\mathrm{m} / \mathrm{z} 1122.64268$ $\left(\mathrm{C}_{70} \mathrm{H}_{90} \mathrm{O}_{12}\right)$, found $\mathrm{m} / \mathrm{z} 1122.64595(\mathrm{M})^{+}$

\section{1, 5-Bis $(3,6,7,10,11$-pentapropoxytriphenylen-2'-yloxy)-pentane (T3D5)}

A mixture of 2-hydroxy-3, 6, 7, 10, 11-pentapropoxytriphenylene (500mg), 1,5-dibromoalkane (0.4 eq.) and anhydrous potassium carbonate $(1.0 \mathrm{~g})$ in THF (50ml) was heated under reflux for $72 \mathrm{~h}$. The mixture was cooled to room temperature, filtered, washed with dichloromethane. The solvent was removed in vacuo, and the residue was purified by column chromatography on silica eluting with dichloromethane and finally recrystallized from a mixture of ethanol and dichloromethane to give pure T3D5 (0.2 g, 47\%): TLC Rf: 0.49 (dichloromethane-ethyl acetate 120:1); (found: $\mathrm{C}, 74.68 ; \mathrm{H}, 8.18 . \mathrm{C}_{71} \mathrm{H}_{92} \mathrm{O}_{12}$ requires: $\mathrm{C}$, 74.97; H, 8.15\%); IR (KBr): $v_{\max } / \mathrm{cm}^{-1} 1260(\mathrm{C}-\mathrm{O}-\mathrm{C}) ; \delta_{\mathrm{H}}\left(300 \mathrm{MHz}, \mathrm{CDCl}_{3}\right) 7.84-7.86(12 \mathrm{H}$, $\mathrm{s}, \mathrm{ArH}), 4.29-4.33\left(4 \mathrm{H}, \mathrm{t}, \mathrm{OCH}_{2}\right), 4.18-4.22\left(20 \mathrm{H}, \mathrm{t}, \mathrm{OCH}_{2}\right), 2.14-2.09\left(4 \mathrm{H}, \mathrm{m}, \mathrm{OCH}_{2} \mathrm{CH}_{2}\right)$, 1.92-2.01 (22H, m, $\left.\mathrm{OCH}_{2} \mathrm{CH}_{2}\right), 1.11-1.17\left(30 \mathrm{H}, \mathrm{m}, \mathrm{CH}_{3}\right) ; \mathrm{HRMS}$ (ESI): calc. $\mathrm{m} / \mathrm{z}$ $1136.65833\left(\mathrm{C}_{71} \mathrm{H}_{92} \mathrm{O}_{12}\right)$, found $\mathrm{m} / \mathrm{z} 1136.65912(\mathrm{M})^{+}$ 


\section{1, 6-Bis $(3,6,7,10,11$-pentapropoxytriphenylen-2'-yloxy)-hexane (T3D6)}

A mixture of 2-hydroxy-3, 6, 7, 10, 11-pentapropoxytriphenylene (500mg), 1,6-dibromoalkane (0.4 eq.) and anhydrous potassium carbonate $(1.0 \mathrm{~g})$ in THF (50ml) was heated under reflux for $72 \mathrm{~h}$. The mixture was cooled to room temperature, filtered, washed with dichloromethane. The solvent was removed in vacuo, and the residue was purified by column chromatography on silica eluting with dichloromethane and finally recrystallized from a mixture of ethanol and dichloromethane to give pure T3D6 $(0.19 \mathrm{~g}, 44 \%)$ : TLC Rf: 0.5 (dichloromethane-ethyl acetate 120:1); (found: $\mathrm{C}, 74.85 ; \mathrm{H}, 8.24 . \mathrm{C}_{72} \mathrm{H}_{94} \mathrm{O}_{12}$ requires: C, $75.10 ; \mathrm{H}, 8.23 \%)$; IR $(\mathrm{KBr}): v_{\max } / \mathrm{cm}^{-1} 1260(\mathrm{C}-\mathrm{O}-\mathrm{C}) ; \delta_{\mathrm{H}}\left(300 \mathrm{MHz}, \mathrm{CDCl}_{3}\right) 7.83-7.84(12 \mathrm{H}$, $\mathrm{s}, \mathrm{ArH}), 4.18-4.30\left(24 \mathrm{H}, \mathrm{t}, \mathrm{OCH}_{2}\right), 1.92-2.01\left(24 \mathrm{H}, \mathrm{m}, \mathrm{OCH}_{2} \mathrm{CH}_{2}\right), 1.74(4 \mathrm{H}, \mathrm{m}$, $\left.\mathrm{OCH}_{2} \mathrm{CH}_{2} \mathrm{CH}_{2}\right), 1.03-1.17$ (30H, m, $\left.\mathrm{CH}_{3}\right)$; HRMS (ESI): calc. m/z $1150.67398\left(\mathrm{C}_{72} \mathrm{H}_{94} \mathrm{O}_{12}\right)$, found $\mathrm{m} / \mathrm{z} 1150.67558(\mathrm{M})^{+}$

\section{1, 7-Bis $(3,6,7,10,11$-pentapropoxytriphenylen-2'-yloxy)-heptane (T3D7)}

A mixture of 2-hydroxy-3, 6, 7, 10, 11-pentapropoxytriphenylene (500mg), 1,7-dibromoalkane (0.4 eq.) and anhydrous potassium carbonate $(1.0 \mathrm{~g})$ in THF (50ml) was heated under reflux for $72 \mathrm{~h}$. The mixture was cooled to room temperature, filtered, washed with dichloromethane. The solvent was removed in vacuo, and the residue was purified by column chromatography on silica eluting with dichloromethane and finally recrystallized from a mixture of ethanol and dichloromethane to give pure T3D7 (0.2 g, 46\%): TLC Rf: 0.49 (dichloromethane-ethyl acetate 120:1); (found: $\mathrm{C}, 72.88 ; \mathrm{H}, 8.15 . \mathrm{C}_{73} \mathrm{H}_{96} \mathrm{O}_{12}$ requires: $\mathrm{C}$, 75.23; H, 8.30\%); IR (KBr): $v_{\max } / \mathrm{cm}^{-1} 1262(\mathrm{C}-\mathrm{O}-\mathrm{C}) ; \delta_{\mathrm{H}}\left(300 \mathrm{MHz}, \mathrm{CDCl}_{3}\right) 7.84(12 \mathrm{H}, \mathrm{s}$, $\mathrm{ArH}), 4.18-4.28\left(24 \mathrm{H}, \mathrm{t}, \mathrm{OCH}_{2}\right), 1.94-2.01\left(24 \mathrm{H}, \mathrm{m}, \mathrm{OCH}_{2} \mathrm{CH}_{2}\right), 1.67\left(6 \mathrm{H}, \mathrm{m}, \mathrm{OCH}_{2} \mathrm{CH}_{2}\right)$, $1.12-1.17\left(30 \mathrm{H}, \mathrm{m}, \mathrm{CH}_{3}\right)$; HRMS (ESI): calc. $\mathrm{m} / \mathrm{z} 1164.68963\left(\mathrm{C}_{73} \mathrm{H}_{96} \mathrm{O}_{12}\right)$, found $\mathrm{m} / \mathrm{z}$ $1164.69227(\mathrm{M})^{+}$

\section{1, 8-Bis $(3,6,7,10,11$-pentapropoxytriphenylen-2'-yloxy)-octane (T3D8)}

A mixture of 2-hydroxy-3, 6, 7, 10, 11-pentapropoxytriphenylene $(500 \mathrm{mg}), 1$, 8-dibromoalkane ( 0.4 eq.) and anhydrous potassium carbonate $(1.0 \mathrm{~g})$ in THF (50ml) was heated under reflux for $72 \mathrm{~h}$. The mixture was cooled to room temperature, filtered, washed with dichloromethane. The solvent was removed in vacuo, and the residue was purified by column chromatography on silica eluting with dichloromethane and finally recrystallized from a mixture of ethanol and dichloromethane to give pure T3D8 $(0.23 \mathrm{~g}, 52 \%)$ : TLC Rf: 0.51 (dichloromethane-ethyl acetate 120:1); (found: $\mathrm{C}, 74.75 ; \mathrm{H}, 8.38 . \mathrm{C}_{74} \mathrm{H}_{98} \mathrm{O}_{12}$ requires: $\mathrm{C}$, 75.35; H, 8.37\%); IR (KBr): $v_{\max } / \mathrm{cm}^{-1} 1262(\mathrm{C}-\mathrm{O}-\mathrm{C}) ; \delta_{\mathrm{H}}\left(300 \mathrm{MHz}, \mathrm{CDCl}_{3}\right) 7.84(12 \mathrm{H}, \mathrm{s}$, $\mathrm{ArH}), 4.18-4.27\left(24 \mathrm{H}, \mathrm{t}, \mathrm{OCH}_{2}\right), 1.94-2.01\left(24 \mathrm{H}, \mathrm{m}, \mathrm{OCH}_{2} \mathrm{CH}_{2}\right), 1.56-1.63(8 \mathrm{H}, \mathrm{m}$, $\left.\mathrm{OCH}_{2} \mathrm{CH}_{2}\right), 1.12-1.17\left(30 \mathrm{H}, \mathrm{m}, \mathrm{CH}_{3}\right)$; HRMS (ESI): calc. m/z $1178.70528\left(\mathrm{C}_{74} \mathrm{H}_{98} \mathrm{O}_{12}\right)$, found $\mathrm{m} / \mathrm{z} 1178.70843(\mathrm{M})^{+}$

\section{1, 9-Bis (3, 6, 7, 10, 11-pentapropoxytriphenylen-2'-yloxy)-nonane (T3D9)}

A mixture of 2-hydroxy-3, 6, 7, 10, 11-pentapropoxytriphenylene (500mg), 1,9-dibromoalkane ( 0.4 eq.) and anhydrous potassium carbonate $(1.0 \mathrm{~g})$ in THF (50ml) was heated under reflux for $72 \mathrm{~h}$. The mixture was cooled to room temperature, filtered, washed with dichloromethane. The solvent was removed in vacuo, and the residue was purified by column chromatography on silica eluting with dichloromethane and finally recrystallized from a mixture of ethanol and dichloromethane to give pure T3D9 (0.22 g, 49\%): TLC Rf: 0.51 (dichloromethane-ethyl acetate 120:1); (found: $\mathrm{C}, 75.04 ; \mathrm{H}, 8.45 . \mathrm{C}_{75} \mathrm{H}_{100} \mathrm{O}_{12}$ requires: $\mathrm{C}$, 
75.47; H, 8.44\%); IR (KBr): $v_{\max } / \mathrm{cm}^{-1} 1255(\mathrm{C}-\mathrm{O}-\mathrm{C}) ; \delta_{\mathrm{H}}\left(300 \mathrm{MHz}, \mathrm{CDCl}_{3}\right) 7.84(12 \mathrm{H}, \mathrm{s}$, $\mathrm{ArH}), 4.18-4.22\left(24 \mathrm{H}, \mathrm{t}, \mathrm{OCH}_{2}\right), 1.94-2.01\left(24 \mathrm{H}, \mathrm{m}, \mathrm{OCH}_{2} \mathrm{CH}_{2}\right), 1.52-1.55\left(4 \mathrm{H}, \mathrm{m}, \mathrm{OCH}_{2} \mathrm{CH}_{2}\right)$, 1.27 (6H, m, $-\mathrm{OCH}_{2} \mathrm{CH}_{2} \mathrm{CH}_{2} \mathrm{CH}_{2} \mathrm{CH}_{2} \mathrm{CH}_{2}$ ), 1.12-1.17 (30H, m, $\left.\mathrm{CH}_{3}\right) ; \mathrm{HRMS}$ (ESI): calc. m/z $1192.72093\left(\mathrm{C}_{75} \mathrm{H}_{100} \mathrm{O}_{12}\right)$, found $\mathrm{m} / \mathrm{z} 1192.72407(\mathrm{M})^{+}$

\section{1, 10-Bis $(3,6,7,10,11$-pentapropoxytriphenylen-2'-yloxy)-decane (T3D10)}

A mixture of 2-hydroxy-3, 6, 7, 10, 11-pentapropoxytriphenylene (500mg), 1,10-dibromoalkane ( 0.4 eq.) and anhydrous potassium carbonate $(1.0 \mathrm{~g})$ in THF (50ml) was heated under reflux for $72 \mathrm{~h}$. The mixture was cooled to room temperature, filtered, washed with dichloromethane. The solvent was removed in vacuo, and the residue was purified by column chromatography on silica eluting with dichloromethane and finally recrystallized from a mixture of ethanol and dichloromethane to give pure T3D10 $(0.23 \mathrm{~g}, 51 \%)$ : TLC Rf: 0.51 (dichloromethane-ethyl acetate 120:1); (found: $\mathrm{C}, 75.30 ; \mathrm{H}, 8.52 . \mathrm{C}_{76} \mathrm{H}_{102} \mathrm{O}_{12}$ requires: $\mathrm{C}$, 75.59; H, 8.51\%); IR (KBr): $v_{\max } / \mathrm{cm}^{-1} 1263(\mathrm{C}-\mathrm{O}-\mathrm{C}) ; \delta_{\mathrm{H}}\left(300 \mathrm{MHz}, \mathrm{CDCl}_{3}\right) 7.84(12 \mathrm{H}, \mathrm{s}$, $\mathrm{ArH}), 4.18-4.22\left(24 \mathrm{H}, \mathrm{t}, \mathrm{OCH}_{2}\right), 1.94-2.01\left(24 \mathrm{H}, \mathrm{m}, \mathrm{OCH}_{2} \mathrm{CH}_{2}\right), 1.52-1.55\left(4 \mathrm{H}, \mathrm{m}, \mathrm{OCH}_{2} \mathrm{CH}_{2}\right)$, $1.41\left(8 \mathrm{H}, \mathrm{m}, \mathrm{OCH}_{2} \mathrm{CH}_{2}\right), 1.12-1.17\left(30 \mathrm{H}, \mathrm{m}, \mathrm{CH}_{3}\right)$; HRMS (ESI): calc. m/z 1206.73658 $\left(\mathrm{C}_{76} \mathrm{H}_{102} \mathrm{O}_{12}\right)$, found $\mathrm{m} / \mathrm{z} 1206.73896(\mathrm{M})^{+}$

\section{1, 11-Bis $(3,6,7,10,11$-pentapropoxytriphenylen-2'-yloxy)-undecane (T3D11)}

A mixture of 2-hydroxy-3, 6, 7, 10, 11-pentapropoxytriphenylene (500mg), 1,11-dibromoalkane (0.4 eq.) and anhydrous potassium carbonate $(1.0 \mathrm{~g})$ in THF (50ml) was heated under reflux for $72 \mathrm{~h}$. The mixture was cooled to room temperature, filtered, washed with dichloromethane. The solvent was removed in vacuo, and the residue was purified by column chromatography on silica eluting with dichloromethane and finally recrystallized from a mixture of ethanol and dichloromethane to give pure T3D11 $(0.22 \mathrm{~g}, 48 \%)$ : TLC Rf: 0.54 (dichloromethane-ethyl acetate 120:1); (found: $\mathrm{C}, 75.38 ; \mathrm{H}, 8.59 . \mathrm{C}_{77} \mathrm{H}_{104} \mathrm{O}_{12}$ requires: $\mathrm{C}$, 75.70; H, 8.58\%); IR (KBr): $v_{\max } / \mathrm{cm}^{-1} 1257(\mathrm{C}-\mathrm{O}-\mathrm{C}) ; \delta_{\mathrm{H}}\left(300 \mathrm{MHz}, \mathrm{CDCl}_{3}\right) 7.84(12 \mathrm{H}, \mathrm{s}$, $\mathrm{ArH}), 4.18-4.26\left(24 \mathrm{H}, \mathrm{t}, \mathrm{OCH}_{2}\right), 1.94-2.03\left(24 \mathrm{H}, \mathrm{m}, \mathrm{OCH}_{2} \mathrm{CH}_{2}\right), 1.52-1.55\left(4 \mathrm{H}, \mathrm{m}, \mathrm{OCH}_{2} \mathrm{CH}_{2}\right)$, $1.38\left(10 \mathrm{H}, \mathrm{m}, \mathrm{OCH}_{2} \mathrm{CH}_{2}\right), 1.12-1.17\left(30 \mathrm{H}, \mathrm{m}, \mathrm{CH}_{3}\right)$; HRMS (ESI): calc. m/z 1220.75223 $\left(\mathrm{C}_{77} \mathrm{H}_{104} \mathrm{O}_{12}\right)$, found $\mathrm{m} / \mathrm{z} 1220.74980(\mathrm{M})^{+}$

\section{1, 12-Bis (3, 6, 7, 10, 11-pentapropoxytriphenylen-2'-yloxy)-dodeane (T3D12)}

A mixture of 2-hydroxy-3, 6, 7, 10, 11-pentapropoxytriphenylene (500mg), 1,3-dibromoalkane ( 0.4 eq.) and anhydrous potassium carbonate $(1.0 \mathrm{~g})$ in THF (50ml) was heated under reflux for $72 \mathrm{~h}$. The mixture was cooled to room temperature, filtered, washed with dichloromethane. The solvent was removed in vacuo, and the residue was purified by column chromatography on silica eluting with dichloromethane and finally recrystallized from a mixture of ethanol and dichloromethane to give pure T3D12 (0.25 g, 54\%): TLC Rf: 0.56 (dichloromethane-ethyl acetate 120:1); (found: $\mathrm{C}, 75.50 ; \mathrm{H}, 8.61 . \mathrm{C}_{78} \mathrm{H}_{106} \mathrm{O}_{12}$ requires: $\mathrm{C}$, 75.82; H, 8.65\%); IR (KBr): $v_{\max } / \mathrm{cm}^{-1} 1257(\mathrm{C}-\mathrm{O}-\mathrm{C}) ; \delta_{\mathrm{H}}\left(300 \mathrm{MHz}, \mathrm{CDCl}_{3}\right) 7.84(12 \mathrm{H}, \mathrm{s}$, $\mathrm{ArH}), 4.18-4.26\left(24 \mathrm{H}, \mathrm{t}, \mathrm{OCH}_{2}\right), 1.94-2.01\left(24 \mathrm{H}, \mathrm{m}, \mathrm{OCH}_{2} \mathrm{CH}_{2}\right), 1.52-1.55\left(4 \mathrm{H}, \mathrm{m}, \mathrm{OCH}_{2} \mathrm{CH}_{2}\right)$, $1.37\left(12 \mathrm{H}, \mathrm{m}, \mathrm{OCH}_{2} \mathrm{CH}_{2}\right), 1.12-1.17\left(30 \mathrm{H}, \mathrm{m}, \mathrm{CH}_{3}\right) ; \mathrm{HRMS}$ (ESI): calc. m/z 1234.7678 $\left(\mathrm{C}_{78} \mathrm{H}_{106} \mathrm{O}_{12}\right)$, found $\mathrm{m} / \mathrm{z} 1234.76785(\mathrm{M})^{+}$

\section{1, 3-Bis $(3,6,7,10,11$-pentapentyloxytriphenylen-2'-yloxy)-propane (T5D3)}

A mixture of 2-hydroxy-3, 6, 7, 10, 11-pentapentyloxytriphenylene (500mg), 1,3-dibromoalkane ( 0.4 eq.) and anhydrous potassium carbonate $(1.0 \mathrm{~g})$ in acetone $(50 \mathrm{ml})$ was heated under reflux for $72 \mathrm{~h}$. The mixture was cooled to room temperature, filtered, 
washed with dichloromethane. The solvent was removed in vacuo, and the residue was purified by column chromatography on silica eluting with dichloromethane and finally recrystallized from a mixture of ethanol and dichloromethane to give pure T5D3 $(0.19 \mathrm{~g}$, 46\%): TLC Rf: 0.54 (dichloromethane-hexane 4:1); (found: C, 76.86; H, 9.33. $\mathrm{C}_{89} \mathrm{H}_{128} \mathrm{O}_{12}$ requires: $\mathrm{C}, 76.91 ; \mathrm{H}, 9.28 \%)$; IR $(\mathrm{KBr}): v_{\max } / \mathrm{cm}^{-1} 1261(\mathrm{C}-\mathrm{O}-\mathrm{C}) ; \delta_{\mathrm{H}}\left(300 \mathrm{MHz}, \mathrm{CDCl}_{3}\right)$ 7.80-7.97 (12H, s, ArH $), 4.58\left(4 \mathrm{H}, \mathrm{t}, \mathrm{OCH}_{2}\right), 4.10-4.26\left(20 \mathrm{H}, \mathrm{t}, \mathrm{OCH}_{2}\right), 2.56(2 \mathrm{H}, \mathrm{m}$, $\left.\mathrm{OCH}_{2} \mathrm{CH}_{2}\right), 1.78-1.95\left(20 \mathrm{H}, \mathrm{m}, \mathrm{OCH}_{2} \mathrm{CH}_{2}\right), 1.27-1.56\left(40 \mathrm{H}, \mathrm{m}, \mathrm{OCH}_{2} \mathrm{CH}_{2} \mathrm{CH}_{2} \mathrm{CH}_{2}\right)$, 1.10-1.20 (30H, m, $\left.\mathrm{CH}_{3}\right)$; HRMS (ESI): calc. $\mathrm{m} / \mathrm{z} 1388.93894\left(\mathrm{C}_{89} \mathrm{H}_{128} \mathrm{O}_{12}\right)$, found $\mathrm{m} / \mathrm{z}$ $1388.94003(\mathrm{M})^{+}$

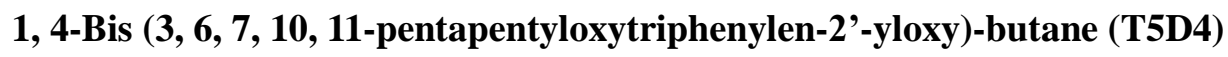

A mixture of 2-hydroxy-3, 6, 7, 10, 11-pentapentyloxytriphenylene (500mg), 1,4-dibromoalkane (0.4 eq.) and anhydrous potassium carbonate $(1.0 \mathrm{~g})$ in acetone $(50 \mathrm{ml})$ was heated under reflux for $72 \mathrm{~h}$. The mixture was cooled to room temperature, filtered, washed with dichloromethane. The solvent was removed in vacuo, and the residue was purified by column chromatography on silica eluting with dichloromethane and finally recrystallized from a mixture of ethanol and dichloromethane to give pure T5D4 $(0.21 \mathrm{~g}$, 50\%): TLC Rf: 0.58 (dichloromethane-hexane 4:1); (found: C, 75.94; H, 9.46. $\mathrm{C}_{90} \mathrm{H}_{130} \mathrm{O}_{12}$ requires: $\mathrm{C}, 76.99 ; \mathrm{H}, 9.33 \%)$; IR $(\mathrm{KBr}): v_{\max } / \mathrm{cm}^{-1} 1261(\mathrm{C}-\mathrm{O}-\mathrm{C}) ; \delta_{\mathrm{H}}\left(300 \mathrm{MHz}, \mathrm{CDCl}_{3}\right)$ 7.81-7.89 (12H, s, ArH $), 4.41\left(4 \mathrm{H}, \mathrm{t}, \mathrm{OCH}_{2}\right), 4.16-4.24\left(20 \mathrm{H}, \mathrm{t}, \mathrm{OCH}_{2}\right), 2.26(2 \mathrm{H}, \mathrm{m}$, $\left.\mathrm{OCH}_{2} \mathrm{CH}_{2}\right), 1.87-1.95\left(20 \mathrm{H}, \mathrm{m}, \mathrm{OCH}_{2} \mathrm{CH}_{2}\right), 1.40-1.56\left(40 \mathrm{H}, \mathrm{m}, \mathrm{OCH}_{2} \mathrm{CH}_{2} \mathrm{CH}_{2} \mathrm{CH}_{2}\right)$, 0.91-1.00 (30H, m, $\left.\mathrm{CH}_{3}\right)$; HRMS (ESI): calc. $\mathrm{m} / \mathrm{z} 1402.95473\left(\mathrm{C}_{90} \mathrm{H}_{130} \mathrm{O}_{12}\right)$, found $\mathrm{m} / \mathrm{z}$ $1402.95568(\mathrm{M})^{+}$

\section{1, 5-Bis (3, 6, 7, 10, 11-pentapentyloxytriphenylen-2'-yloxy)-pentane (T5D5)}

A mixture of 2-hydroxy-3, 6, 7, 10, 11-pentapentyloxytriphenylene (500mg), 1,5-dibromoalkane (0.4 eq.) and anhydrous potassium carbonate $(1.0 \mathrm{~g})$ in acetone $(50 \mathrm{ml})$ was heated under reflux for $72 \mathrm{~h}$. The mixture was cooled to room temperature, filtered, washed with dichloromethane. The solvent was removed in vacuo, and the residue was purified by column chromatography on silica eluting with dichloromethane and finally recrystallized from a mixture of ethanol and dichloromethane to give pure T5D5 $(0.2 \mathrm{~g}, 48 \%)$ : TLC Rf: 0.58 (dichloromethane-hexane 4:1); (found: C, 77.03; H, 9.43. $\mathrm{C}_{91} \mathrm{H}_{132} \mathrm{O}_{12}$ requires: C, 77.08; H, 9.38\%); IR (KBr): $v_{\max } / \mathrm{cm}^{-1} 1261(\mathrm{C}-\mathrm{O}-\mathrm{C}) ; \delta_{\mathrm{H}}\left(300 \mathrm{MHz}, \mathrm{CDCl}_{3}\right) 7.83-7.86$ (12H, s, ArH), 4.22-4.33 (24H, t, $\left.\mathrm{OCH}_{2}\right), 1.88-2.13\left(24 \mathrm{H}, \mathrm{m}, \mathrm{OCH}_{2} \mathrm{CH}_{2}\right), 1.37-1.62(42 \mathrm{H}, \mathrm{m}$, $\left.\mathrm{OCH}_{2} \mathrm{CH}_{2} \mathrm{CH}_{2} \mathrm{CH}_{2}\right), 0.92-1.00\left(30 \mathrm{H}, \mathrm{m}, \mathrm{CH}_{3}\right) ; \mathrm{HRMS}$ (ESI): calc. m/z 1416.97127 $\left(\mathrm{C}_{91} \mathrm{H}_{132} \mathrm{O}_{12}\right)$, found $\mathrm{m} / \mathrm{z} 1416.97133(\mathrm{M})^{+}$

\section{1, 6-Bis (3, 6, 7, 10, 11-pentapentyloxytriphenylen-2'-yloxy)-hexane (T5D6)}

A mixture of 2-hydroxy-3, 6, 7, 10, 11-pentapentyloxytriphenylene (500mg), 1,6-dibromoalkane (0.4 eq.) and anhydrous potassium carbonate $(1.0 \mathrm{~g})$ in acetone $(50 \mathrm{ml})$ was heated under reflux for $72 \mathrm{~h}$. The mixture was cooled to room temperature, filtered, washed with dichloromethane. The solvent was removed in vacuo, and the residue was purified by column chromatography on silica eluting with dichloromethane and finally recrystallized from a mixture of ethanol and dichloromethane to give pure T5D6 $(0.21 \mathrm{~g}$, 49\%): TLC Rf: 0.58 (dichloromethane-hexane 4:1); (found: C, 77.19; H, 9.47. $\mathrm{C}_{92} \mathrm{H}_{134} \mathrm{O}_{12}$ requires: $\mathrm{C}, 77.16 ; \mathrm{H}, 9.43 \%)$; IR $(\mathrm{KBr}): v_{\max } / \mathrm{cm}^{-1} 1263(\mathrm{C}-\mathrm{O}-\mathrm{C}) ; \delta_{\mathrm{H}}\left(300 \mathrm{MHz}, \mathrm{CDCl}_{3}\right)$ 7.82-7.83 (12H, s, ArH), 4.23-4.27 (24H, t, $\left.\mathrm{OCH}_{2}\right), 1.91-1.98\left(24 \mathrm{H}, \mathrm{m}, \mathrm{OCH}_{2} \mathrm{CH}_{2}\right)$, 
1.40-1.74 (44H, m, $\left.\mathrm{OCH}_{2} \mathrm{CH}_{2} \mathrm{CH}_{2} \mathrm{CH}_{2}\right), 0.93-1.00$ (30H, m, $\left.\mathrm{CH}_{3}\right)$; HRMS (ESI): calc. m/z $1430.98653\left(\mathrm{C}_{92} \mathrm{H}_{134} \mathrm{O}_{12}\right)$, found $\mathrm{m} / \mathrm{z} 1430.98698(\mathrm{M})^{+}$

\section{1, 7-Bis (3, 6, 7, 10, 11-pentapentyloxytriphenylen-2'-yloxy)-heptane (T5D7)}

A mixture of 2-hydroxy-3, 6, 7, 10, 11-pentapentyloxytriphenylene (500mg), 1,3-dibromoalkane (0.4 eq.) and anhydrous potassium carbonate $(1.0 \mathrm{~g})$ in acetone $(50 \mathrm{ml})$ was heated under reflux for $72 \mathrm{~h}$. The mixture was cooled to room temperature, filtered, washed with dichloromethane. The solvent was removed in vacuo, and the residue was purified by column chromatography on silica eluting with dichloromethane and finally recrystallized from a mixture of ethanol and dichloromethane to give pure T5D7 $(0.21 \mathrm{~g}$, 49\%): TLC Rf: 0.59 (dichloromethane-hexane 4:1); (found: C, 77.23; H, 9.48. $\mathrm{C}_{93} \mathrm{H}_{136} \mathrm{O}_{12}$ requires: C, 77.24; H, 9.48\%); IR (KBr): $v_{\max } / \mathrm{cm}^{-1} 1263(\mathrm{C}-\mathrm{O}-\mathrm{C}) ; \delta_{\mathrm{H}}\left(300 \mathrm{MHz}, \mathrm{CDCl}_{3}\right) 7.83$ (12H, s, ArH), 4.21-4.25 (24H, t, $\left.\mathrm{OCH}_{2}\right), 1.93-1.98\left(24 \mathrm{H}, \mathrm{m}, \mathrm{OCH}_{2} \mathrm{CH}_{2}\right), 1.44-1.56(46 \mathrm{H}, \mathrm{m}$, $\left.\mathrm{OCH}_{2} \mathrm{CH}_{2} \mathrm{CH}_{2} \mathrm{CH}_{2}\right), 0.93-1.00\left(30 \mathrm{H}, \mathrm{m}, \mathrm{CH}_{3}\right) ; \mathrm{HRMS}$ (ESI): calc. m/z 1445.00501 $\left(\mathrm{C}_{93} \mathrm{H}_{136} \mathrm{O}_{12}\right)$, found $\mathrm{m} / \mathrm{z} 1445.00263(\mathrm{M})^{+}$

\section{1, 8-Bis $(3,6,7,10,11$-pentapentyloxytriphenylen-2'-yloxy)-octane (T5D8)}

A mixture of 2-hydroxy-3, 6, 7, 10, 11-pentapentyloxytriphenylene (500mg), 1,8-dibromoalkane ( 0.4 eq.) and anhydrous potassium carbonate $(1.0 \mathrm{~g})$ in acetone $(50 \mathrm{ml})$ was heated under reflux for $72 \mathrm{~h}$. The mixture was cooled to room temperature, filtered, washed with dichloromethane. The solvent was removed in vacuo, and the residue was purified by column chromatography on silica eluting with dichloromethane and finally recrystallized from a mixture of ethanol and dichloromethane to give pure T5D8 $(0.21 \mathrm{~g}$, 48\%): TLC Rf: 0.59 (dichloromethane-hexane 4:1); (found: C, 77.35; H, 9.54. $\mathrm{C}_{94} \mathrm{H}_{138} \mathrm{O}_{12}$ requires: $\mathrm{C}, 77.32 ; \mathrm{H}, 9.53 \%)$; IR (KBr): $v_{\max } / \mathrm{cm}^{-1} 1263(\mathrm{C}-\mathrm{O}-\mathrm{C}) ; \delta_{\mathrm{H}}\left(300 \mathrm{MHz}, \mathrm{CDCl}_{3}\right) 7.83$ (12H, s, ArH), 4.21-4.26 (24H, t, $\left.\mathrm{OCH}_{2}\right), 1.93-1.98\left(24 \mathrm{H}, \mathrm{m}, \mathrm{OCH}_{2} \mathrm{CH}_{2}\right), 1.44-1.56(48 \mathrm{H}, \mathrm{m}$, $\left.\mathrm{OCH}_{2} \mathrm{CH}_{2} \mathrm{CH}_{2} \mathrm{CH}_{2}\right), \quad 0.93-1.00$ (30H, m, $\left.\mathrm{CH}_{3}\right) ; \mathrm{HRMS}$ (ESI): calc. m/z 1459.01841 $\left(\mathrm{C}_{94} \mathrm{H}_{138} \mathrm{O}_{12}\right)$, found $\mathrm{m} / \mathrm{z} 1459.01828(\mathrm{M})^{+}$

\section{1, 9-Bis (3, 6, 7, 10, 11-pentapentyloxytriphenylen-2'-yloxy)-nonane (T5D9)}

A mixture of 2-hydroxy-3, 6, 7, 10, 11-pentapentyloxytriphenylene (500mg), 1,9-dibromoalkane (0.4 eq.) and anhydrous potassium carbonate $(1.0 \mathrm{~g})$ in acetone $(50 \mathrm{ml})$ was heated under reflux for $72 \mathrm{~h}$. The mixture was cooled to room temperature, filtered, washed with dichloromethane. The solvent was removed in vacuo, and the residue was purified by column chromatography on silica eluting with dichloromethane and finally recrystallized from a mixture of ethanol and dichloromethane to give pure T5D9 $(0.21 \mathrm{~g}$, 47\%): TLC Rf: 0.64 (dichloromethane-hexane 4:1); (found: C, 77.41; $\mathrm{H}, 9.60 . \mathrm{C}_{95} \mathrm{H}_{140} \mathrm{O}_{12}$ requires: C, 77.40; H, 9.57\%); IR (KBr): $v_{\max } / \mathrm{cm}^{-1} 1263(\mathrm{C}-\mathrm{O}-\mathrm{C}) ; \delta_{\mathrm{H}}\left(300 \mathrm{MHz}, \mathrm{CDCl}_{3}\right) 7.83$ (12H, s, ArH), 4.21-4.26 (24H, t, $\left.\mathrm{OCH}_{2}\right), 1.93-1.98\left(24 \mathrm{H}, \mathrm{m}, \mathrm{OCH}_{2} \mathrm{CH}_{2}\right), 1.42-1.56(50 \mathrm{H}, \mathrm{m}$, $\left.\mathrm{OCH}_{2} \mathrm{CH}_{2} \mathrm{CH}_{2} \mathrm{CH}_{2}\right), 0.93-1.00\left(30 \mathrm{H}, \mathrm{m}, \mathrm{CH}_{3}\right) ; \mathrm{HRMS}$ (ESI): calc. $\mathrm{m} / \mathrm{z} 1473.03319$ $\left(\mathrm{C}_{95} \mathrm{H}_{140} \mathrm{O}_{12}\right)$, found $\mathrm{m} / \mathrm{z} 1473.03393(\mathrm{M})^{+}$

\section{1, 10-Bis (3, 6, 7, 10, 11-pentapentyloxytriphenylen-2'-yloxy)-decane (T5D10)}

A mixture of 2-hydroxy-3, 6, 7, 10, 11-pentapentyloxytriphenylene (500mg), 1,10-dibromoalkane ( 0.4 eq.) and anhydrous potassium carbonate $(1.0 \mathrm{~g})$ in acetone $(50 \mathrm{ml})$ was heated under reflux for $72 \mathrm{~h}$. The mixture was cooled to room temperature, filtered, washed with dichloromethane. The solvent was removed in vacuo, and the residue was purified by column chromatography on silica eluting with dichloromethane and finally 
recrystallized from a mixture of ethanol and dichloromethane to give pure T5D10 $(0.2 \mathrm{~g}$, 45\%): TLC Rf: 0.66 (dichloromethane-hexane 4:1); (found: C, 77.42; H, 9.41. $\mathrm{C}_{96} \mathrm{H}_{142} \mathrm{O}_{12}$ requires: C, 77.48; H, 9.62\%); IR (KBr): $v_{\max } / \mathrm{cm}^{-1} 1263(\mathrm{C}-\mathrm{O}-\mathrm{C}) ; \delta_{\mathrm{H}}\left(300 \mathrm{MHz}, \mathrm{CDCl}_{3}\right) 7.83$ $(12 \mathrm{H}, \mathrm{s}, \mathrm{ArH}), 4.21-4.26\left(24 \mathrm{H}, \mathrm{t}, \mathrm{OCH}_{2}\right), 1.91-1.98\left(24 \mathrm{H}, \mathrm{m}, \mathrm{OCH}_{2} \mathrm{CH}_{2}\right), 1.44-1.56(52 \mathrm{H}, \mathrm{m}$, $\left.\mathrm{OCH}_{2} \mathrm{CH}_{2} \mathrm{CH}_{2} \mathrm{CH}_{2}\right), \quad 0.95-1.00$ (30H, m, $\left.\mathrm{CH}_{3}\right) ; \mathrm{HRMS}$ (ESI): calc. m/z 1487.04797 $\left(\mathrm{C}_{96} \mathrm{H}_{142} \mathrm{O}_{12}\right)$, found $\mathrm{m} / \mathrm{z} 1487.04958(\mathrm{M})^{+}$

\section{1, 11-Bis $(3,6,7,10,11$-pentapentyloxytriphenylen-2'-yloxy)-undecane (T5D11)}

A mixture of 2-hydroxy-3, 6, 7, 10, 11-pentapentyloxytriphenylene (500mg), 1,11-dibromoalkane (0.4 eq.) and anhydrous potassium carbonate $(1.0 \mathrm{~g})$ in acetone $(50 \mathrm{ml})$ was heated under reflux for $72 \mathrm{~h}$. The mixture was cooled to room temperature, filtered, washed with dichloromethane. The solvent was removed in vacuo, and the residue was purified by column chromatography on silica eluting with dichloromethane and finally recrystallized from a mixture of ethanol and dichloromethane to give pure T5D11 $(0.21 \mathrm{~g}$, 47\%): TLC Rf: 0.68 (dichloromethane-hexane 4:1); (found: $\mathrm{C}, 77.43 ; \mathrm{H}, 9.63 . \mathrm{C}_{97} \mathrm{H}_{144} \mathrm{O}_{12}$ requires: C, 77.56; $\mathrm{H}, 9.66 \%) ; \mathrm{IR}(\mathrm{KBr}): v_{\max } / \mathrm{cm}^{-1} 1263(\mathrm{C}-\mathrm{O}-\mathrm{C}) ; \delta_{\mathrm{H}}\left(300 \mathrm{MHz}, \mathrm{CDCl}_{3}\right) 7.83(12 \mathrm{H}, \mathrm{s}, \mathrm{ArH})$, 4.21-4.26 $\left(24 \mathrm{H}, \mathrm{t}, \mathrm{OCH}_{2}\right), 1.91-1.98\left(24 \mathrm{H}, \mathrm{m}, \mathrm{OCH}_{2} \mathrm{CH}_{2}\right), 1.42-1.59\left(54 \mathrm{H}, \mathrm{m}, \mathrm{OCH}_{2} \mathrm{CH}_{2} \mathrm{CH}_{2} \mathrm{CH}_{2}\right)$, 0.95-1.00 (30H, m, $\left.\mathrm{CH}_{3}\right)$; HRMS (ESI): calc. $\mathrm{m} / \mathrm{z} 1501.06436\left(\mathrm{C}_{97} \mathrm{H}_{144} \mathrm{O}_{12}\right)$, found $\mathrm{m} / \mathrm{z} 1501.06523$ $(\mathrm{M})^{+}$

\section{1, 12-Bis $(3,6,7,10,11$-pentapentyloxytriphenylen-2'-yloxy)-dodeane (T5D12)}

A mixture of 2-hydroxy-3, 6, 7, 10, 11-pentapentyloxytriphenylene (500mg), 1,12-dibromoalkane ( 0.4 eq.) and anhydrous potassium carbonate $(1.0 \mathrm{~g})$ in acetone $(50 \mathrm{ml})$ was heated under reflux for $72 \mathrm{~h}$. The mixture was cooled to room temperature, filtered, washed with dichloromethane. The solvent was removed in vacuo, and the residue was purified by column chromatography on silica eluting with dichloromethane and finally recrystallized from a mixture of ethanol and dichloromethane to give pure T5D12 $(0.23 \mathrm{~g}$, 51\%): TLC Rf: 0.73 (dichloromethane-hexane 4:1); (found: C, 77.64; $\mathrm{H}, 9.70 . \mathrm{C}_{98} \mathrm{H}_{146} \mathrm{O}_{12}$ requires: C, 77.63; H, 9.71\%); IR (KBr): $v_{\max } / \mathrm{cm}^{-1} 1268(\mathrm{C}-\mathrm{O}-\mathrm{C}) ; \delta_{\mathrm{H}}\left(300 \mathrm{MHz}, \mathrm{CDCl}_{3}\right) 7.83$ (12H, s, ArH), 4.21-4.26 (24H, t, $\left.\mathrm{OCH}_{2}\right), 1.91-1.98\left(24 \mathrm{H}, \mathrm{m}, \mathrm{OCH}_{2} \mathrm{CH}_{2}\right), 1.42-1.59(56 \mathrm{H}, \mathrm{m}$, $\left.\mathrm{OCH}_{2} \mathrm{CH}_{2} \mathrm{CH}_{2} \mathrm{CH}_{2}\right), \quad 0.86-1.00 \quad\left(30 \mathrm{H}, \quad \mathrm{m}, \quad \mathrm{CH}_{3}\right) ; \quad \mathrm{HRMS} \quad(\mathrm{ESI}): \quad$ calc. $\mathrm{m} / \mathrm{z}$ 1515.08437 $\left(\mathrm{C}_{98} \mathrm{H}_{146} \mathrm{O}_{12}\right)$, found $\mathrm{m} / \mathrm{z} 1515.08088(\mathrm{M})^{+}$ 


\section{2. ${ }^{1} \mathrm{H}$ NMR and FT-IR spectra}
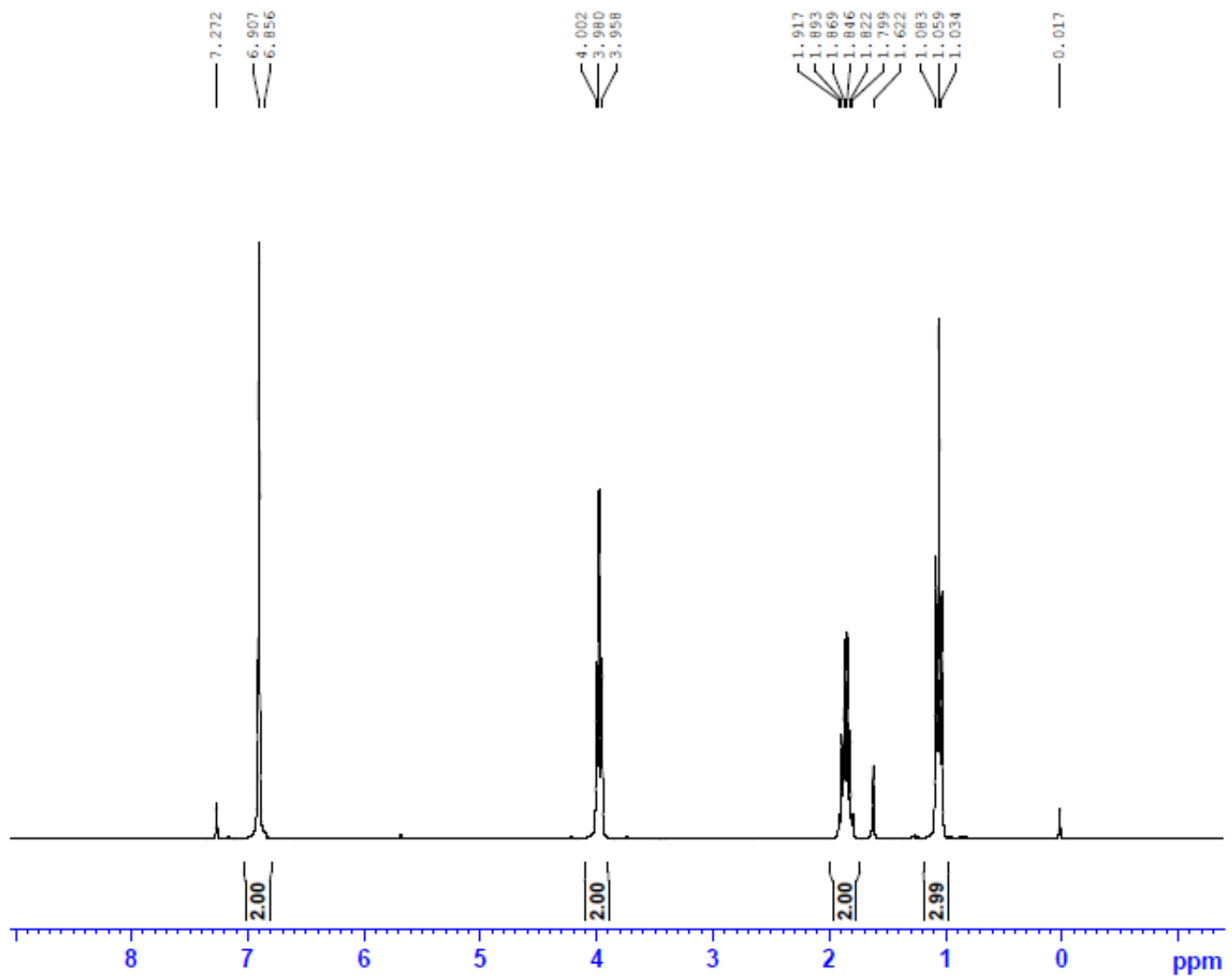

Fig. 1S ${ }^{1} \mathrm{H}$ NMR spectra of 1
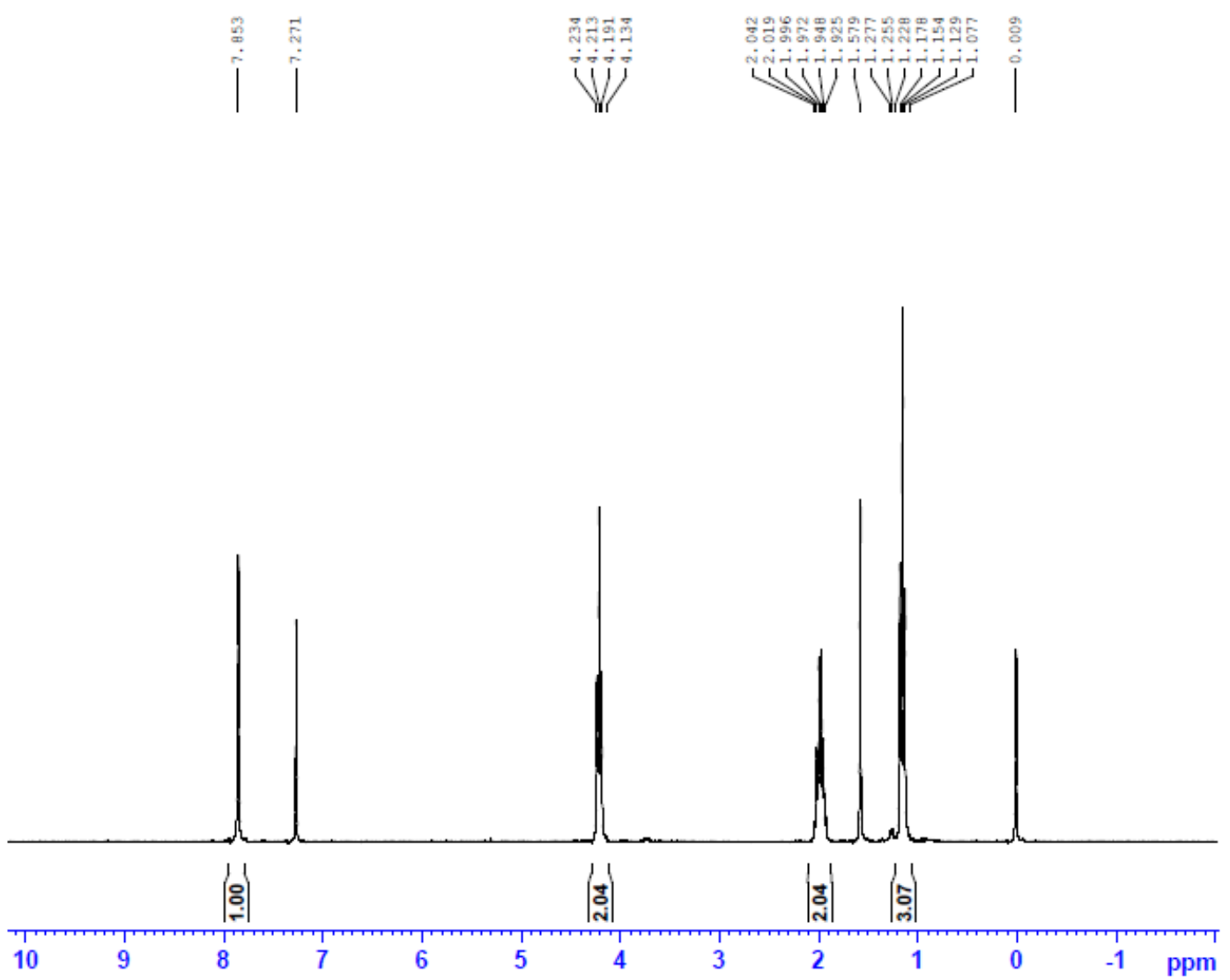

Fig. $2 S{ }^{1} \mathrm{H}$ NMR spectra of 2 

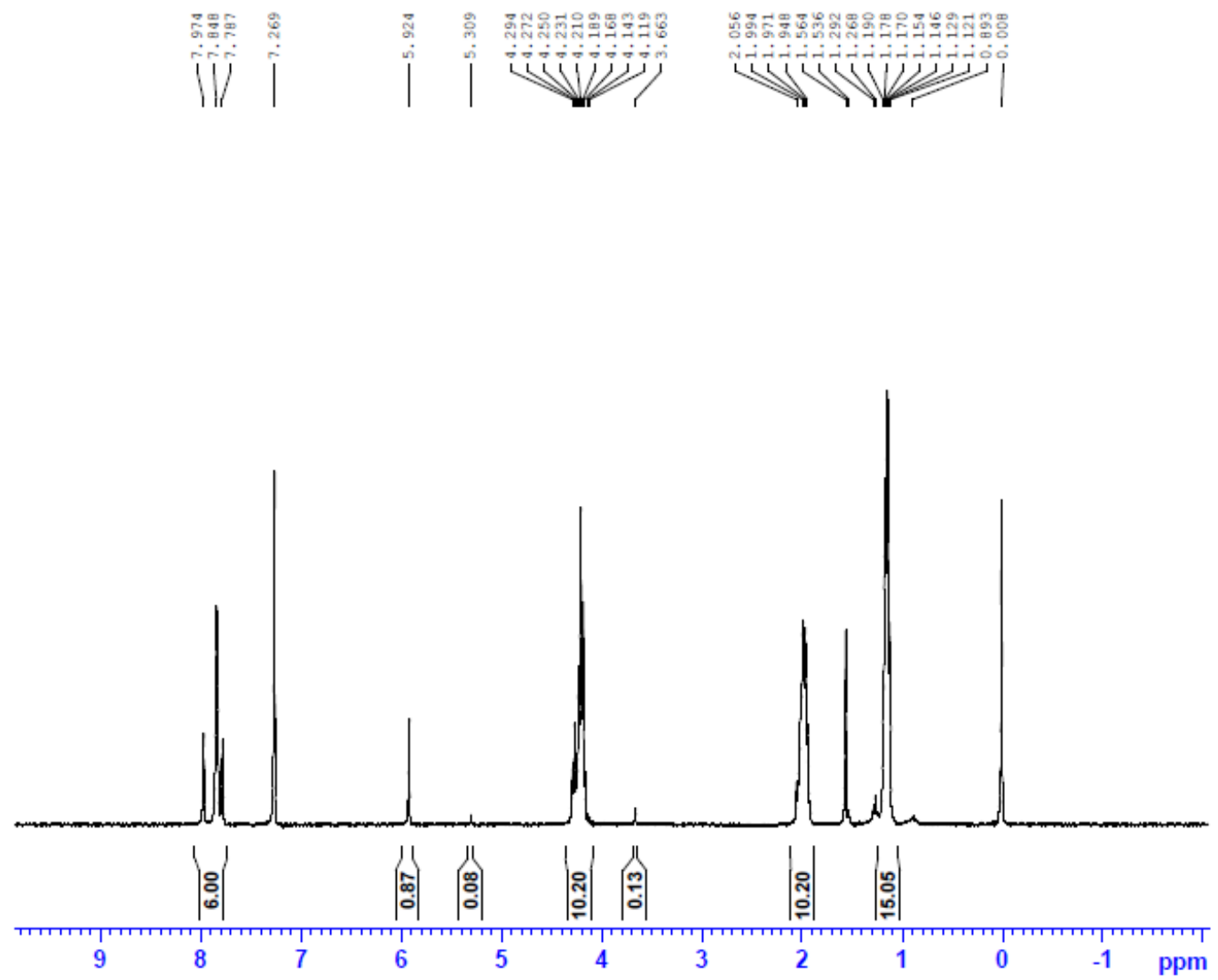

Fig. 3S ${ }^{1} \mathrm{H}$ NMR spectra of 3

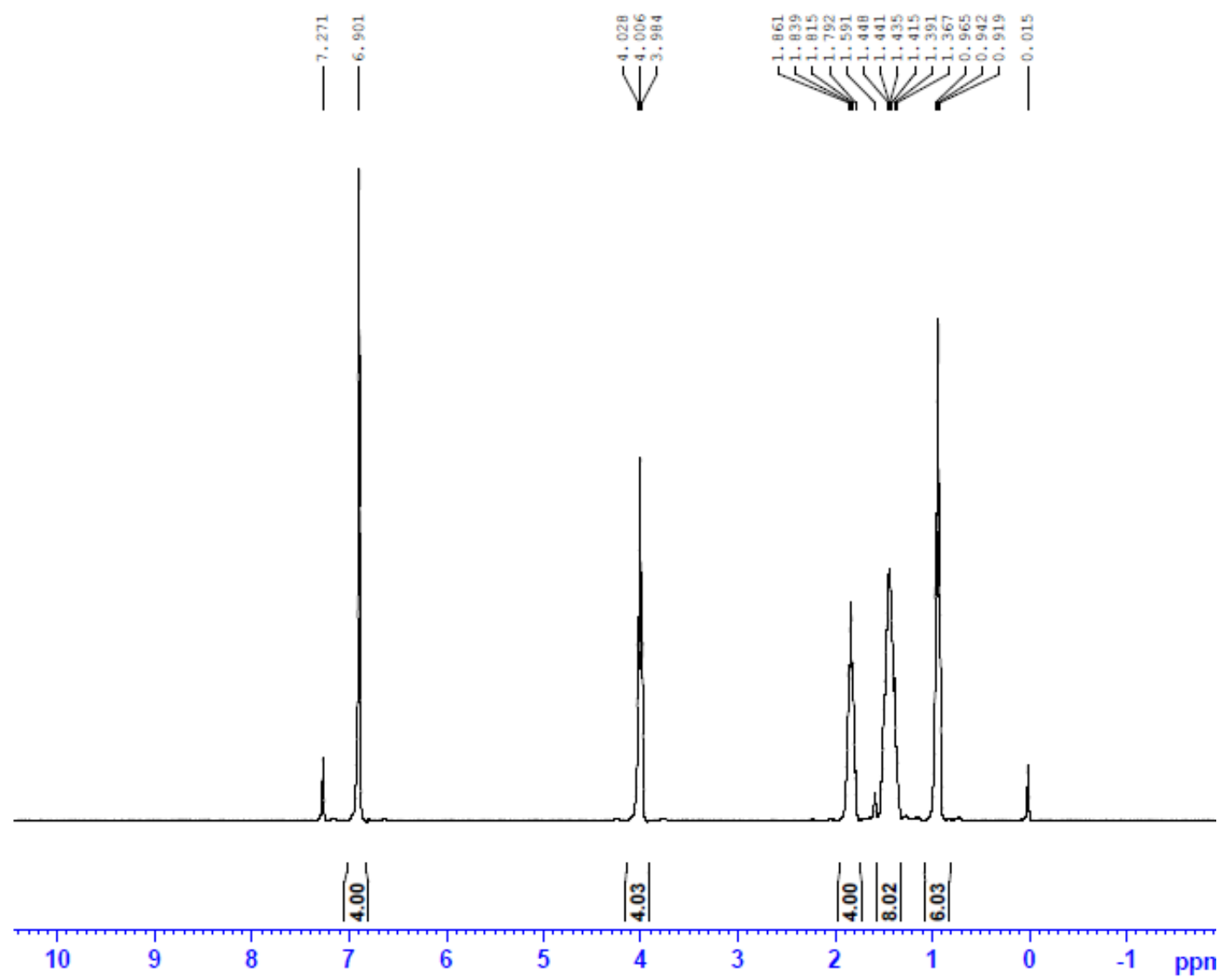

Fig. $4 S^{1} \mathrm{H}$ NMR spectra of 5 


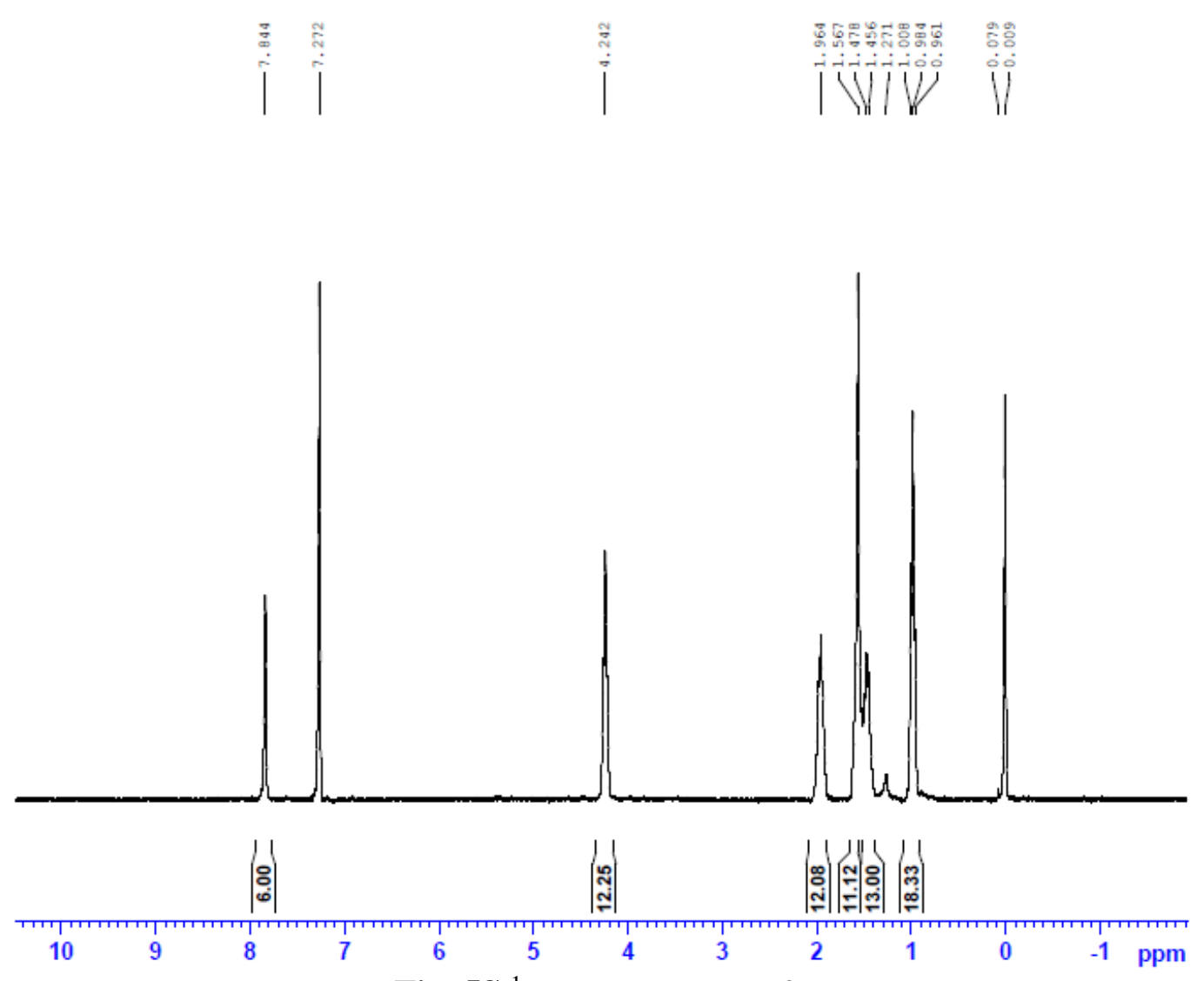

Fig. 5S ${ }^{1} \mathrm{H}$ NMR spectra of 6



Fig. 6S ${ }^{1} \mathrm{H}$ NMR spectra of 7 


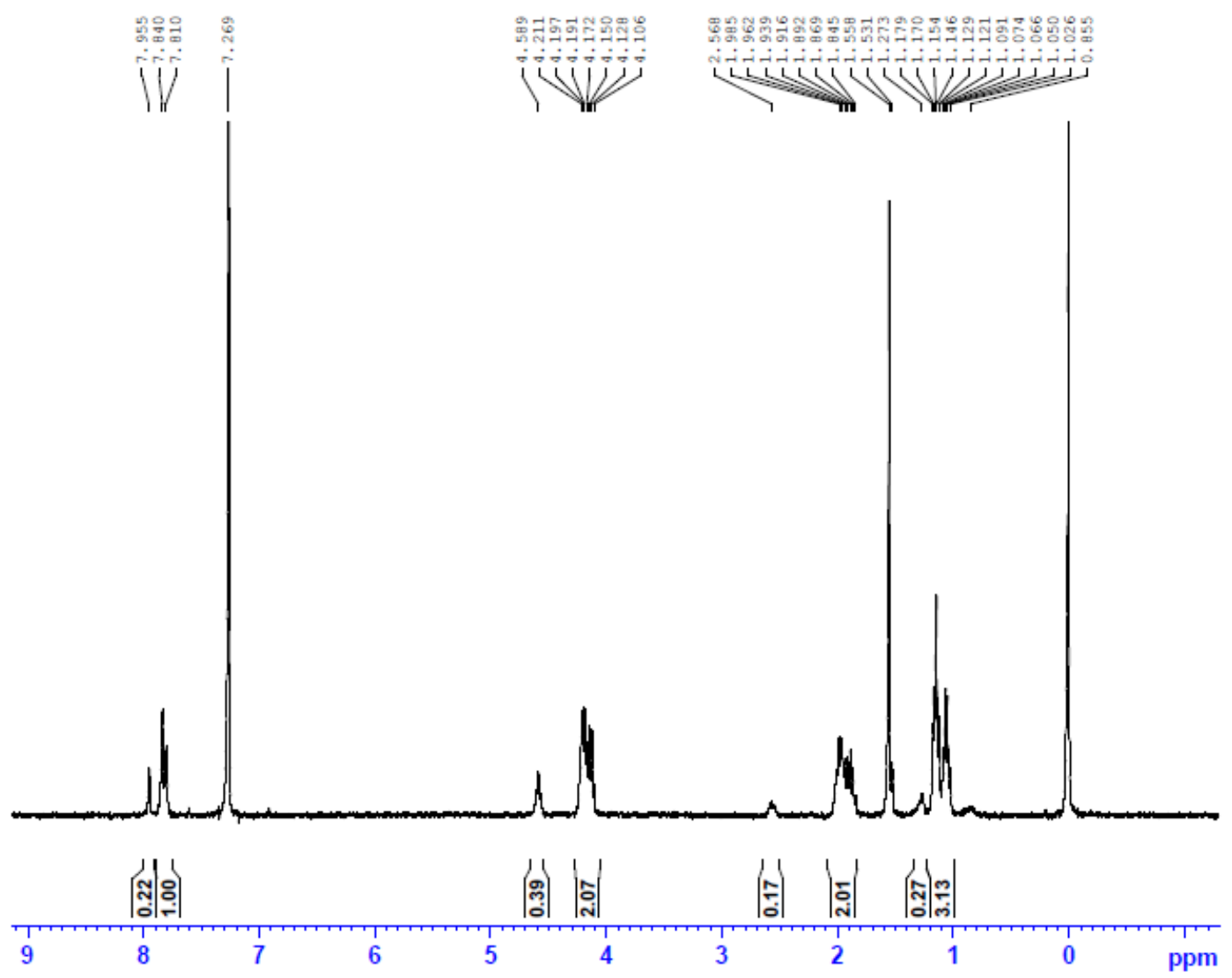

Fig. 7S ${ }^{1} \mathrm{H}$ NMR spectra of T3D3

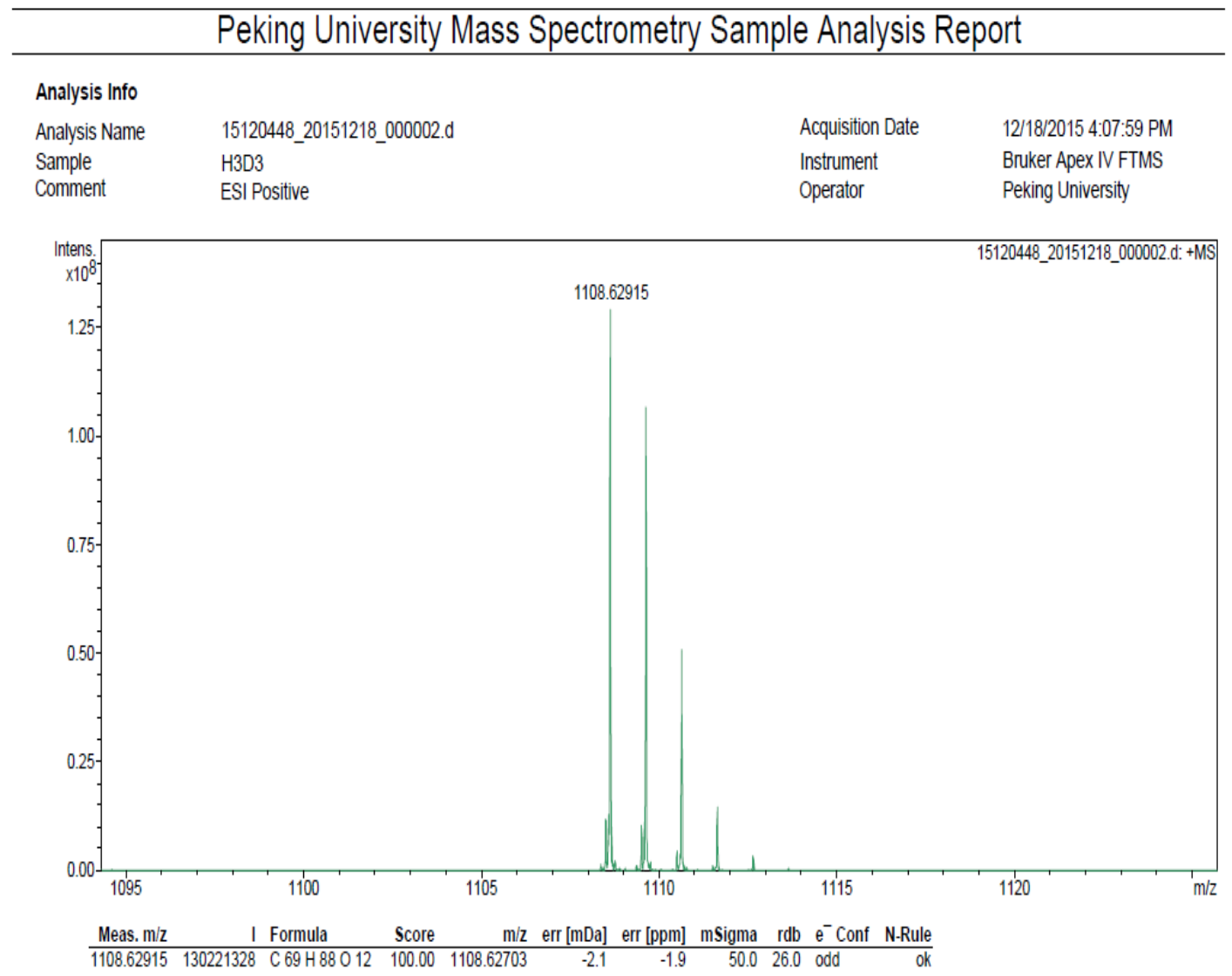

Fig. 8S HRSM spectra of T3D3 


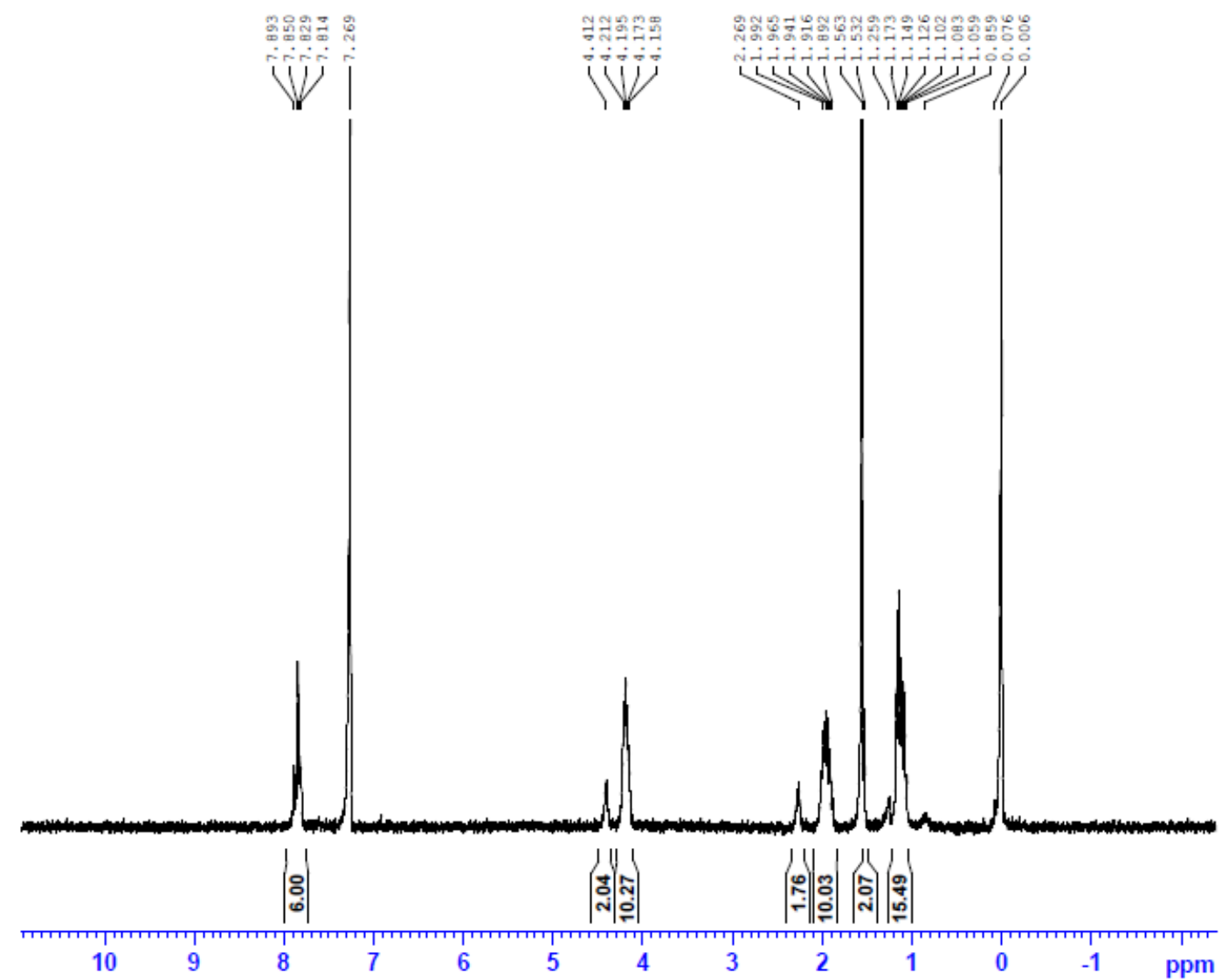

Fig. 9S ${ }^{1} \mathrm{H}$ NMR spectra of T3D4

\begin{tabular}{|c|c|c|c|}
\hline \multicolumn{4}{|c|}{ Peking University Mass Spectrometry Sample Analysis Report } \\
\hline Analysis Info & & & \\
\hline $\begin{array}{l}\text { Analysis Name } \\
\text { Sample } \\
\text { Comment }\end{array}$ & $\begin{array}{l}\text { 15120469_20151218_000002.d } \\
\text { H3D4 } \\
\text { ESI Positive }\end{array}$ & $\begin{array}{l}\text { Acquisition Date } \\
\text { Instrument } \\
\text { Operator }\end{array}$ & $\begin{array}{l}\text { 12/18/2015 4:13:16 PM } \\
\text { Buker Apex IV FTMS } \\
\text { Peking University }\end{array}$ \\
\hline
\end{tabular}

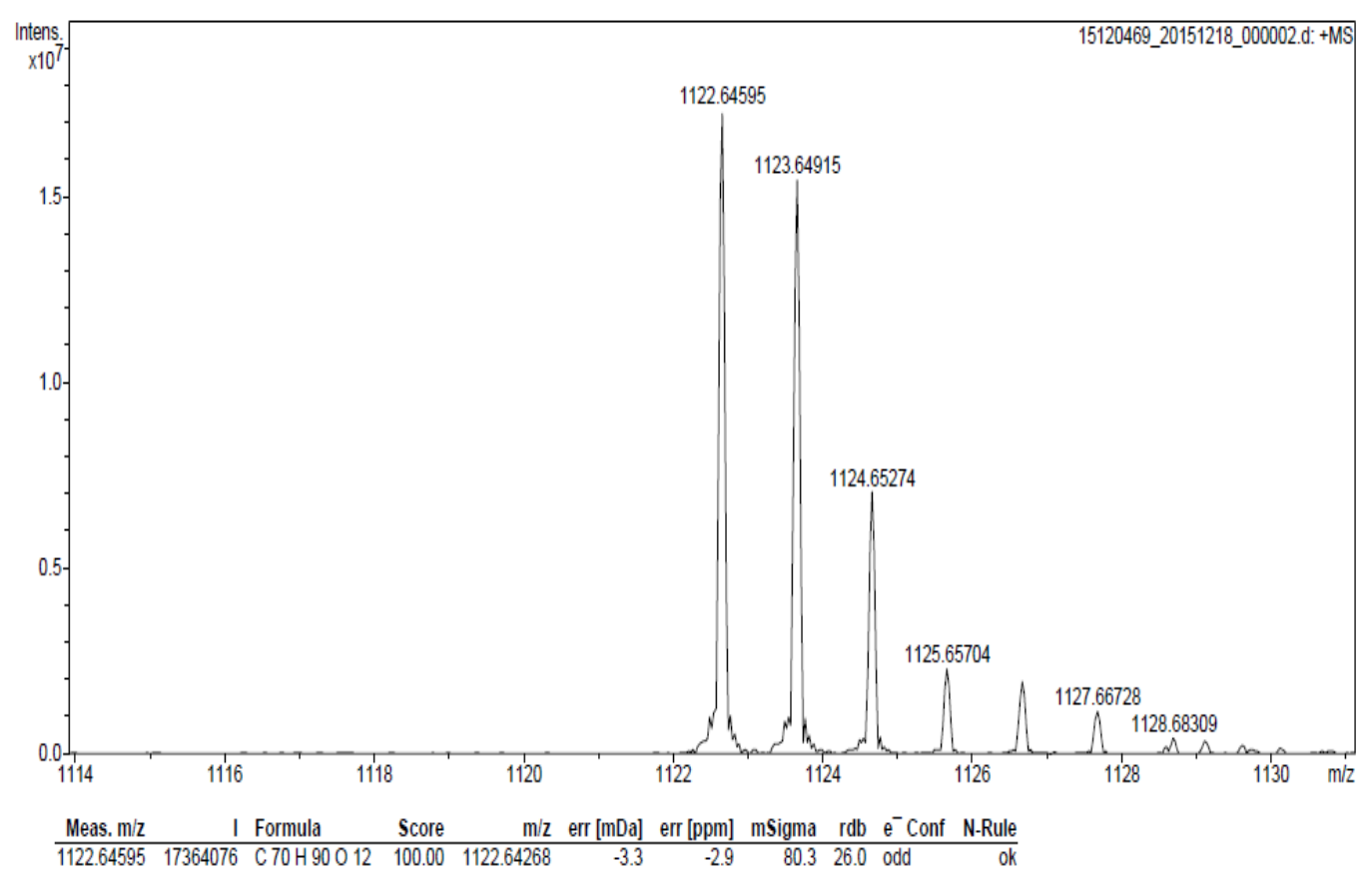

Fig. 10S HRSM spectra of T3D4 


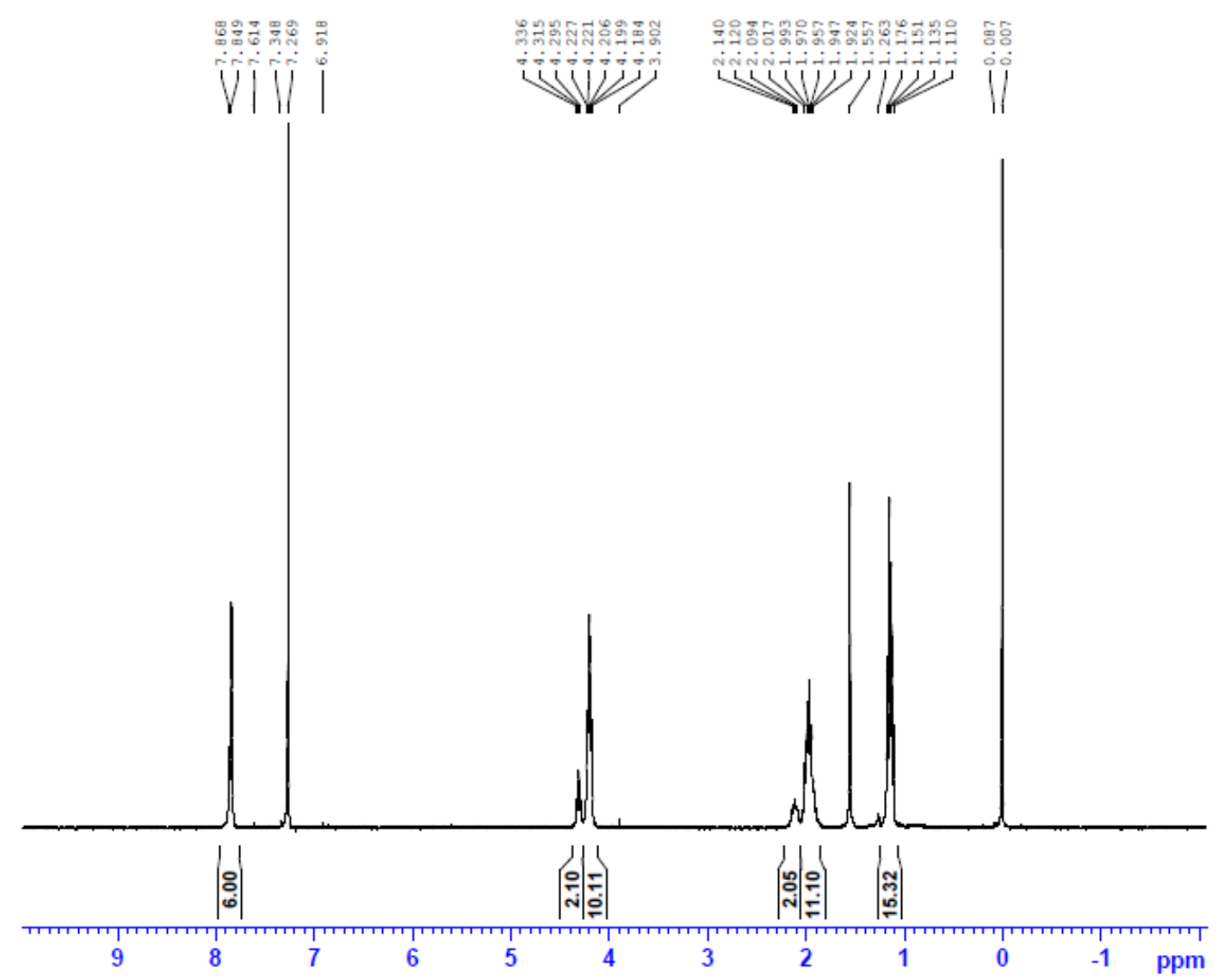

Fig. 11S ${ }^{1} \mathrm{H}$ NMR spectra of T3D5

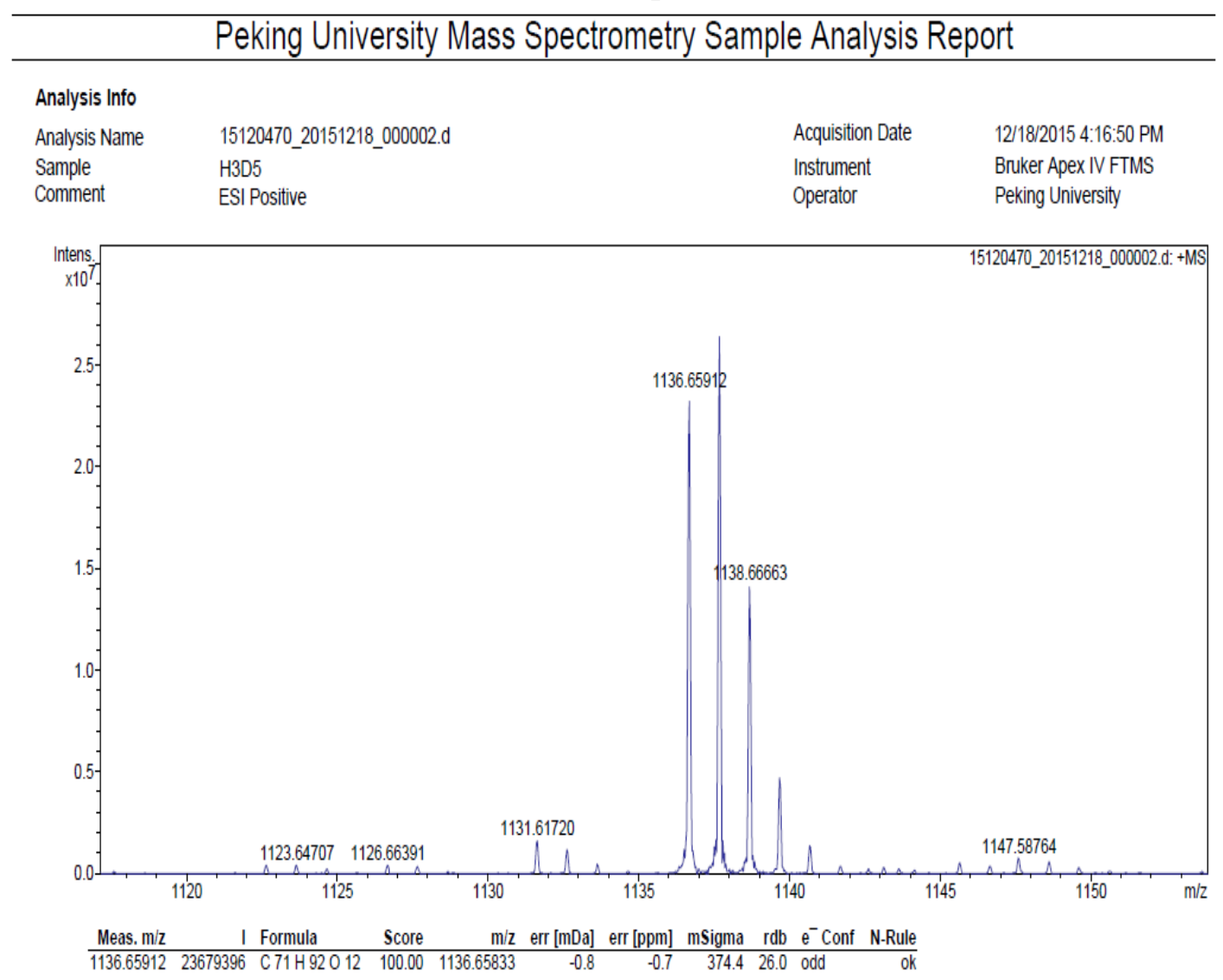

Fig. 12S HRMS spectra of T3D5 


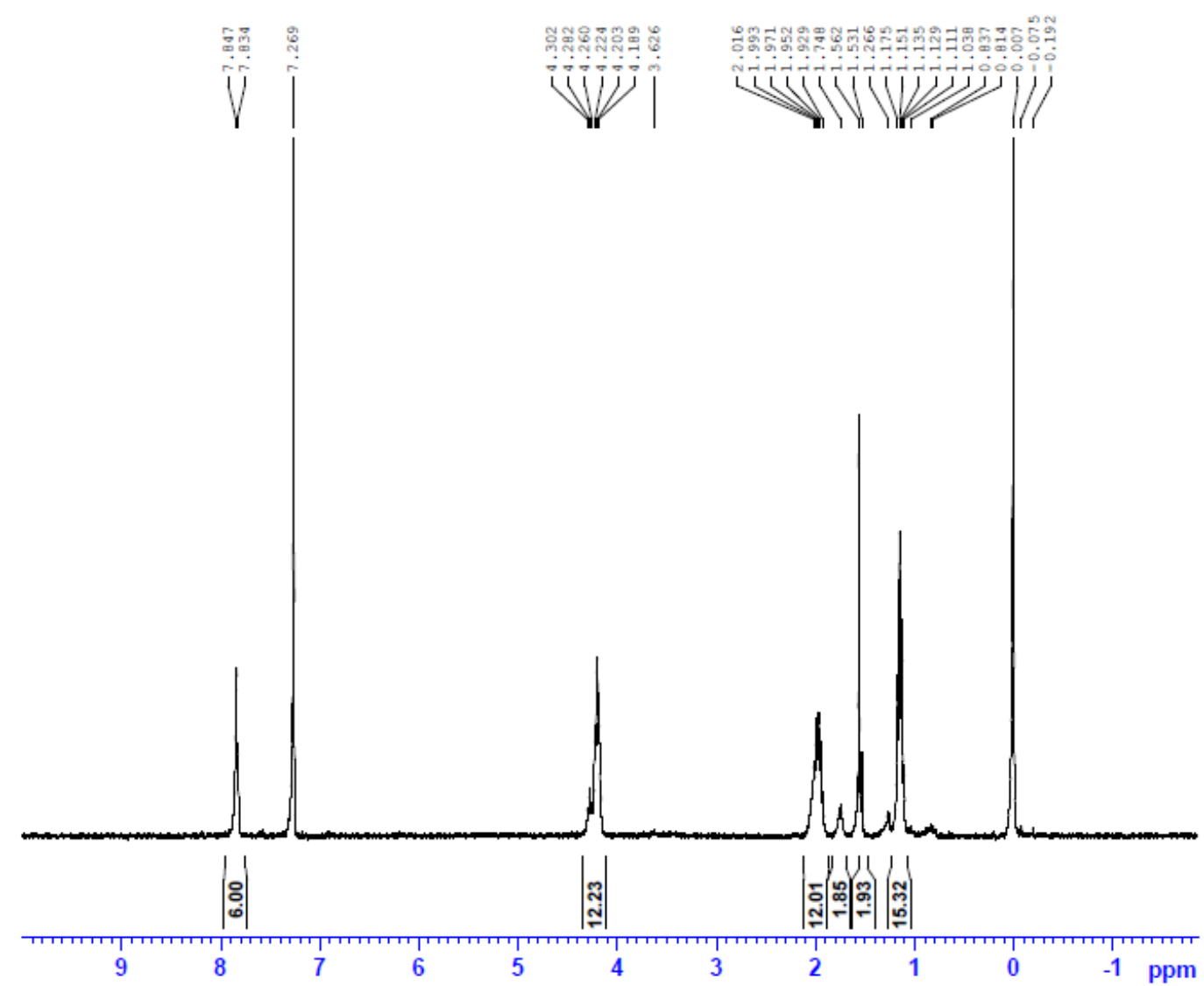

Fig. 13S ${ }^{1} \mathrm{H}$ NMR spectra of T3D6

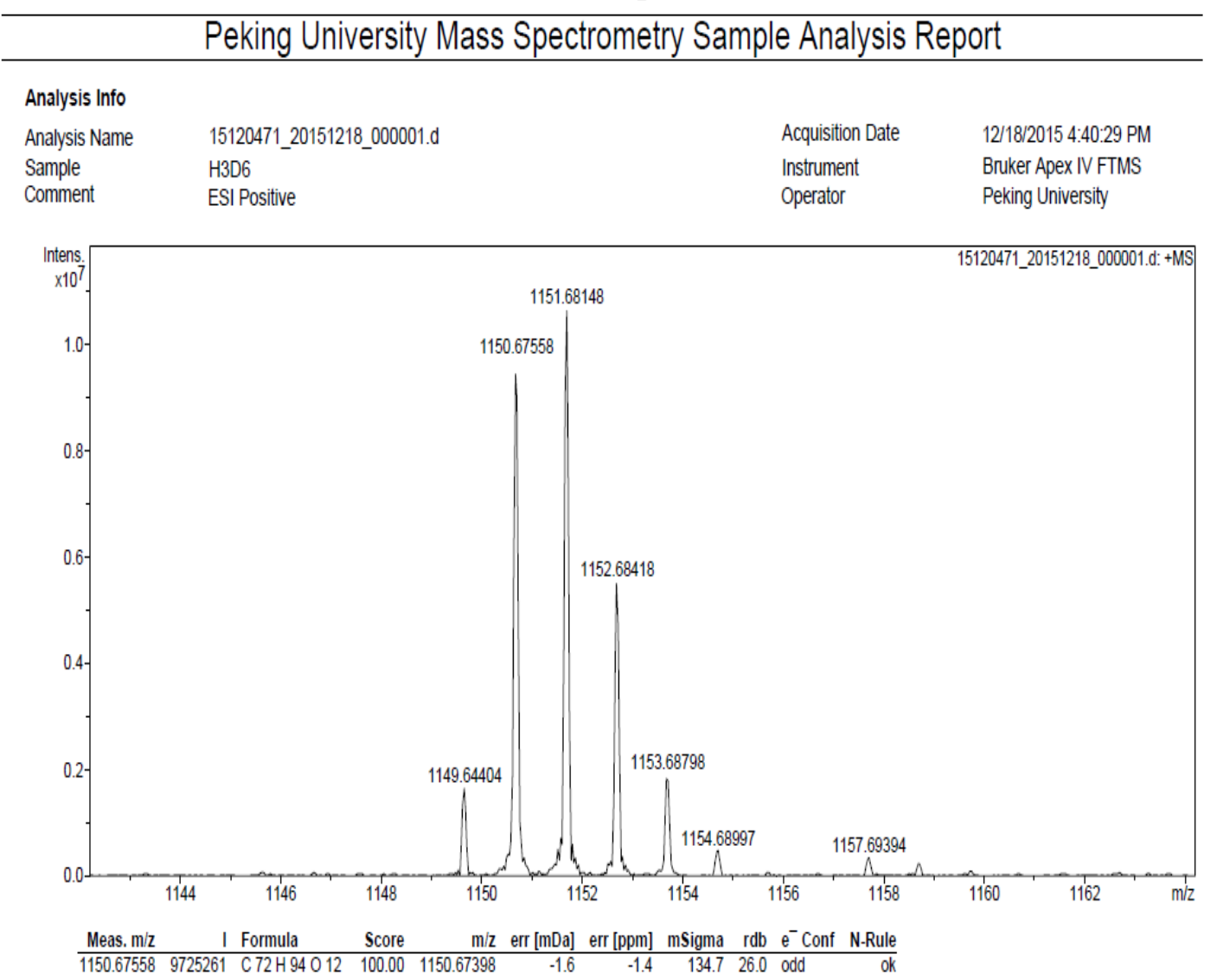

Fig. 14S HRMS spectra of T3D6 


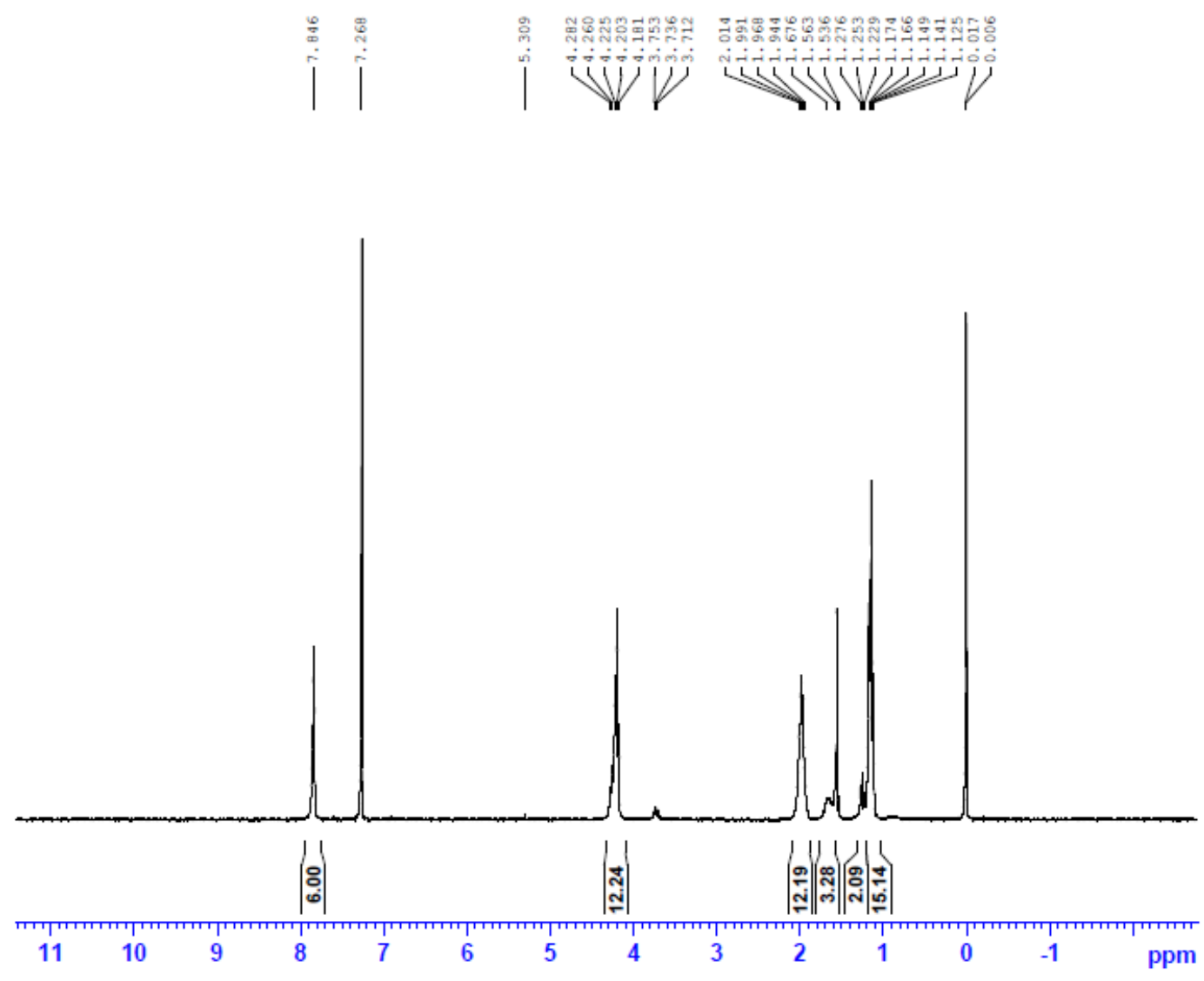

Fig. 15S ${ }^{1} \mathrm{H}$ NMR spectra of T3D7

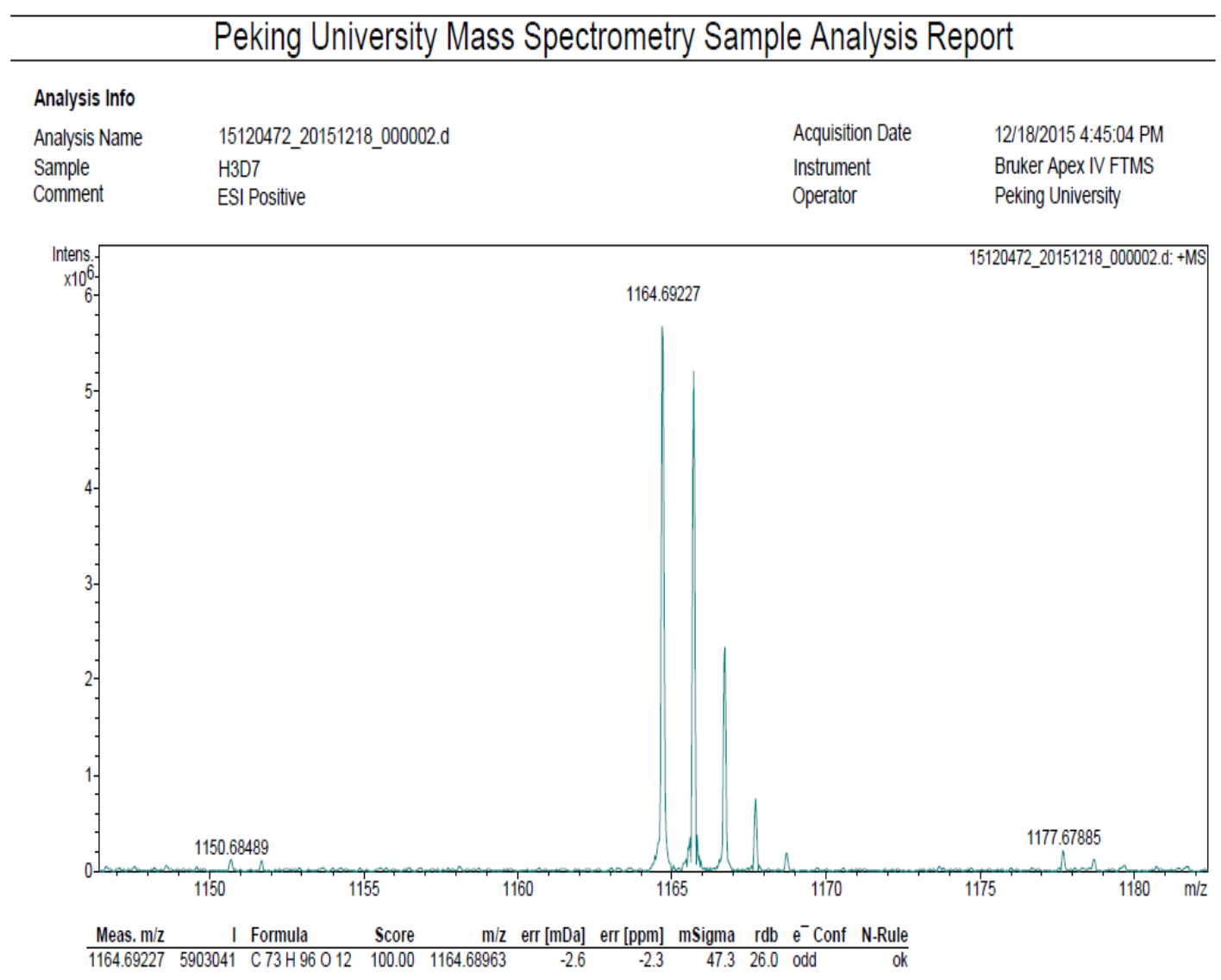

Fig. 16S HRMS spectra of T3D7 


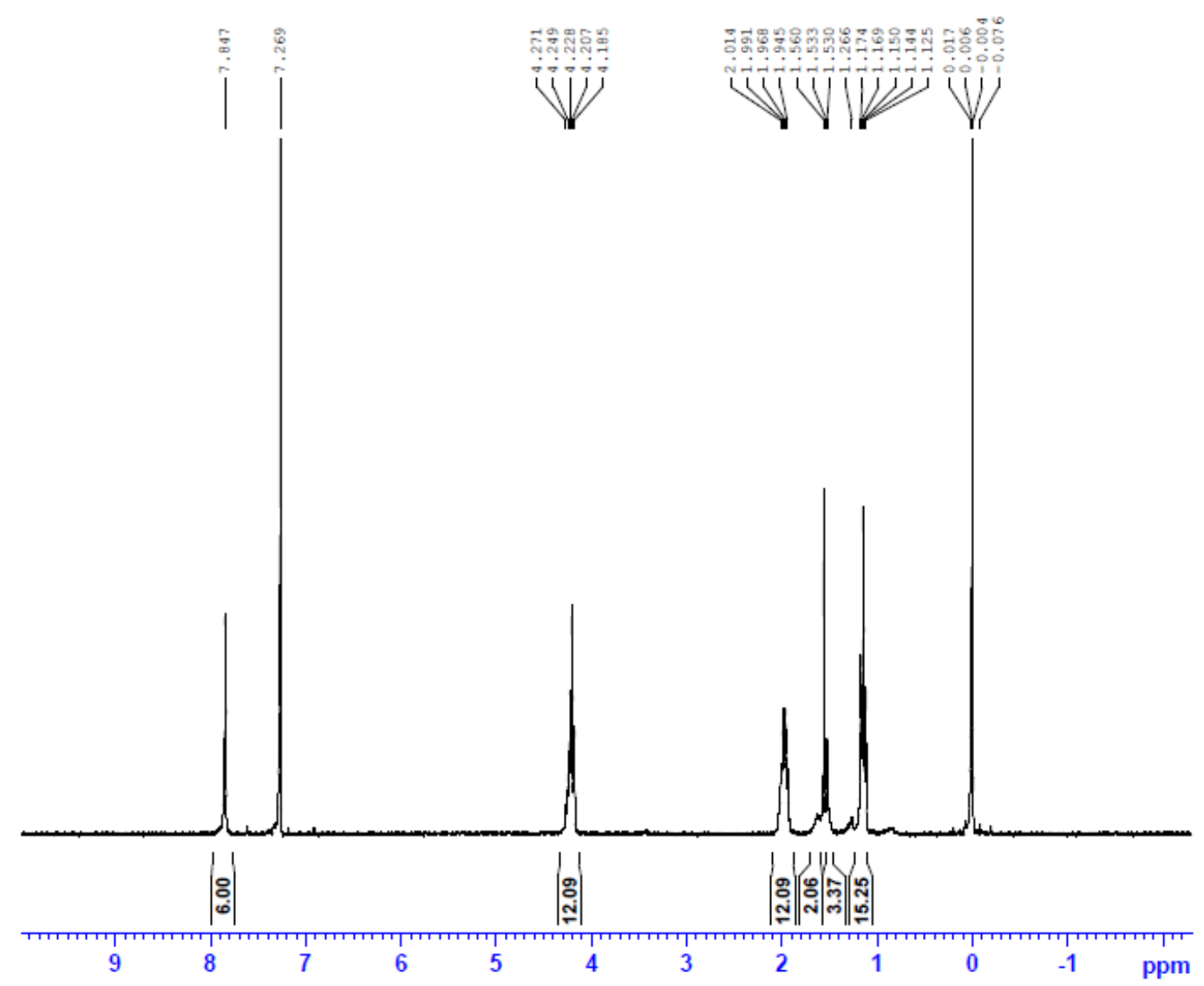

Fig. 17S ${ }^{1} \mathrm{H}$ NMR spectra of T3D8

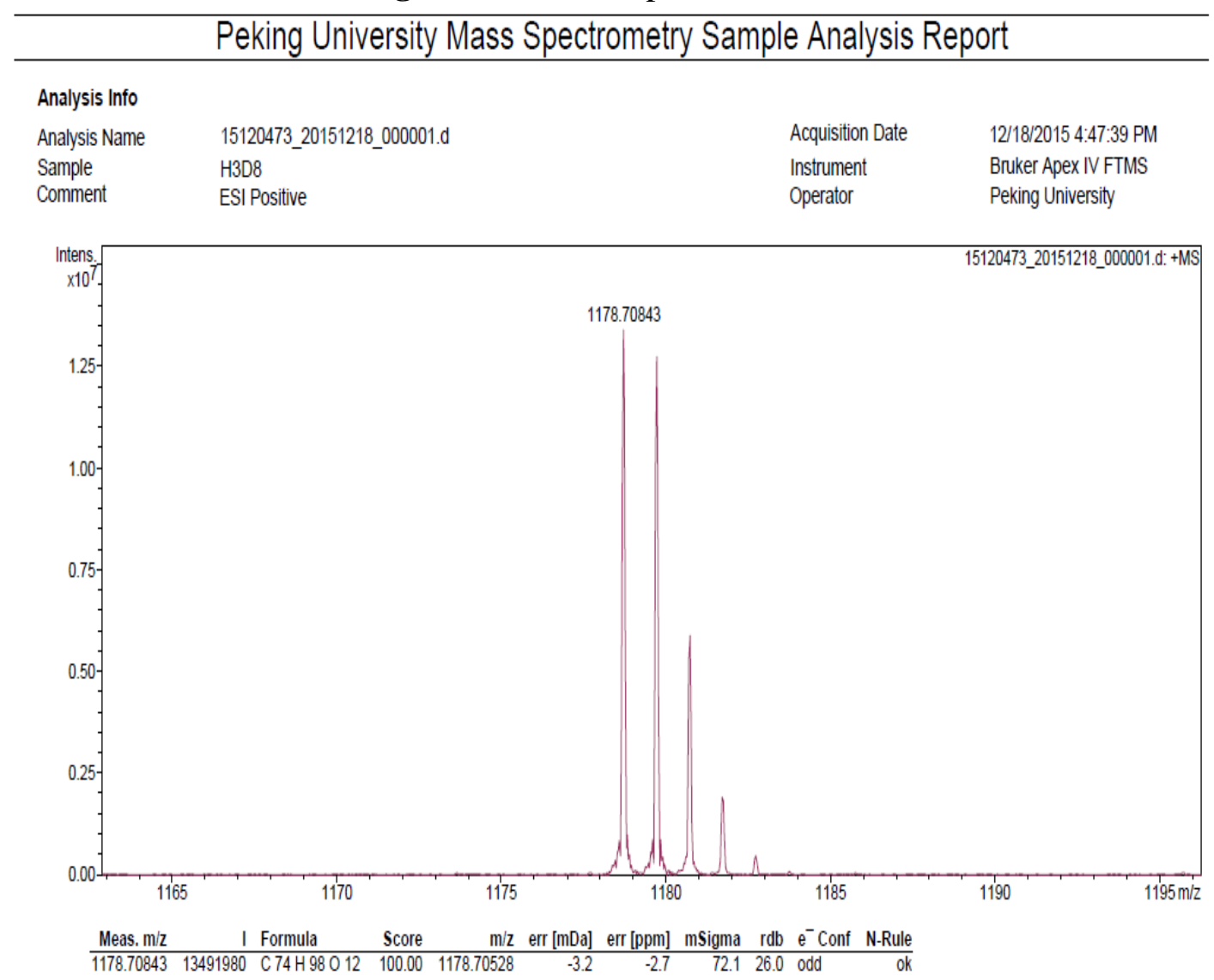

Fig. 18S HRMS spectra of T3D8 


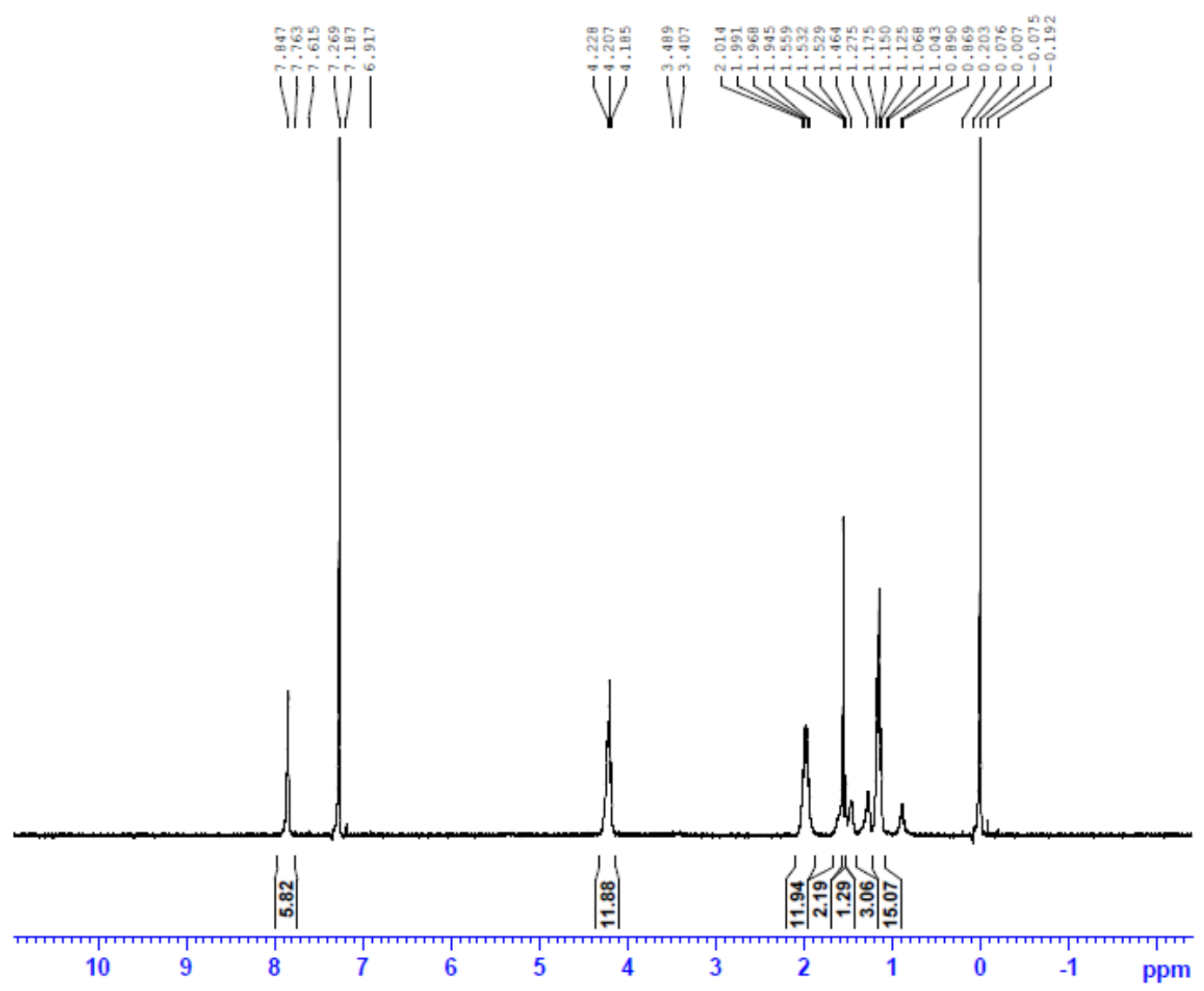

Fig. 19S ${ }^{1} \mathrm{H}$ NMR spectra of T3D9

\begin{tabular}{llll}
\hline & Peking University Mass Spectrometry Sample Analysis Report \\
\hline Analysis Info & & & \\
Analysis Name & 15120474 20151218_000001.d & Acquisition Date & $12 / 18 / 2015$ 4:52:36 PM \\
Sample & H3D9 & Instrument & Bruker Apex IV FTMS \\
Comment & ESI Positive & Operator & Peking University
\end{tabular}

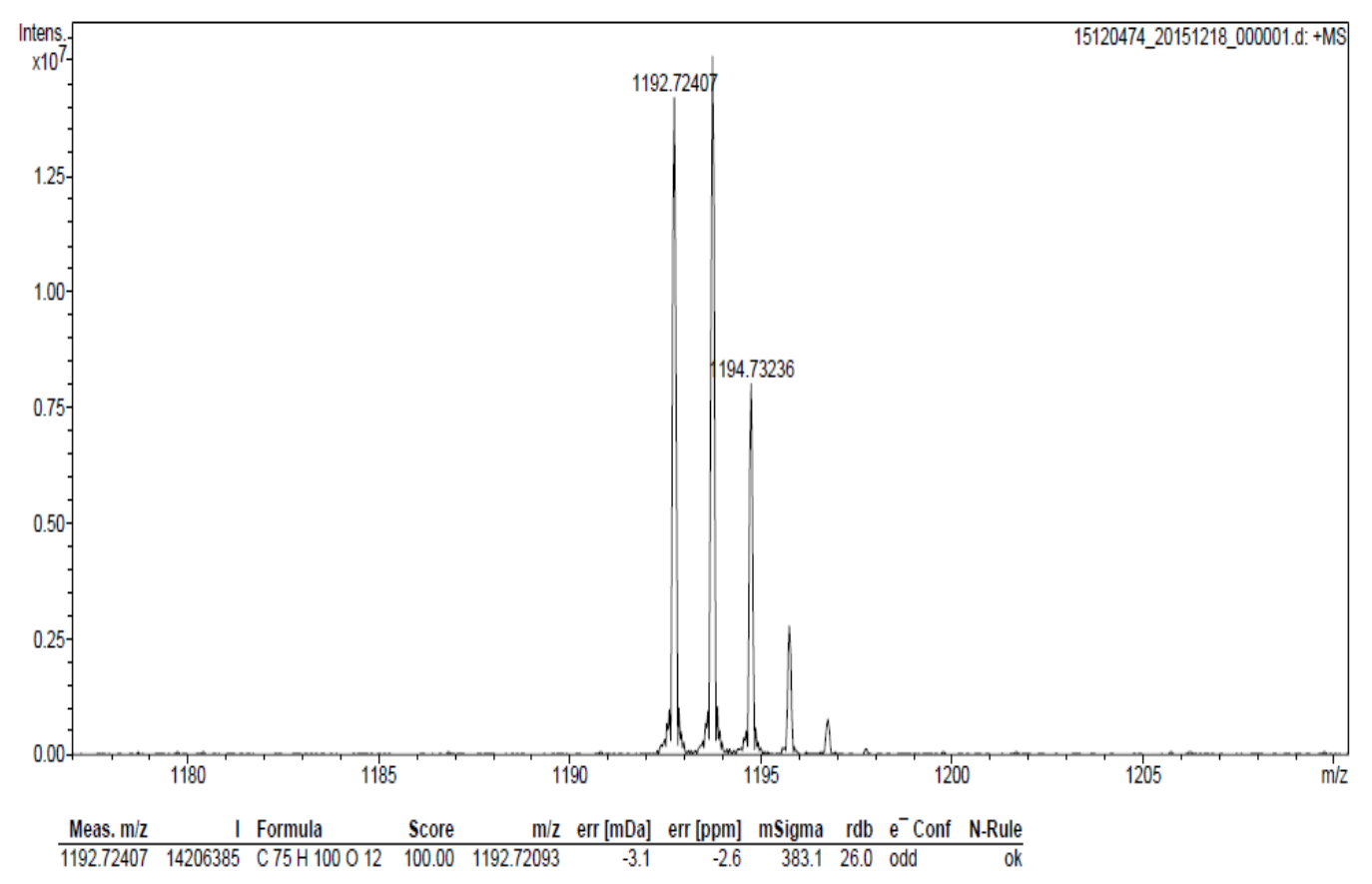

Fig. 20S HRMS spectra of T3D9 


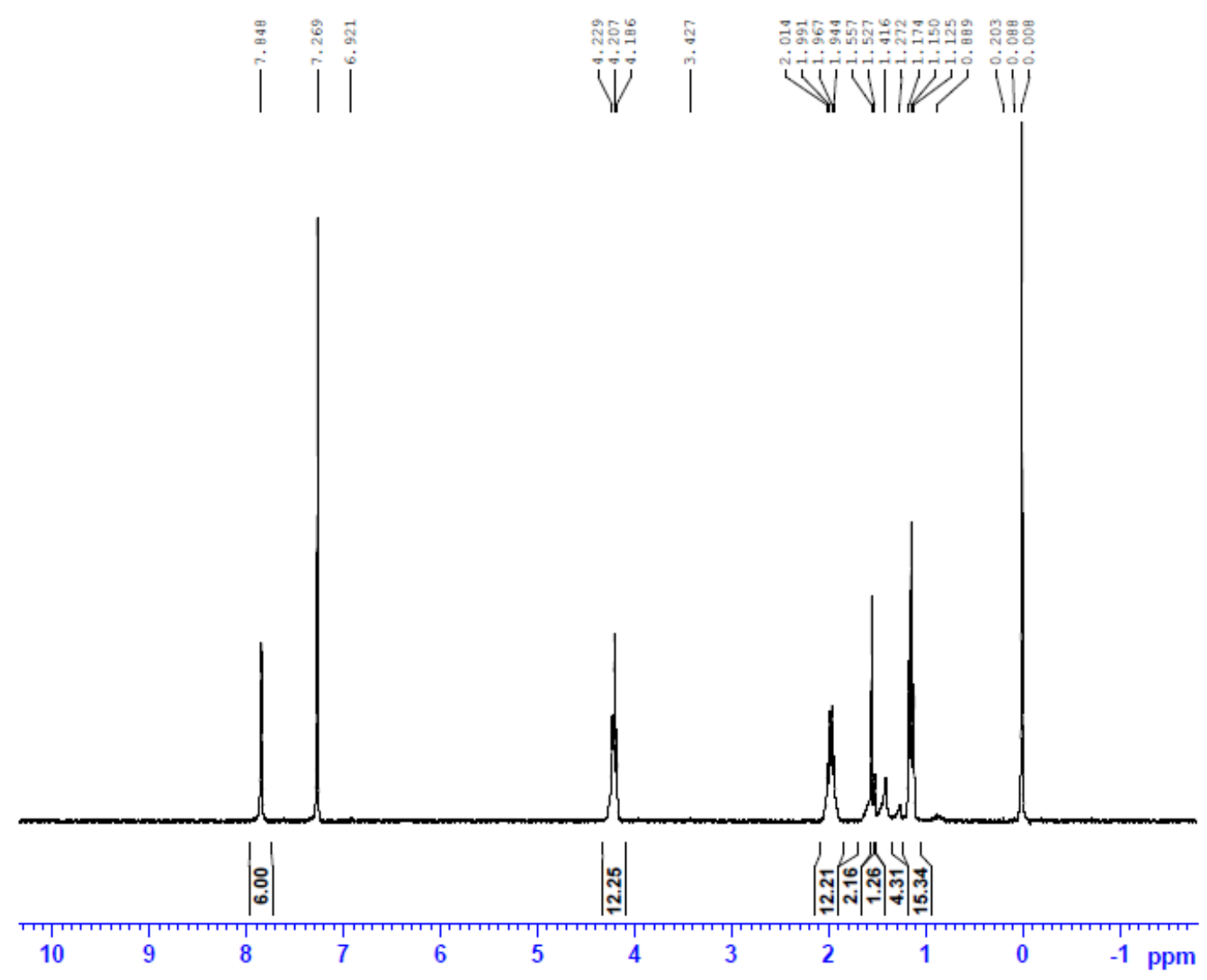

Fig. 21S ${ }^{1} \mathrm{H}$ NMR spectra of T3D10

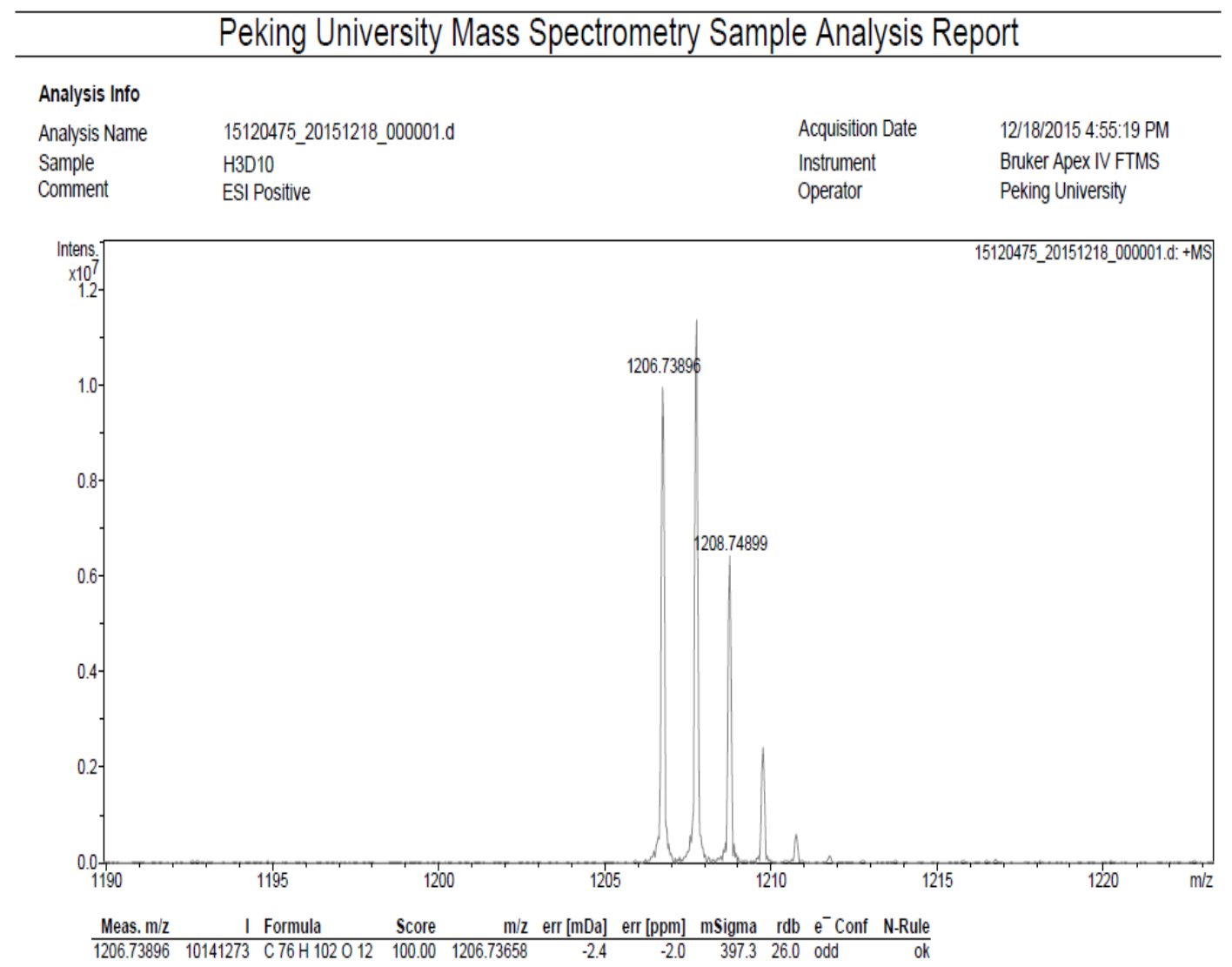

Fig. 22S HRMS spectra of T3D10 


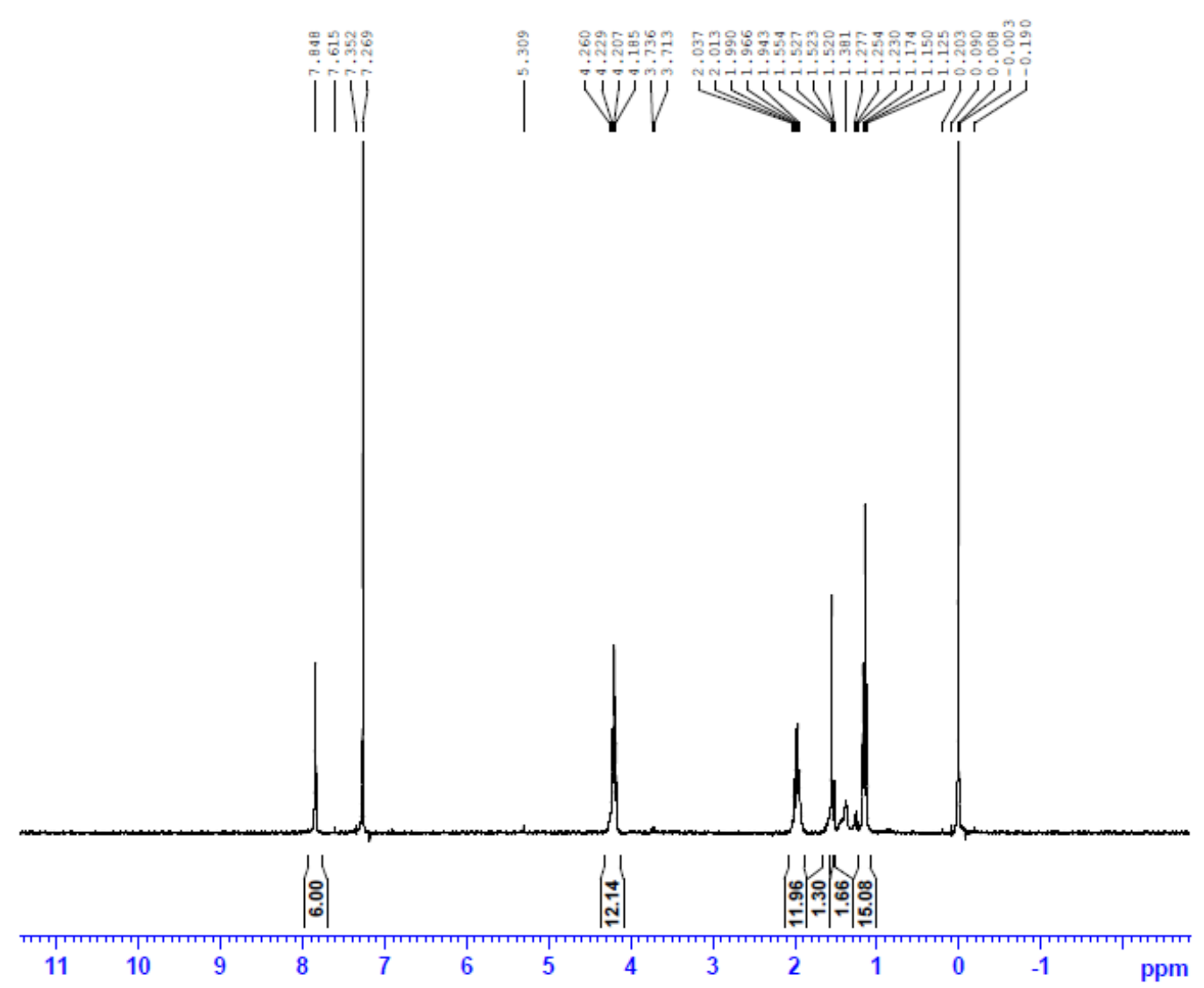

Fig. 23S ${ }^{1} \mathrm{H}$ NMR spectra of T3D11



Fig. 24S HRMS spectra of T3D11 


\section{il}
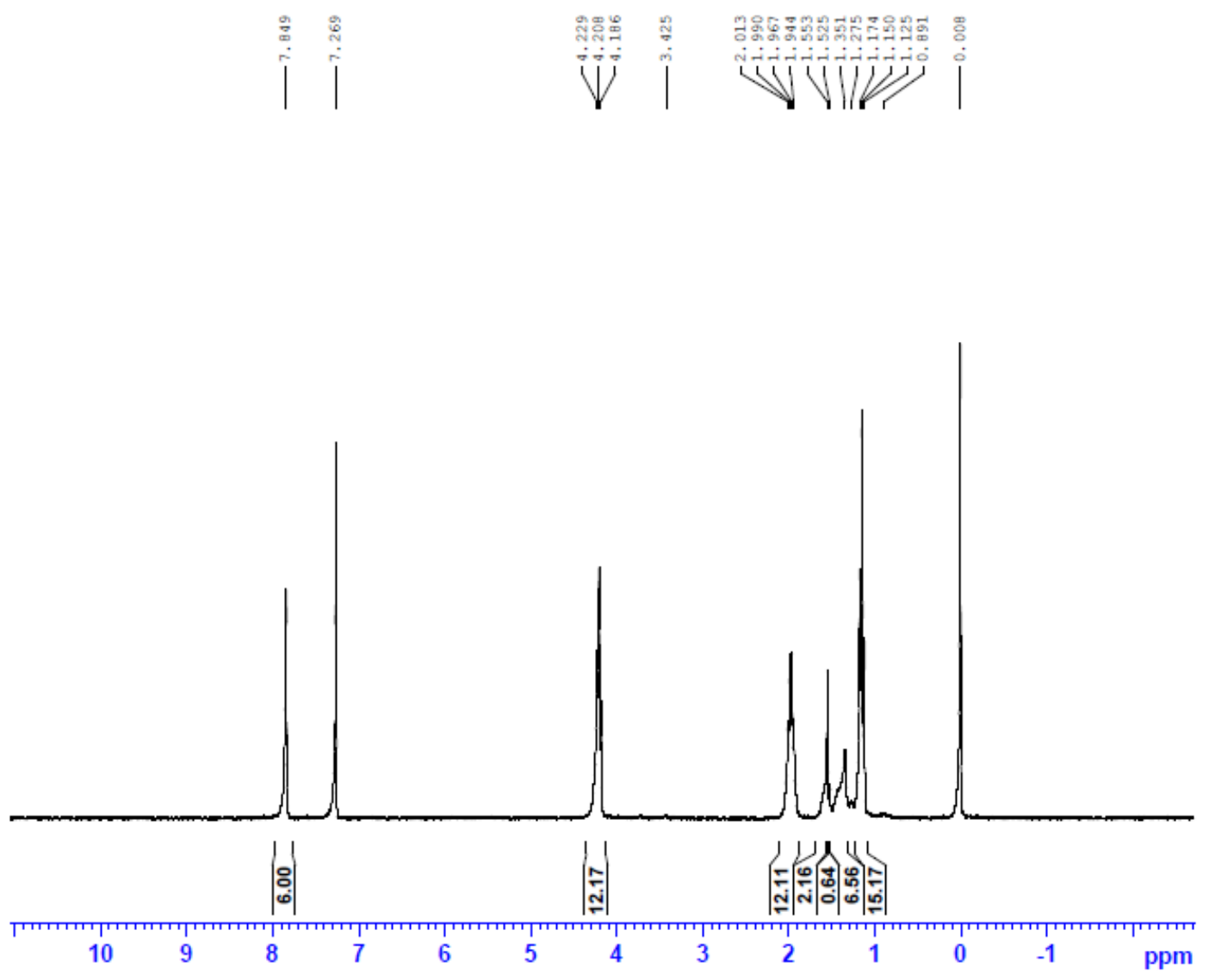

Fig. 25S ${ }^{1} \mathrm{H}$ NMR spectra of T3D12

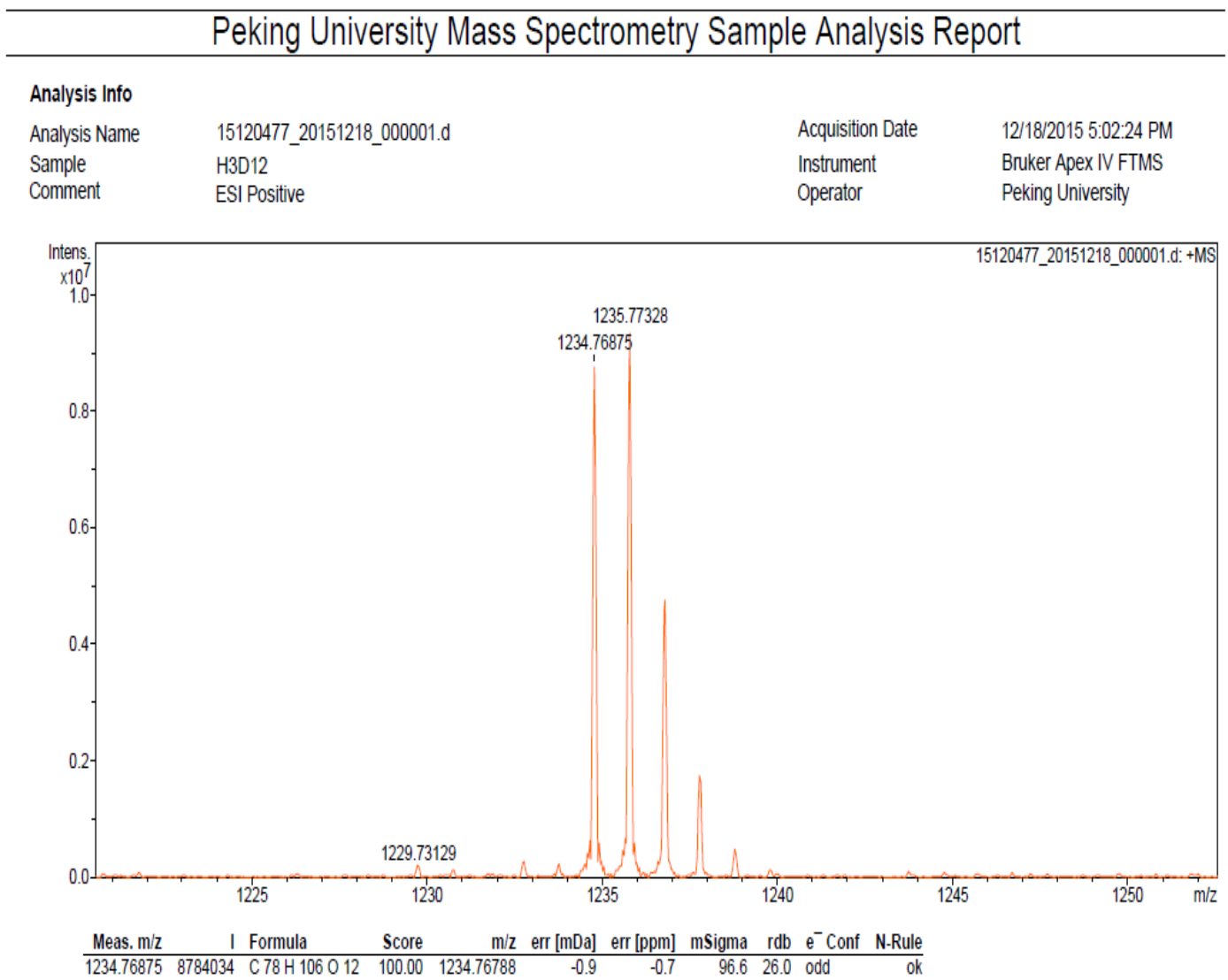

Fig. 26S HRMS spectra of T3D12 


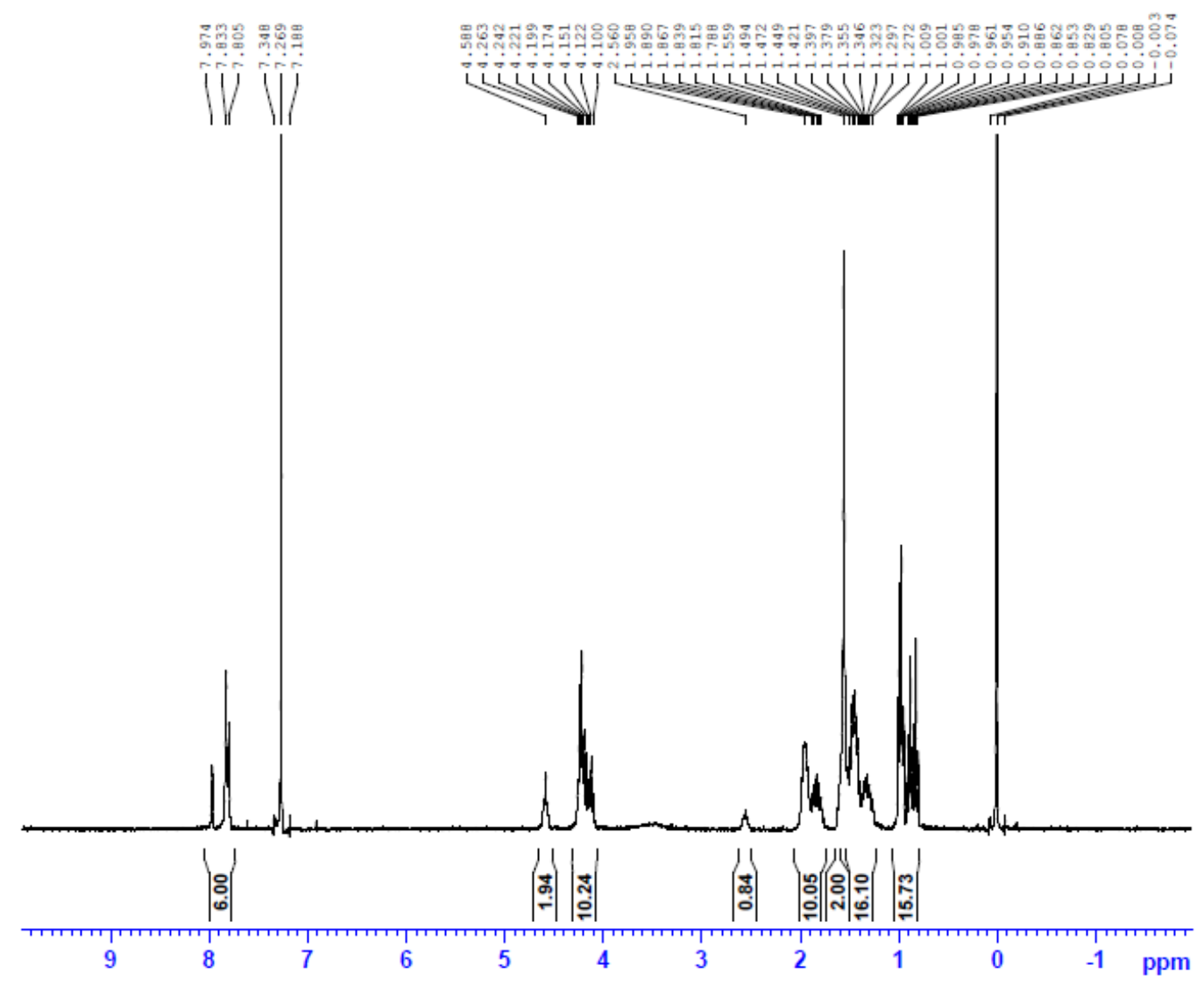

Fig. 27S ${ }^{1} \mathrm{H}$ NMR spectra of T5D3

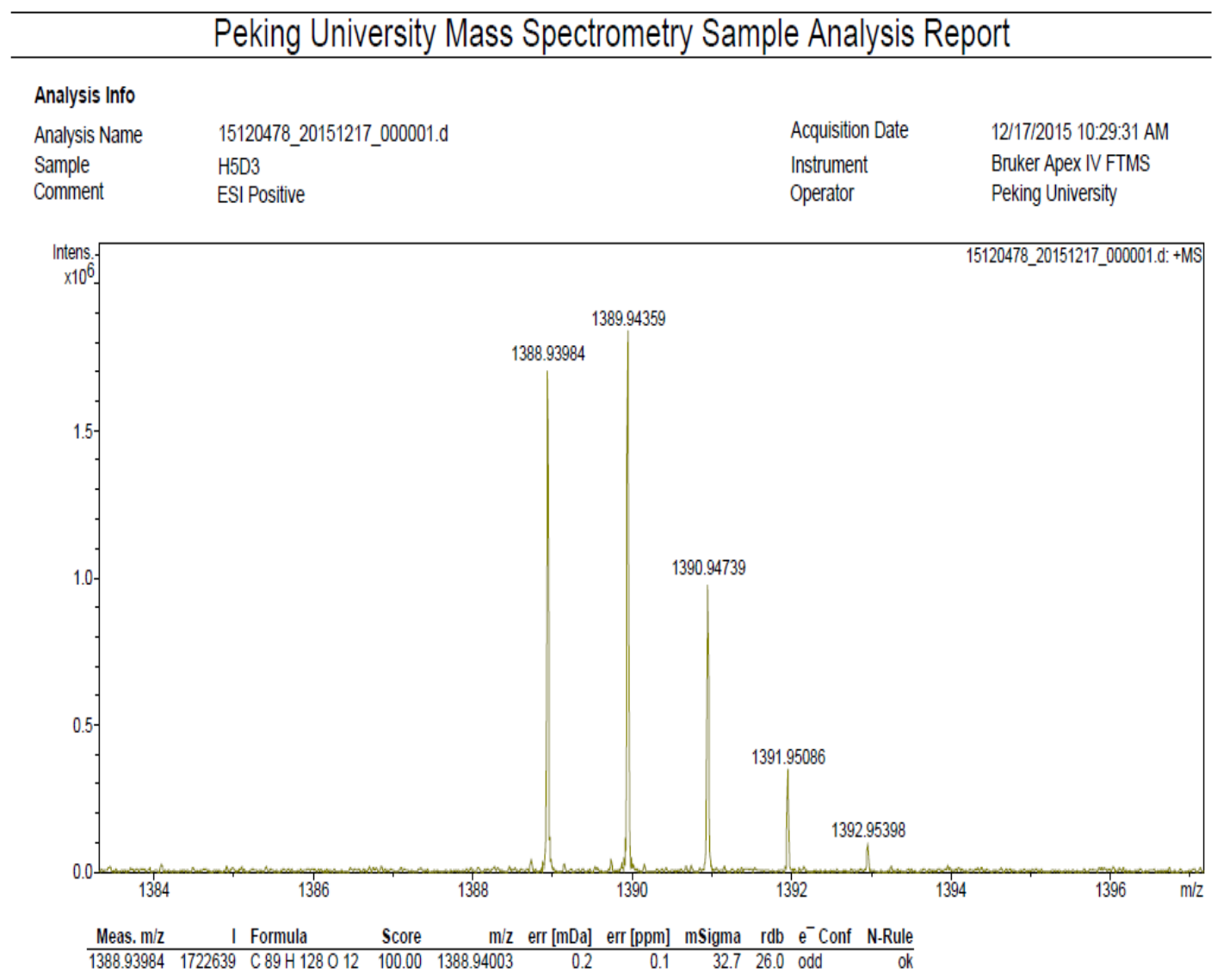

Fig. 28S HRMS spectra of T5D3 


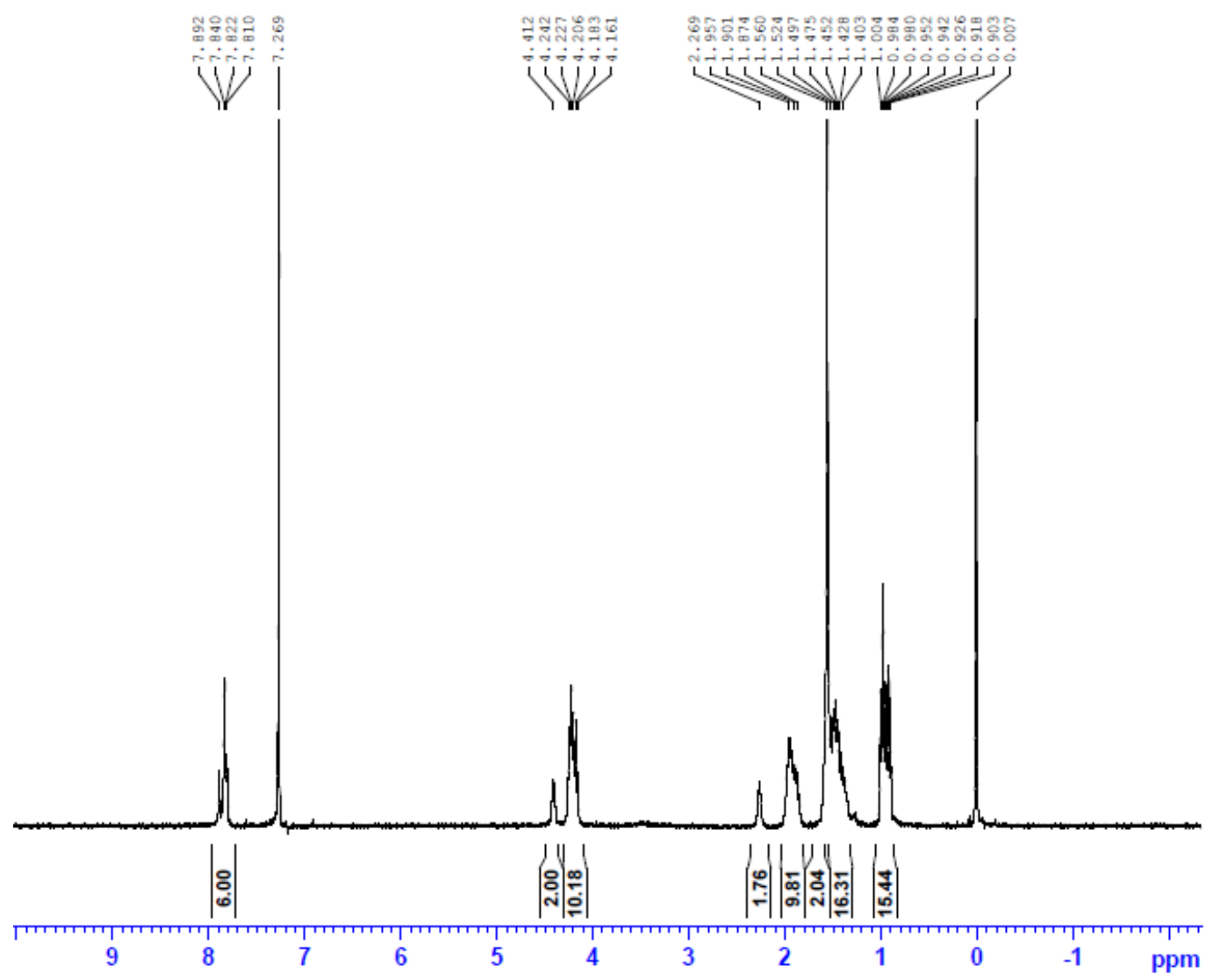

Fig. 29S ${ }^{1} \mathrm{H}$ NMR spectra of T5D4

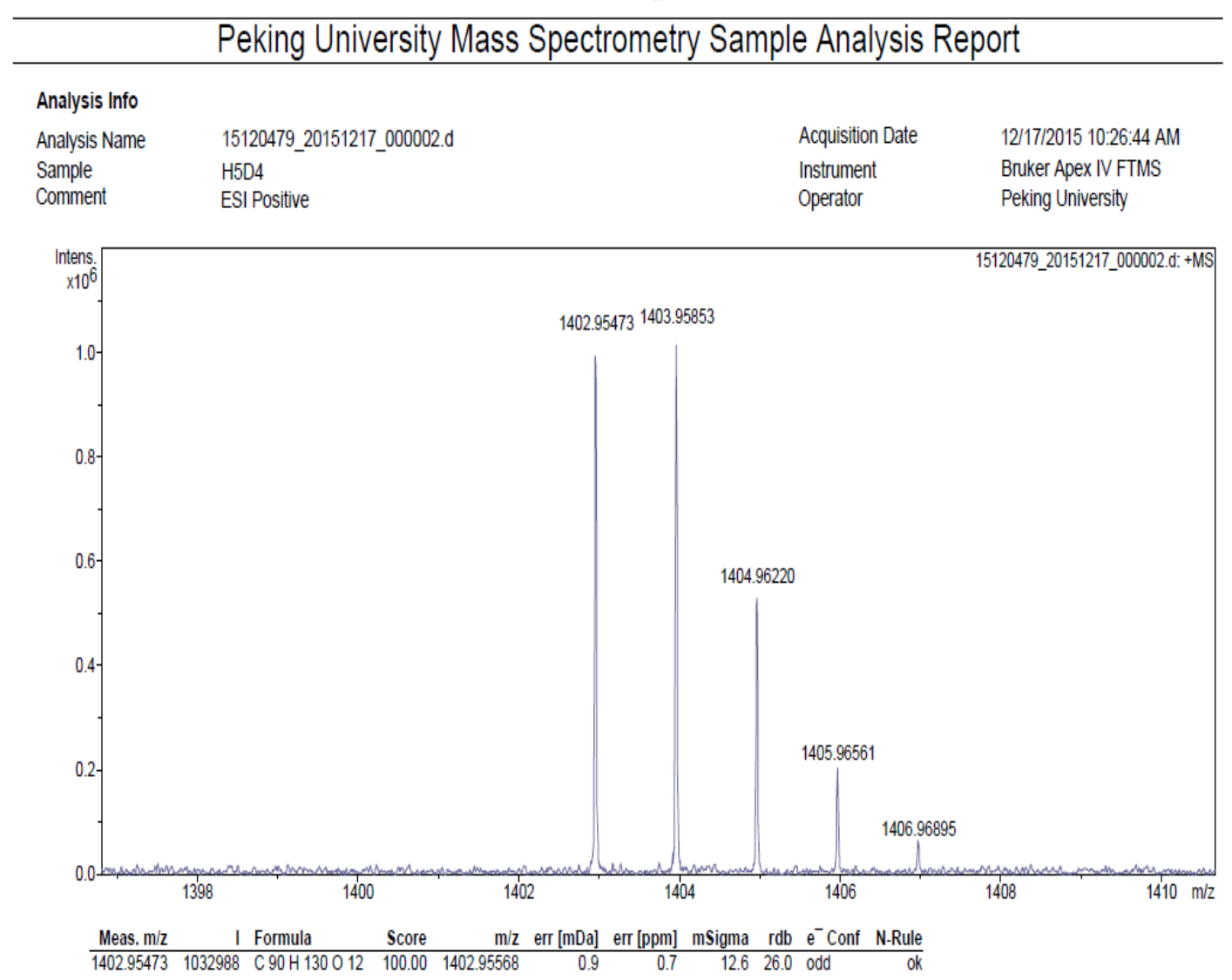

Fig. 30S HRMS spectra of T5D4 


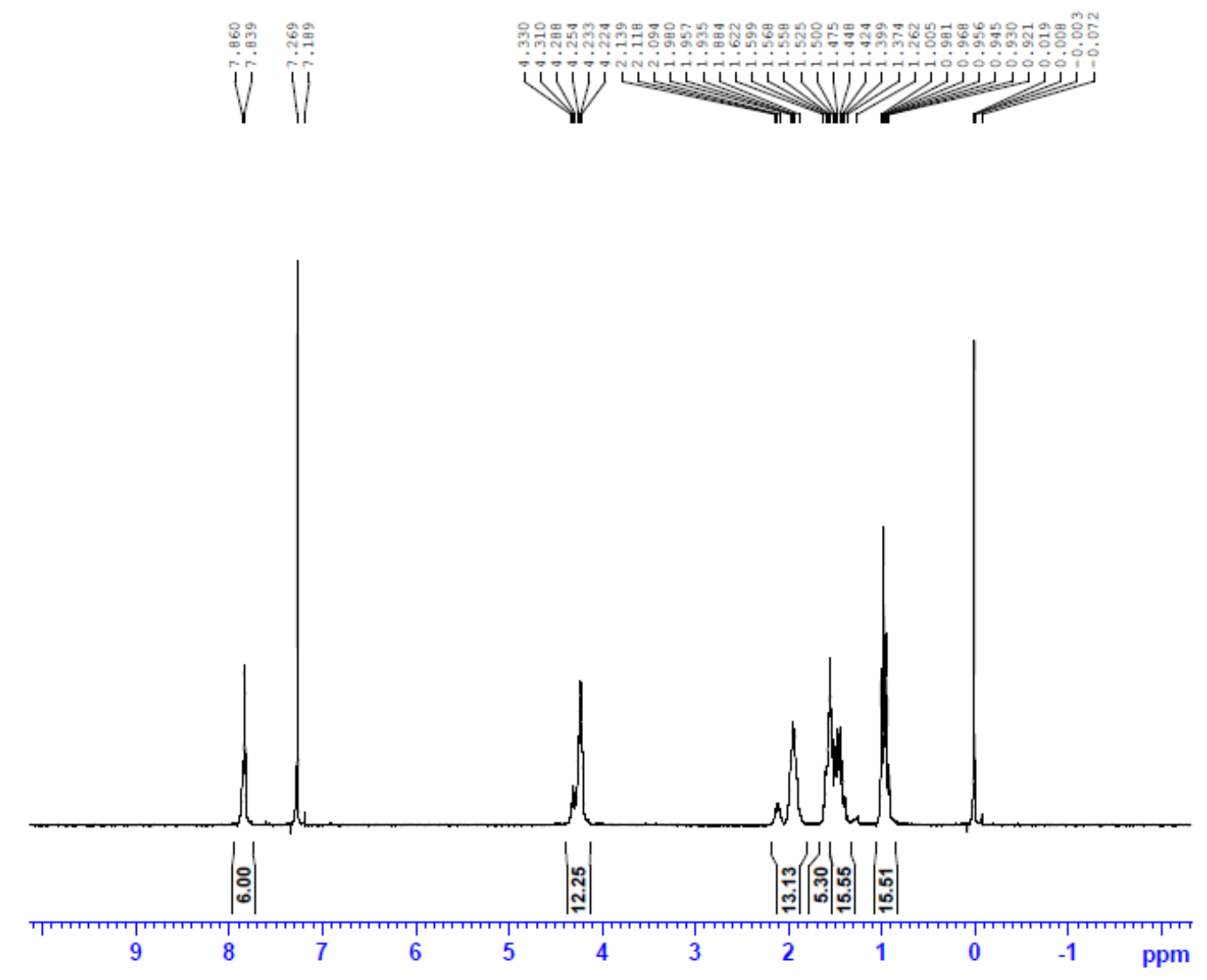

Fig. 31S ${ }^{1} \mathrm{H}$ NMR spectra of T5D5

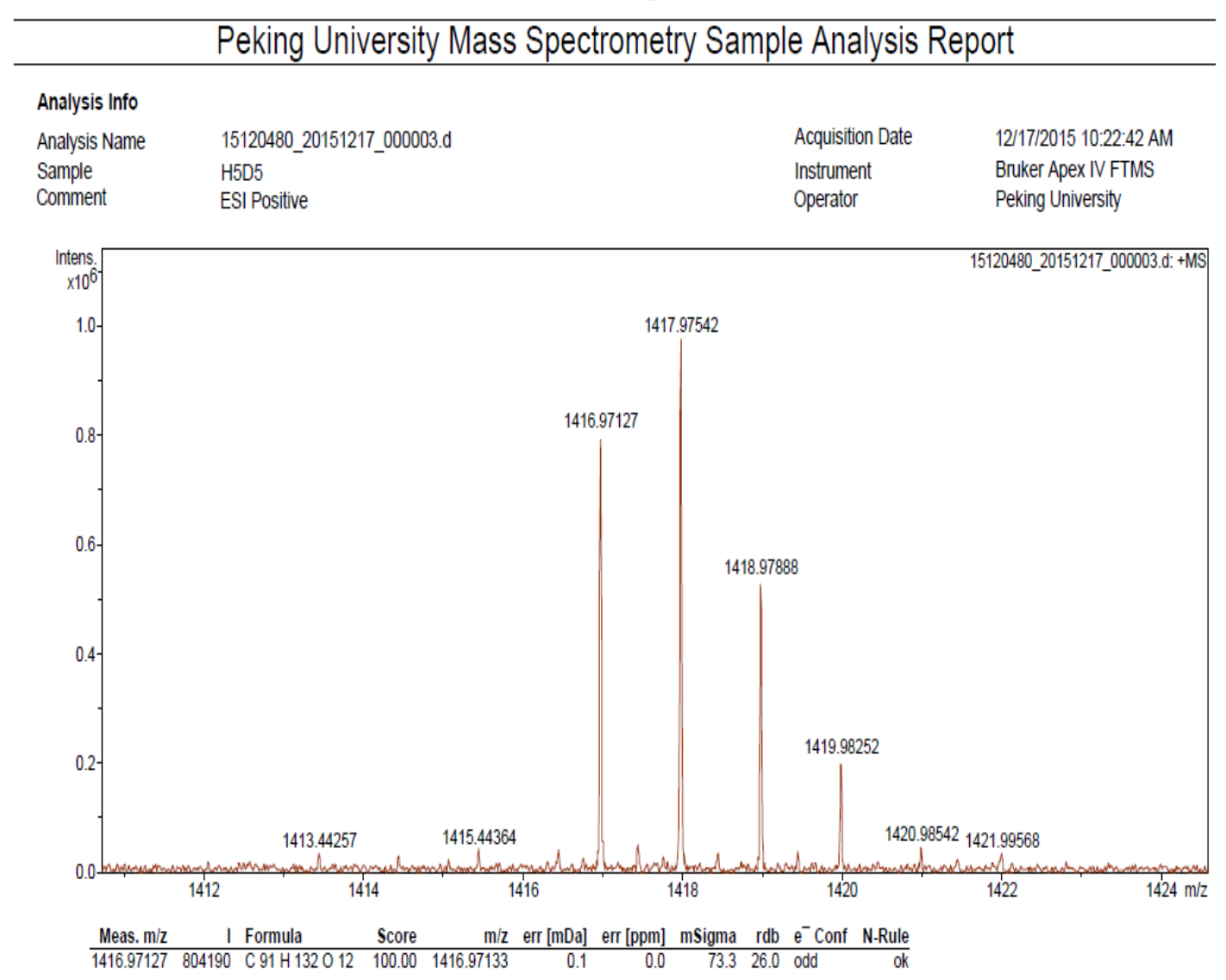

Fig. 32S HRMS spectra of T5D5 


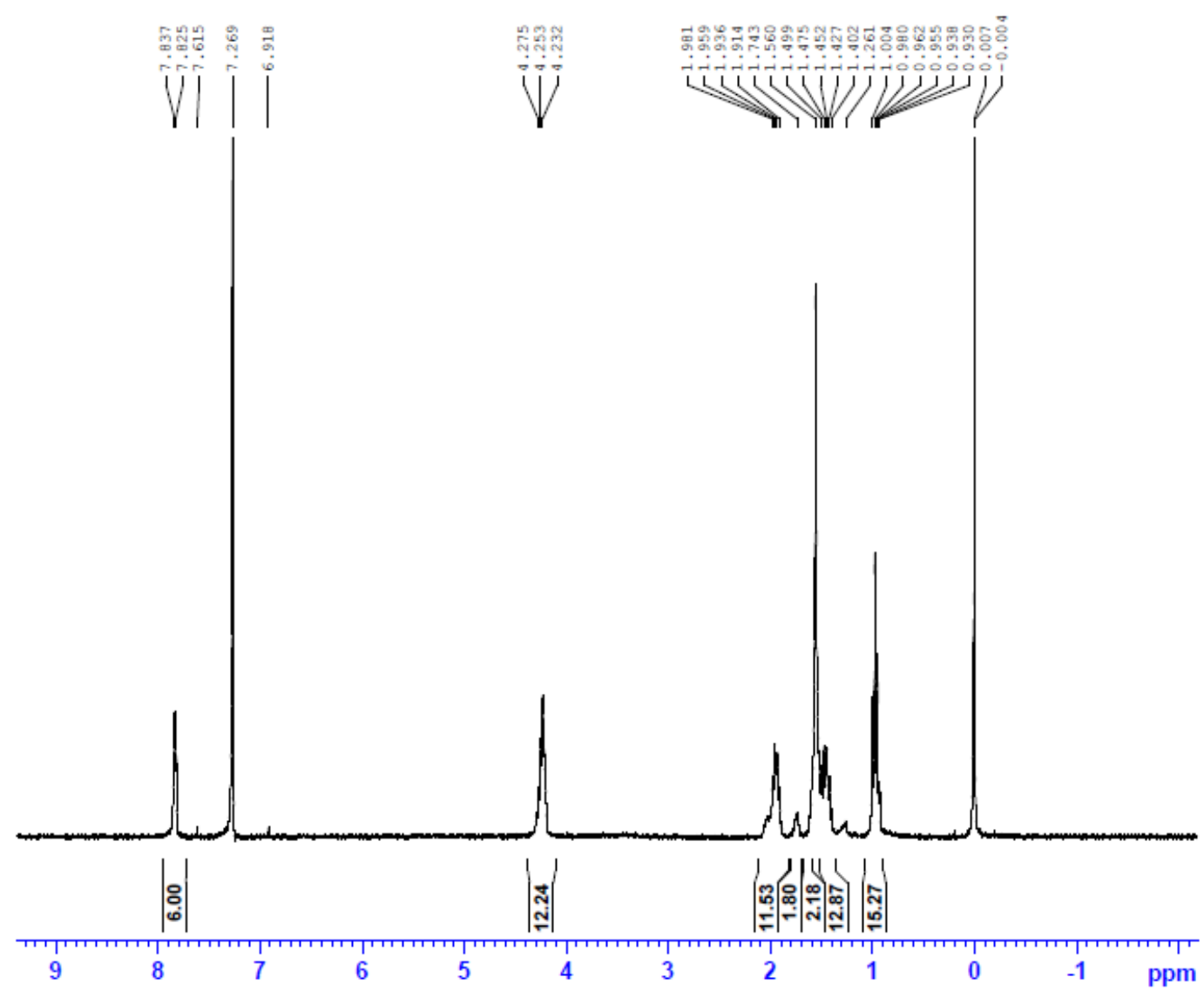

Fig. 33S ${ }^{1} \mathrm{H}$ NMR spectra of T5D6

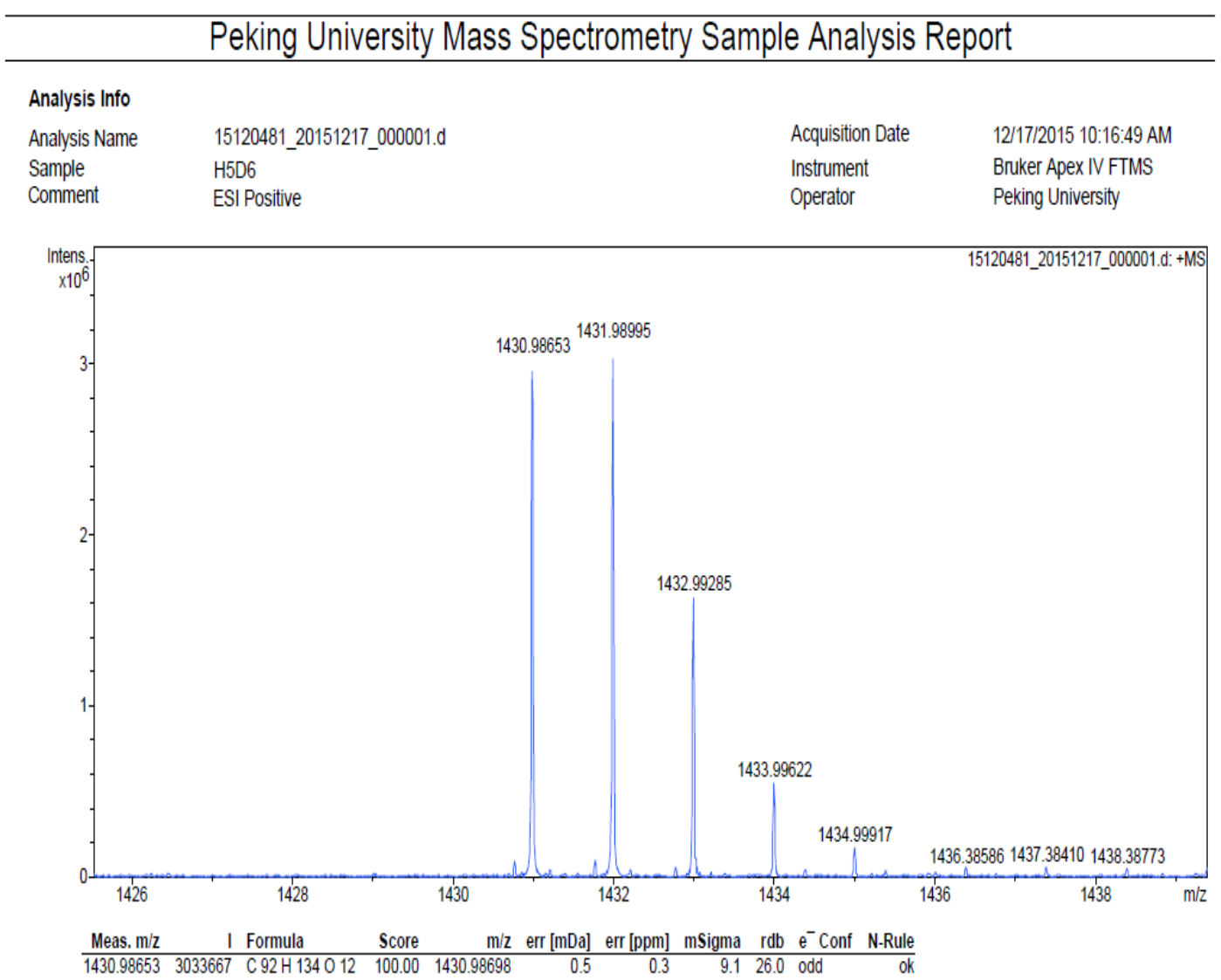

Fig. 34S HRMS spectra of T5D6 


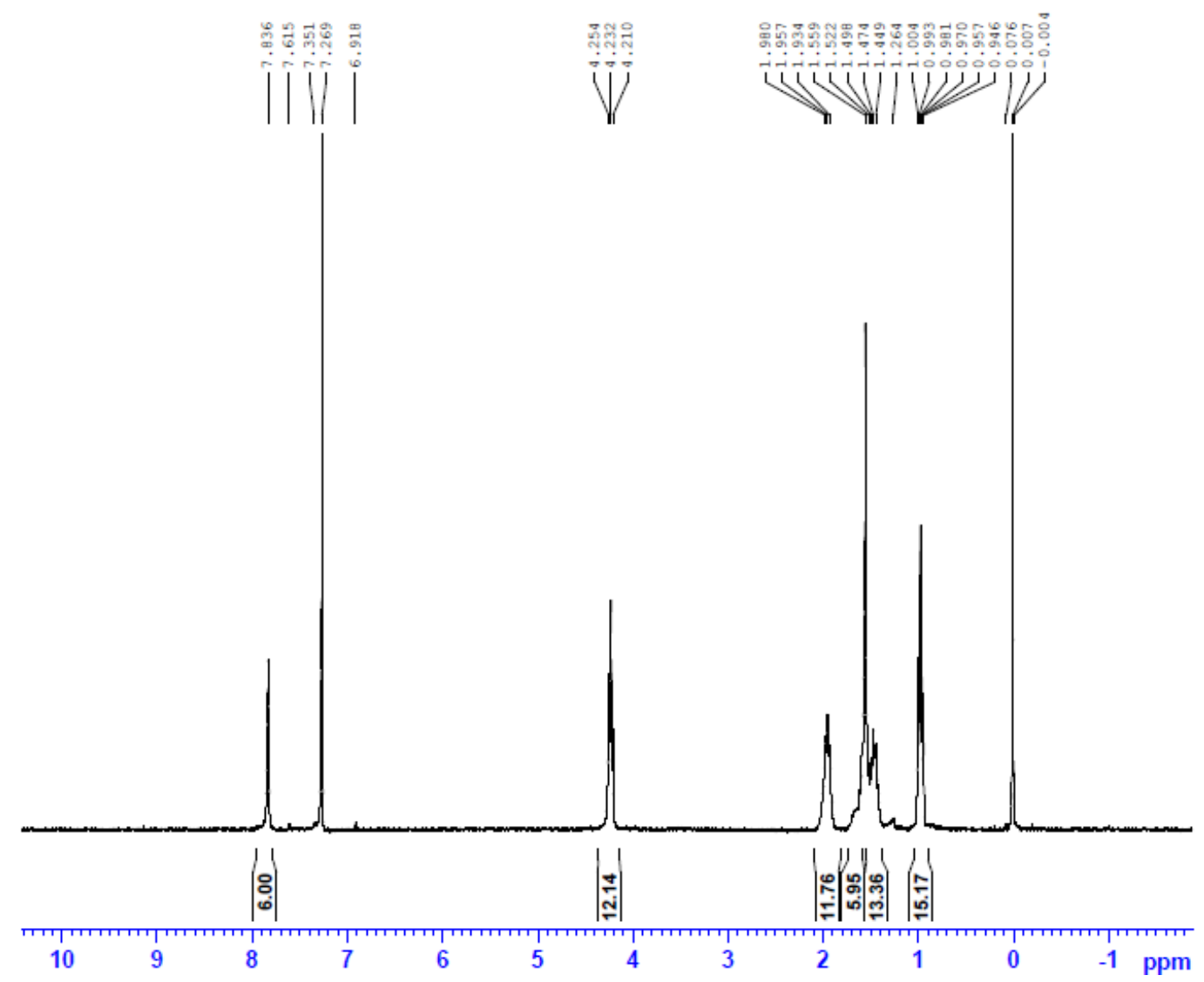

Fig. 35S ${ }^{1} \mathrm{H}$ NMR spectra of T5D7

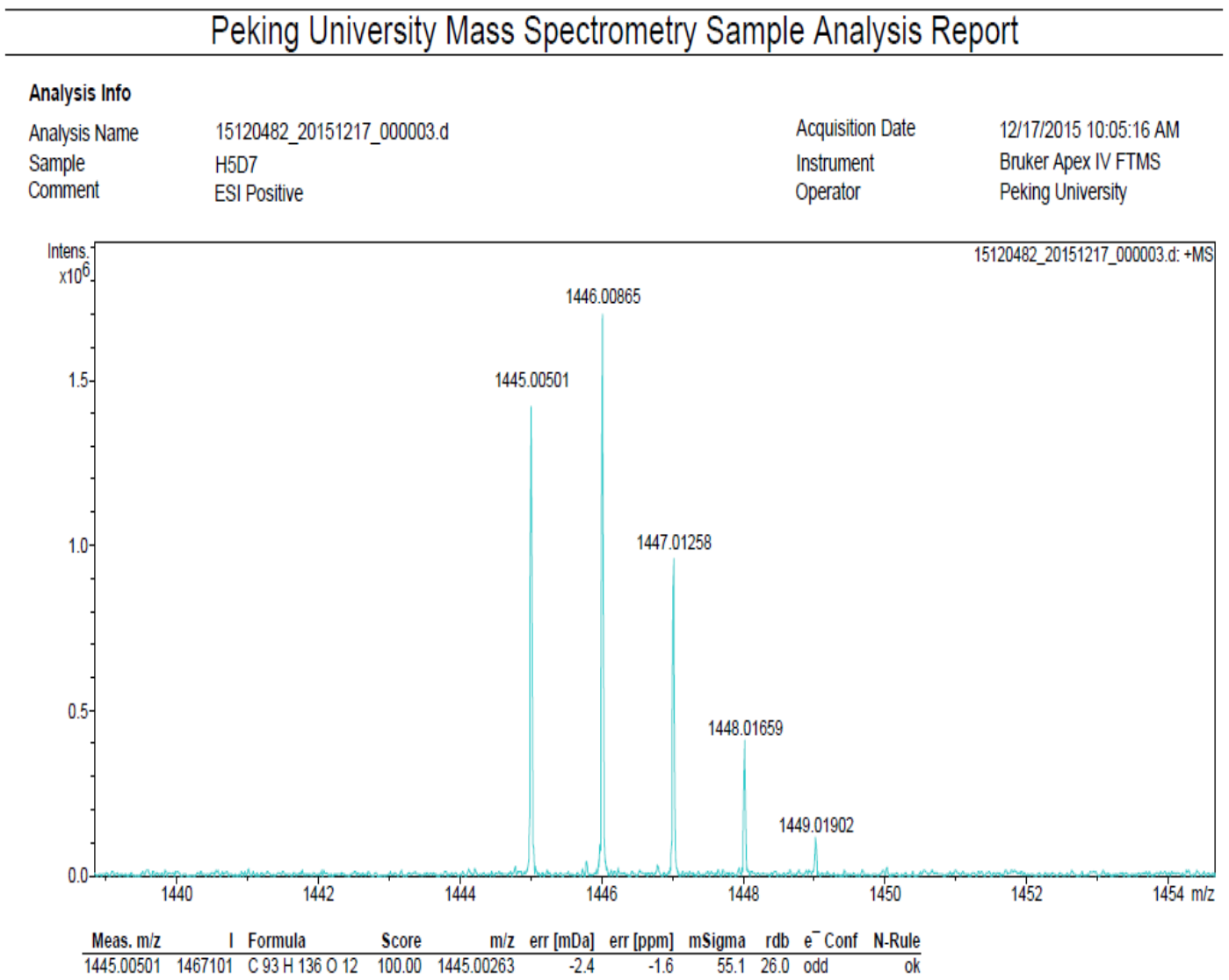

Fig. 36S HRMS spectra of T5D7 




Fig. 37S ${ }^{1} \mathrm{H}$ NMR spectra of T5D8

\begin{tabular}{llll}
\hline & Peking University Mass Spectrometry Sample Analysis Report \\
\hline Analysis Info & & & \\
Analysis Name & 15120483_20151217_000002.d & Acquisition Date & 12/17/2015 9:51:45 AM \\
Sample & H5D8 & Instrument & Bruker Apex IV FTMS \\
Comment & ESI Positive & Operator & Peking University
\end{tabular}

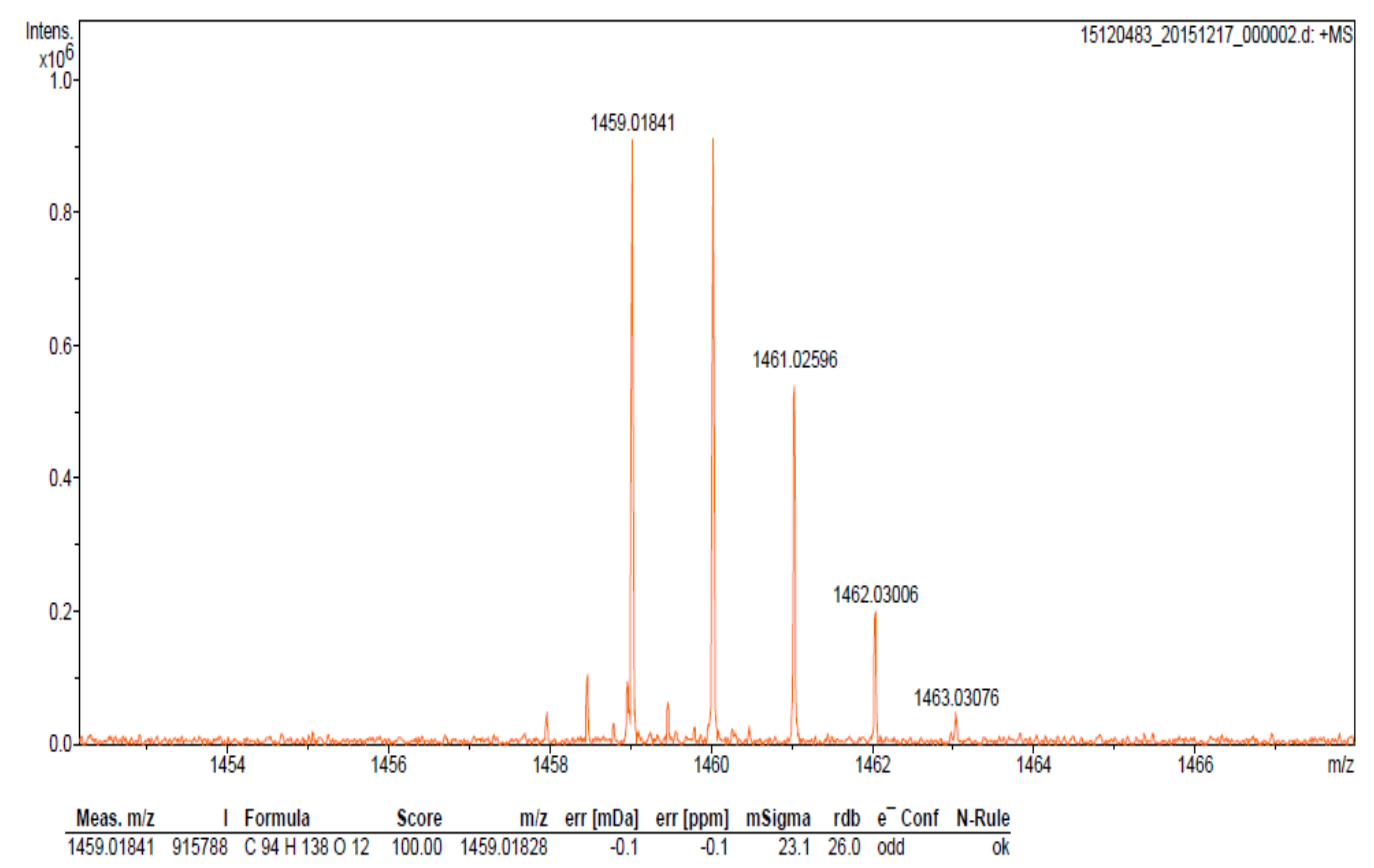

Fig. 38S HRMS spectra of T5D8 


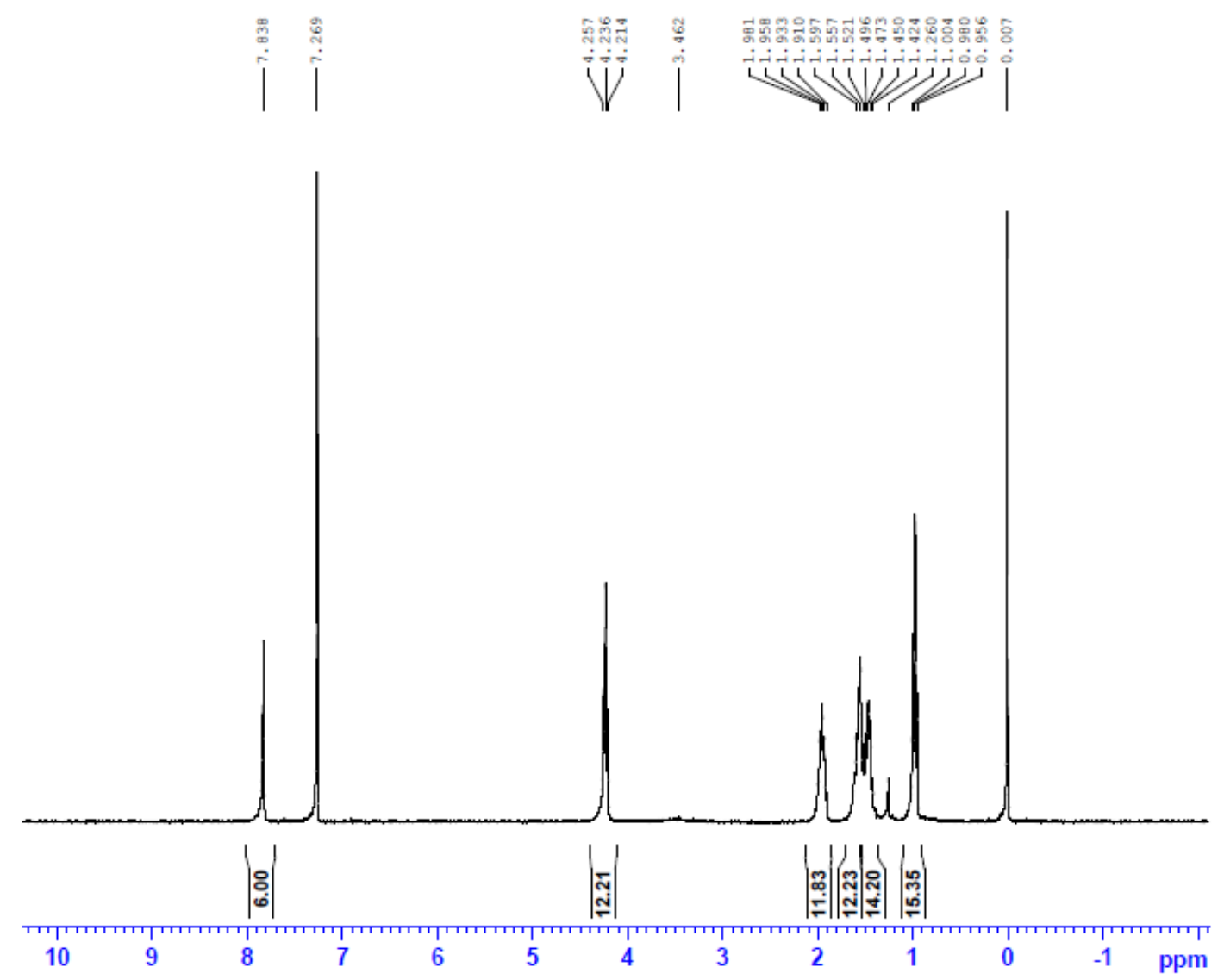

Fig. 39S ${ }^{1} \mathrm{H}$ NMR spectra of T5D9

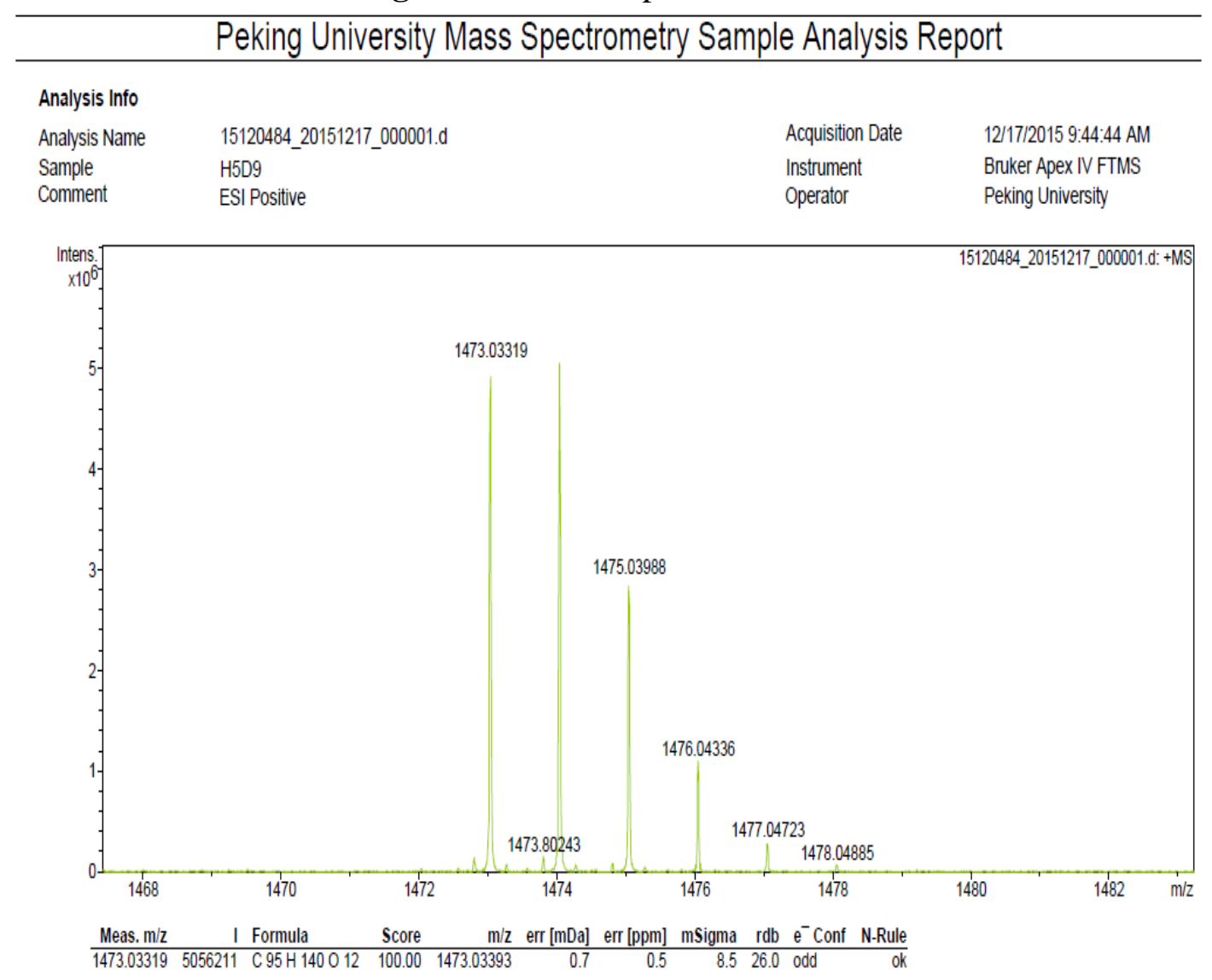

Fig. 40S HRMS spectra of T5D9 


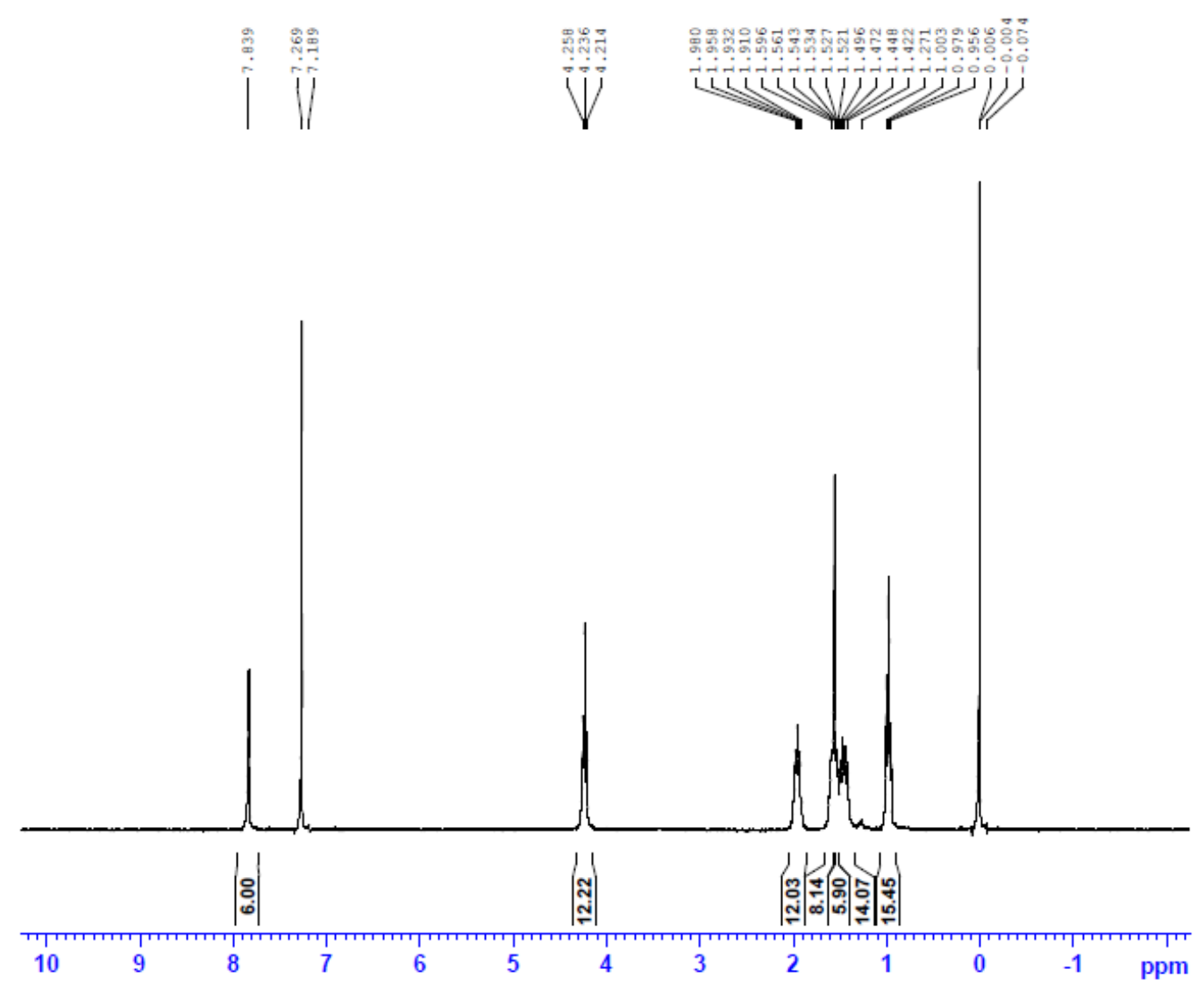

Fig. 41S ${ }^{1} \mathrm{H}$ NMR spectra of T5D10



Fig. 42S HRMS spectra of T5D10 


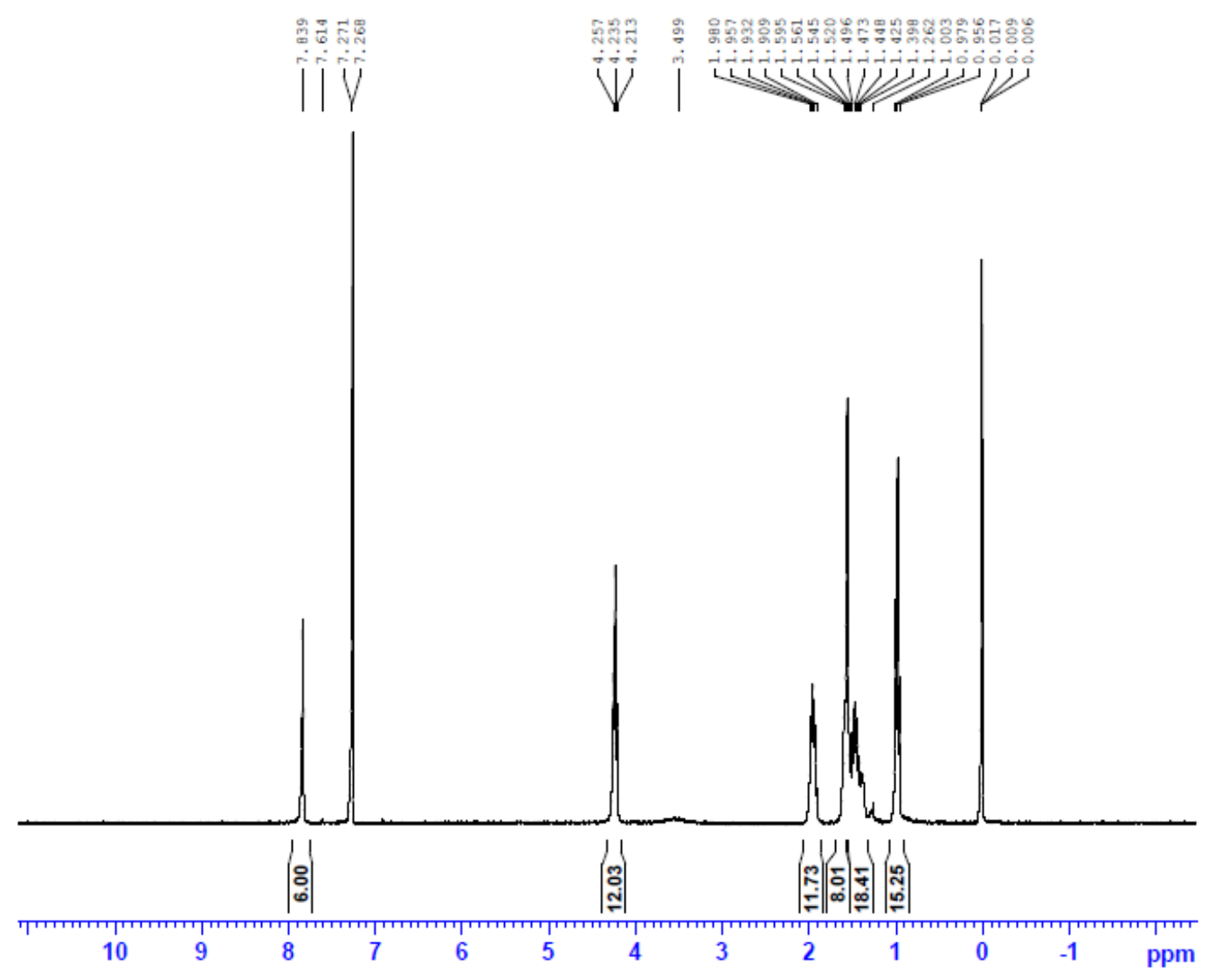

Fig. 43S ${ }^{1} \mathrm{H}$ NMR spectra of T5D11

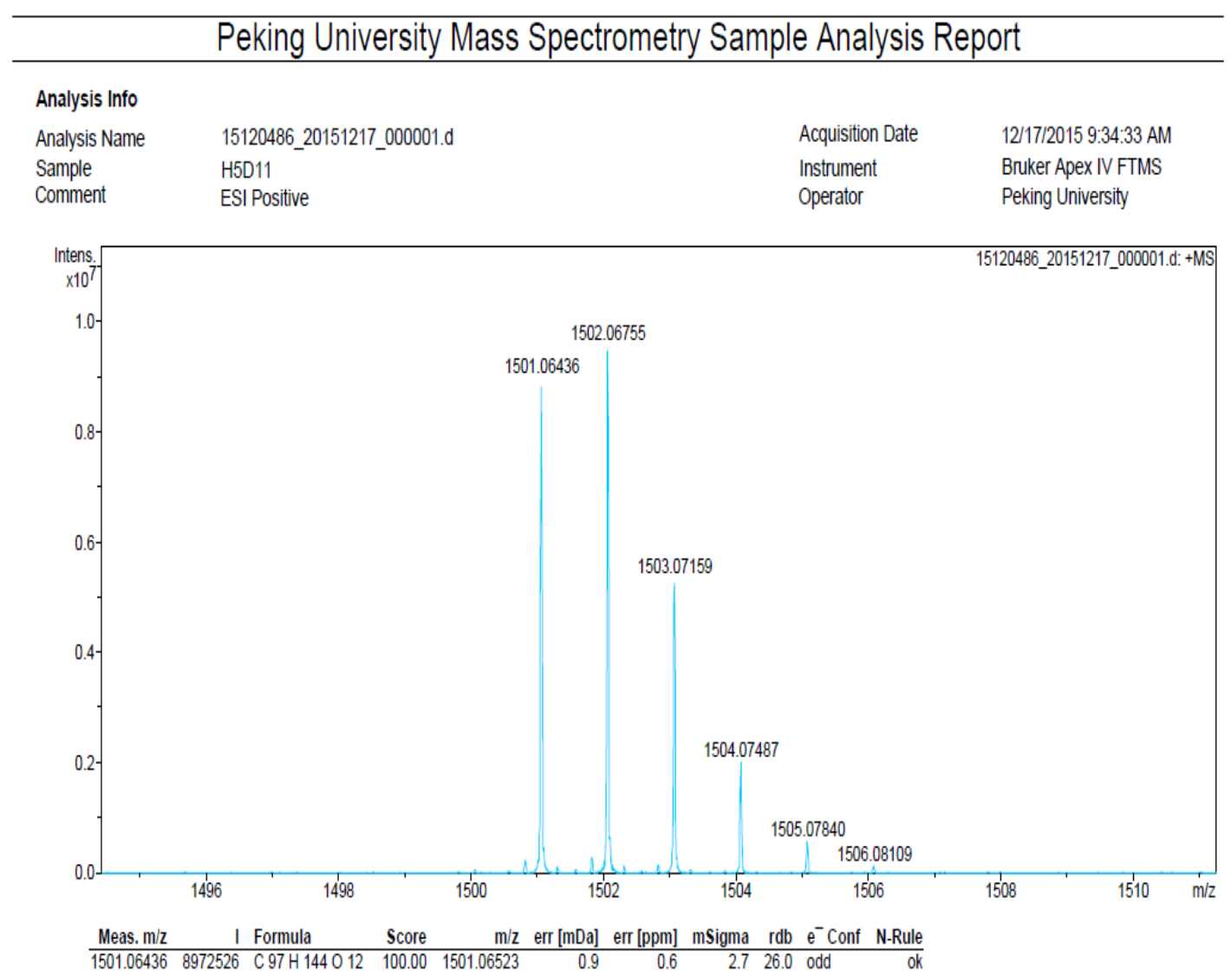

Fig. 44S HRMS spectra of T5D11 


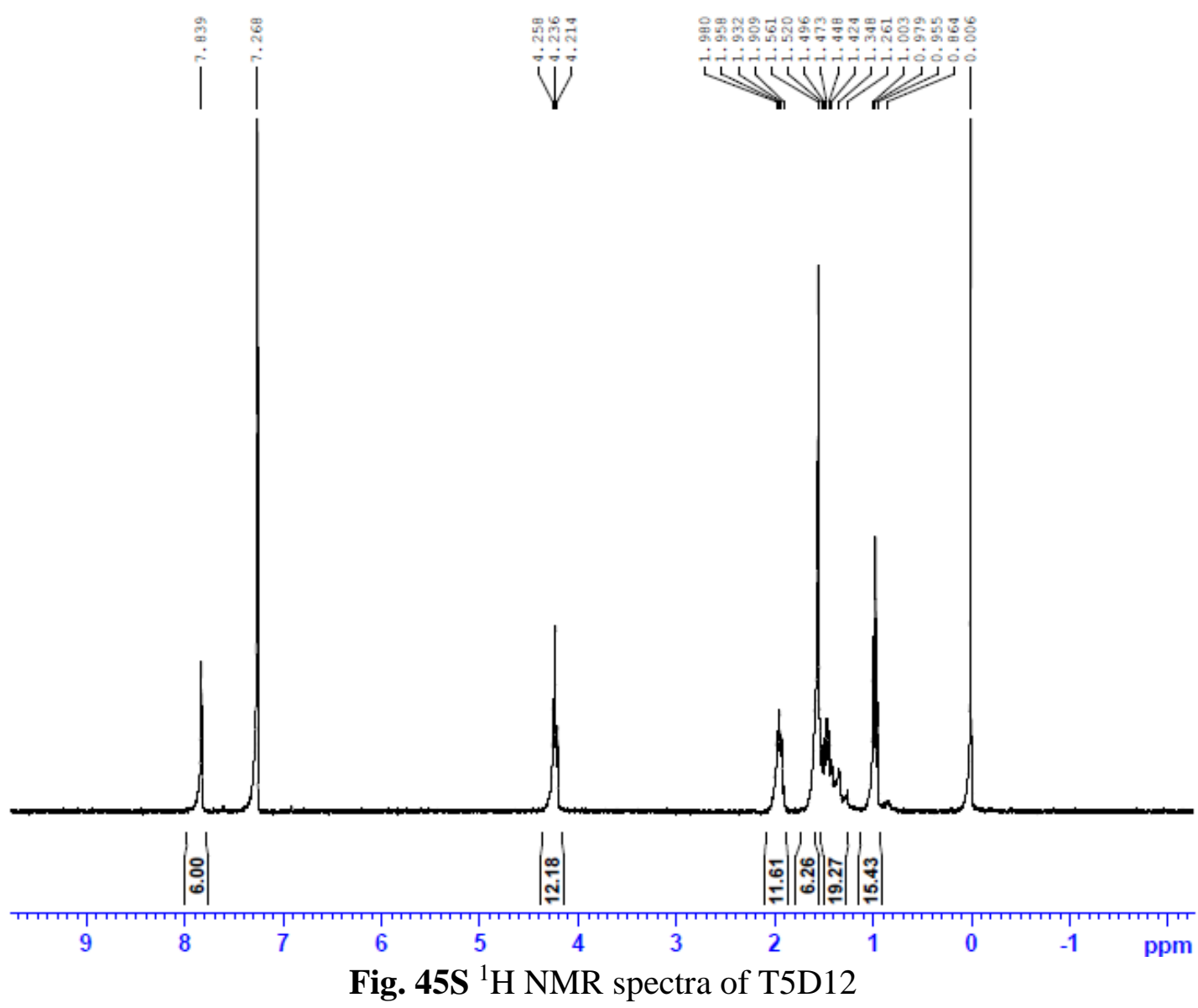

Fig. $45 \mathrm{~S}{ }^{1} \mathrm{H}$ NMR spectra of T5D12

Peking University Mass Spectrometry Sample Analysis Report

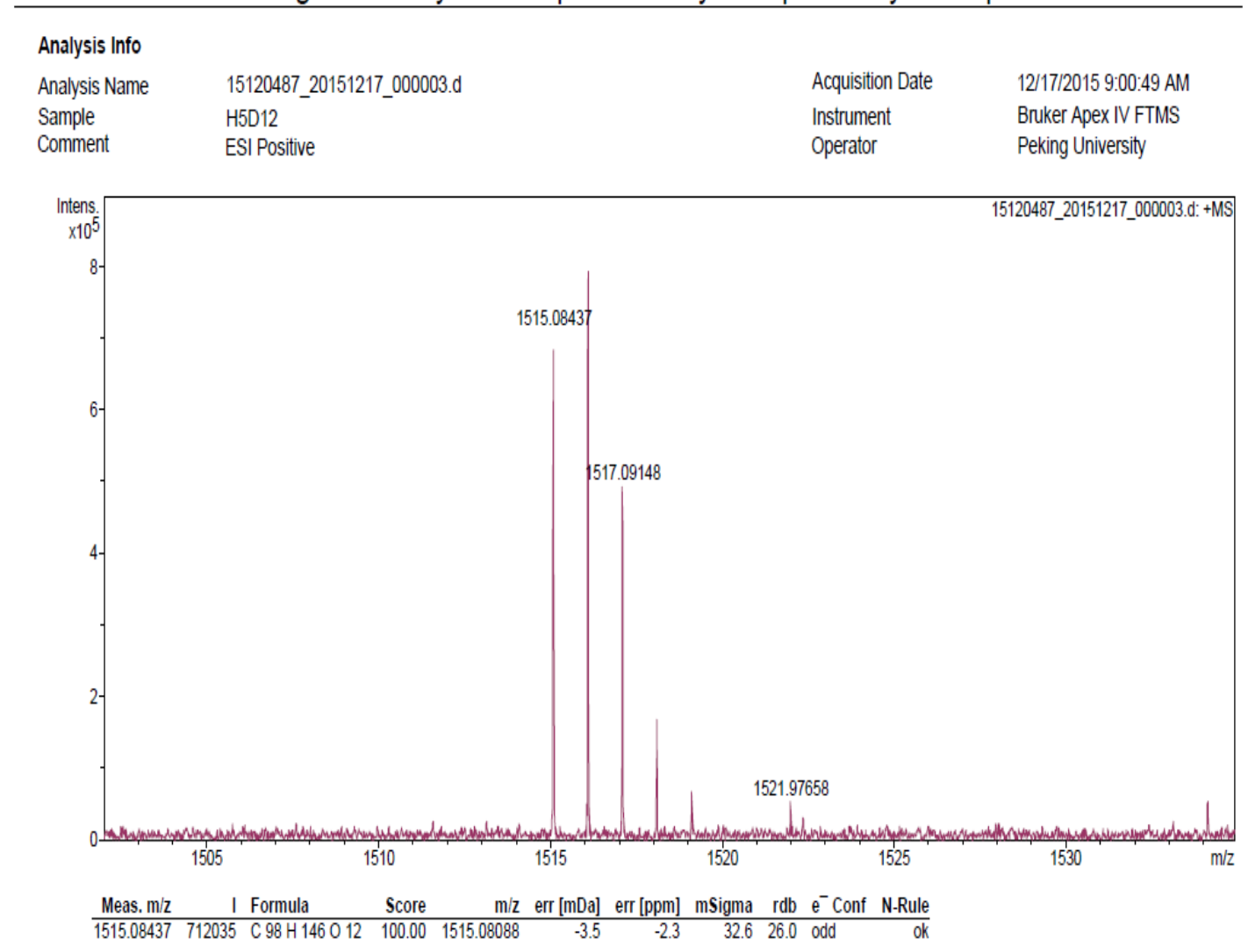

Fig. 46S HRMS spectra of T5D12 


\section{Mesomorphism}

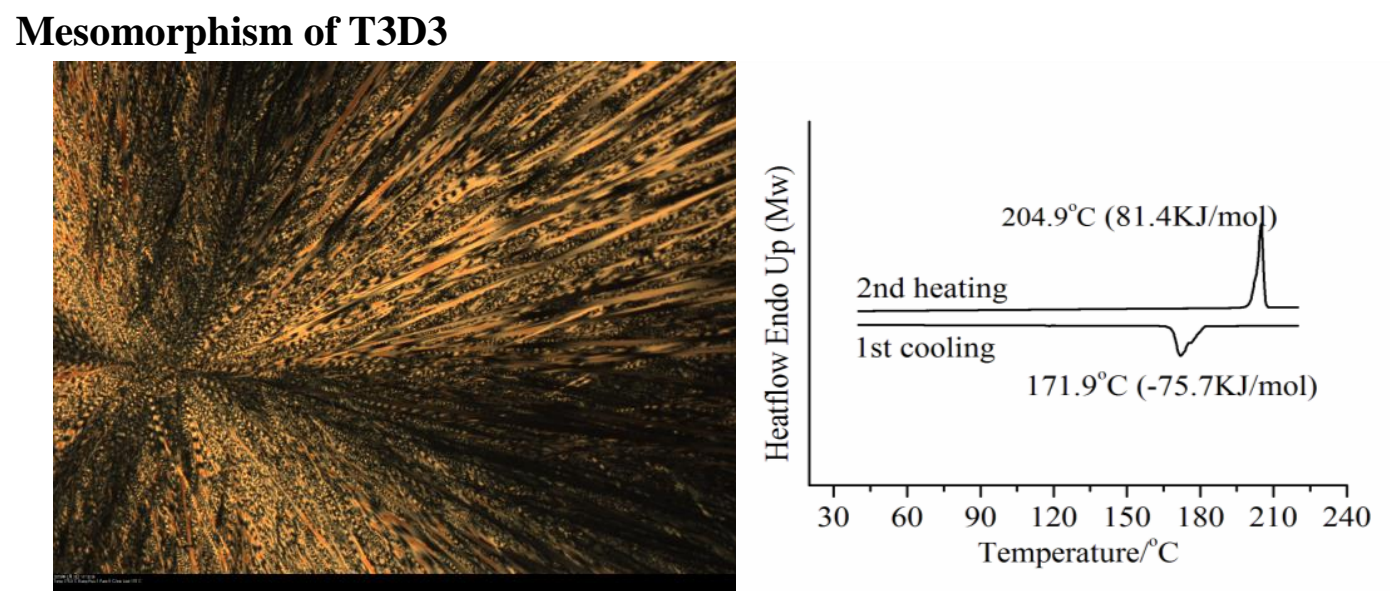

Fig. 47S Crystalline texture observed by POM with $90^{\circ}$ angle of compound T3D3 sandwiched between clean glass slides on cooling from isotropic phase at $175^{\circ} \mathrm{C}(\mathrm{left})$; DSC trace of compound T3D3 run at $10^{\circ} \mathrm{Cmin}^{-1}$ under $\mathrm{N}^{2}$ (right).

\section{Mesomorphism of T3D4}
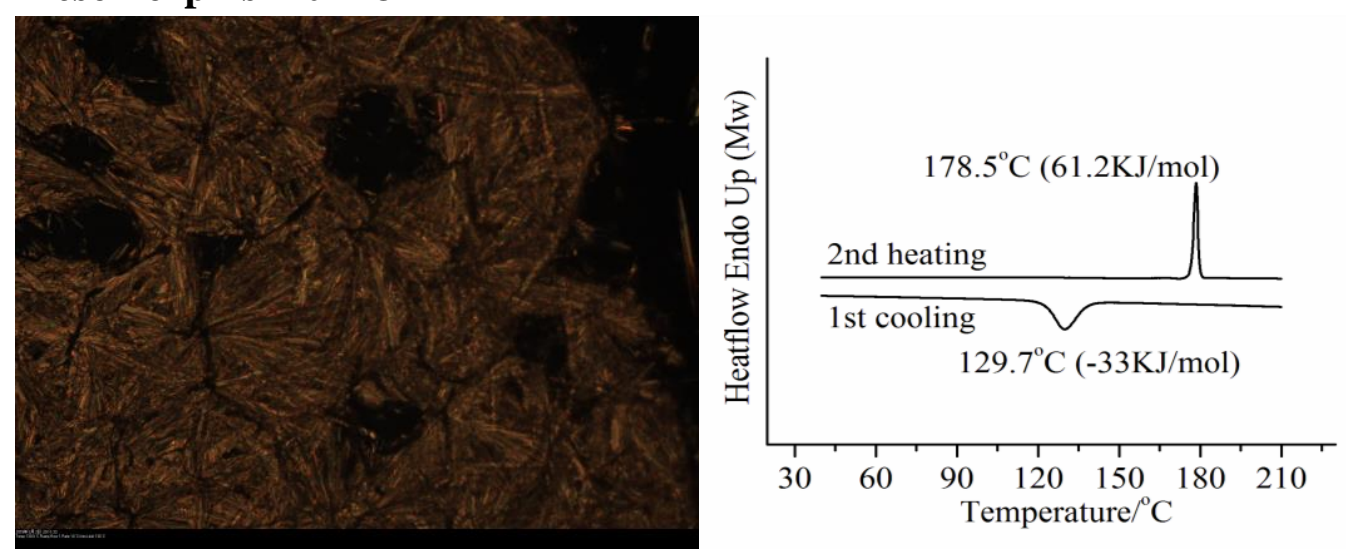

Fig. 48S Crystalline texture observed by POM with $90^{\circ}$ angle of compound T3D4 sandwiched between clean glass slides on cooling from isotropic phase at $120^{\circ} \mathrm{C}(\mathrm{left})$; DSC trace of compound T3D4 run at $10^{\circ} \mathrm{Cmin}^{-1}$ under $\mathrm{N}^{2}$ (right).

\section{Mesoorphism of T3D5}

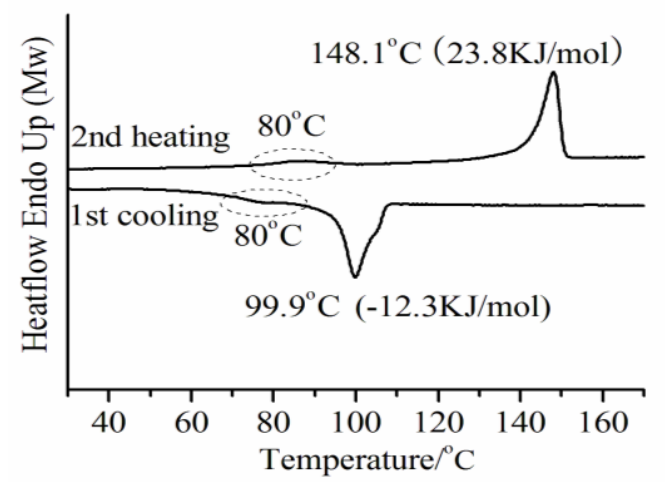

Fig. 49S DSC trace of compound T3D5 run at $10^{\circ} \mathrm{Cmin}^{-1}$ under $\mathrm{N}^{2}$ (right). 


\section{Mesomorphism of T3D6}

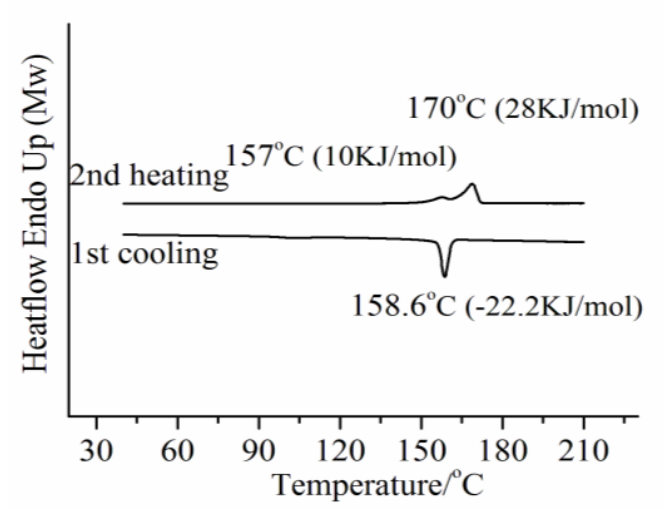

Fig. 50S DSC trace of compound T3D6 run at $10^{\circ} \mathrm{Cmin}^{-1}$ under $\mathrm{N}^{2}$ (right).

\section{Mesomorphism of T3D7}

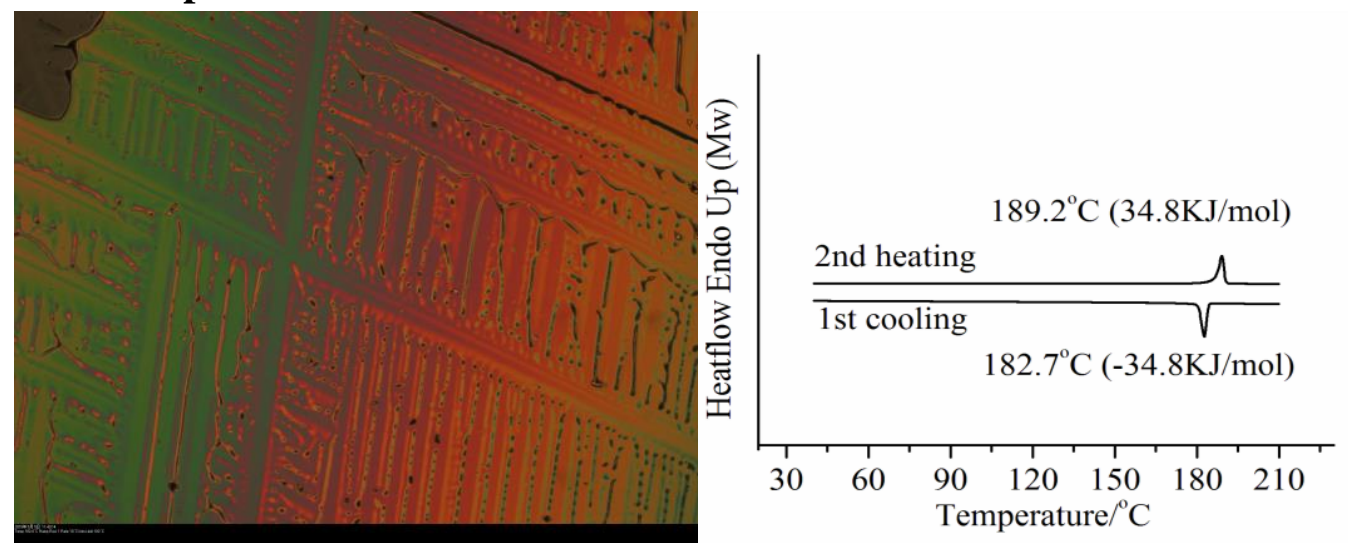

Fig. 51S Dendritic texture observed by POM with $90^{\circ}$ angle of compound T3D7 sandwiched between clean glass slides on cooling from isotropic phase at $179^{\circ} \mathrm{C}(\mathrm{left})$; DSC trace of compound T3D7 run at $10^{\circ} \mathrm{Cmin}^{-1}$ under $\mathrm{N}^{2}$ (right).

\section{Mesomorphism of T3D8}

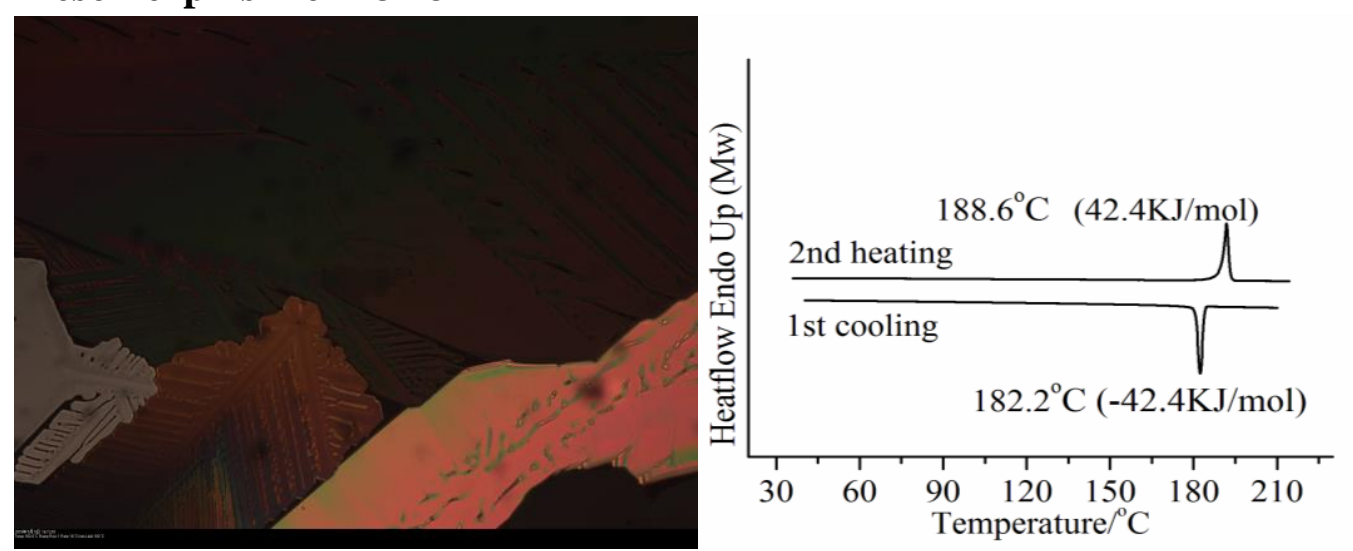

Fig. $52 \mathrm{~S}$ Dendritic texture observed by POM with $90^{\circ}$ angle of compound T3D8 sandwiched between clean glass slides on cooling from isotropic phase at $178^{\circ} \mathrm{C}(\mathrm{left})$; DSC trace of compound T3D8run at $10^{\circ} \mathrm{Cmin}^{-1}$ under $\mathrm{N}^{2}$ (right). 


\section{Mesomorphism of T3D9}
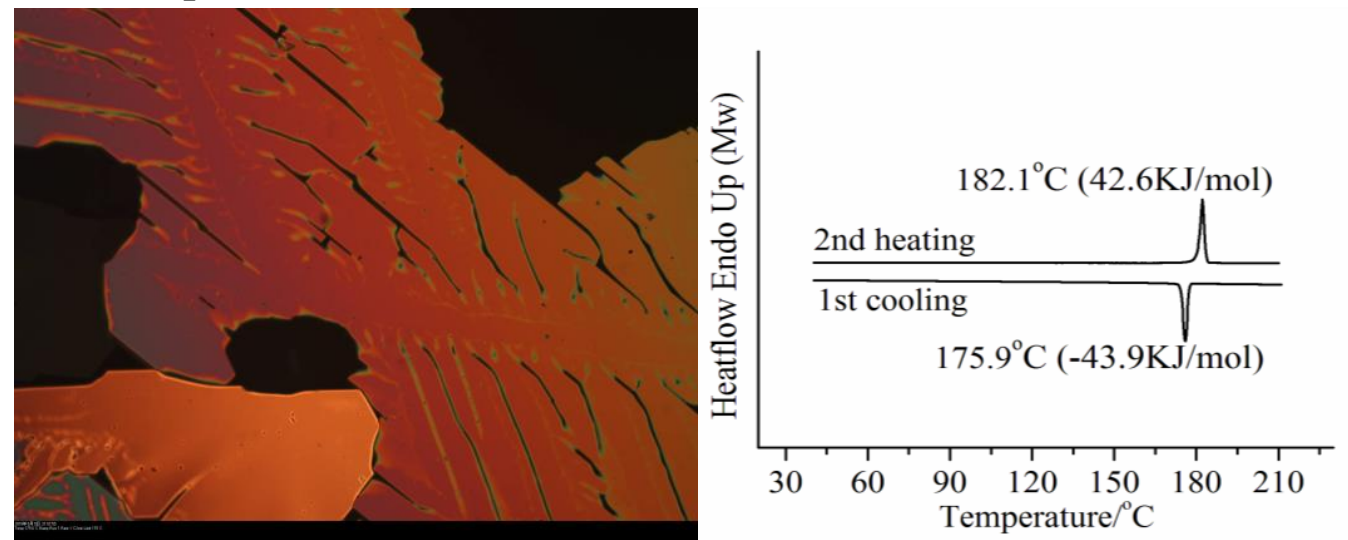

Fig. 53S Dendritic texture observed by POM with $90^{\circ}$ angle of compound T3D 9 sandwiched between clean glass slides on cooling from isotropic phase at $172^{\circ} \mathrm{C}(\mathrm{left})$; DSC trace of compound T3D9run at $10^{\circ} \mathrm{Cmin}^{-1}$ under $\mathrm{N}^{2}$ (right).

\section{Msemorphism of T3D10}
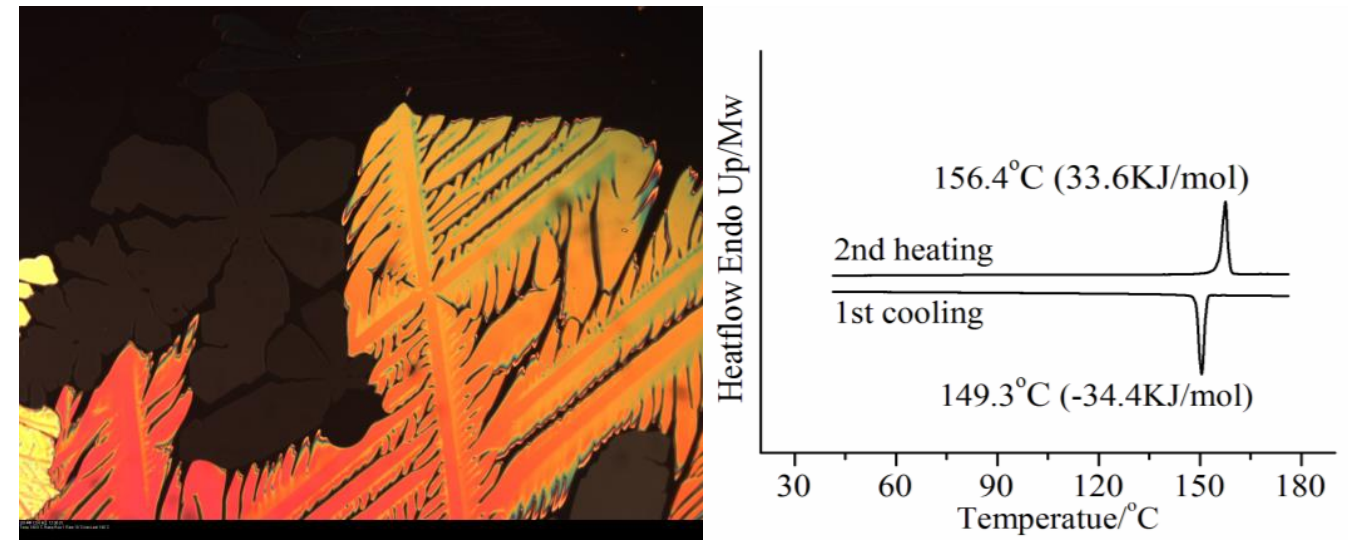

Fig. 54S Dendritic texture observed by POM with $90^{\circ}$ angle of compound T3D10 sandwiched between clean glass slides on cooling from isotropic phase at $140^{\circ} \mathrm{C}(\mathrm{left})$; DSC trace of compound T3D10run at $10^{\circ} \mathrm{Cmin}^{-1}$ under $\mathrm{N}^{2}$ (right).

\section{Mesomorphism of T3D11}
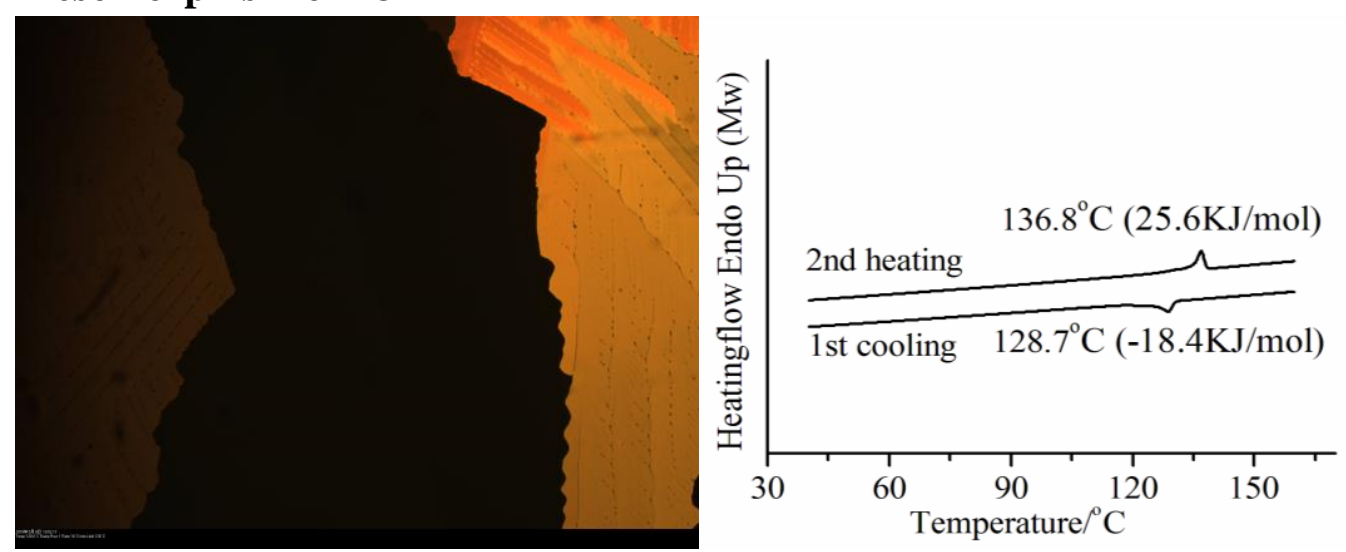

Fig. 55S Dendritic texture observed by POM with $90^{\circ}$ angle of compound T3D11 sandwiched between clean glass slides on cooling from isotropic phase at $118^{\circ} \mathrm{C}(\mathrm{left})$; DSC trace of compound T3D11run at $10^{\circ} \mathrm{Cmin}^{-1}$ under $\mathrm{N}^{2}$ (right). 


\section{Mesomorphism of T3D12}
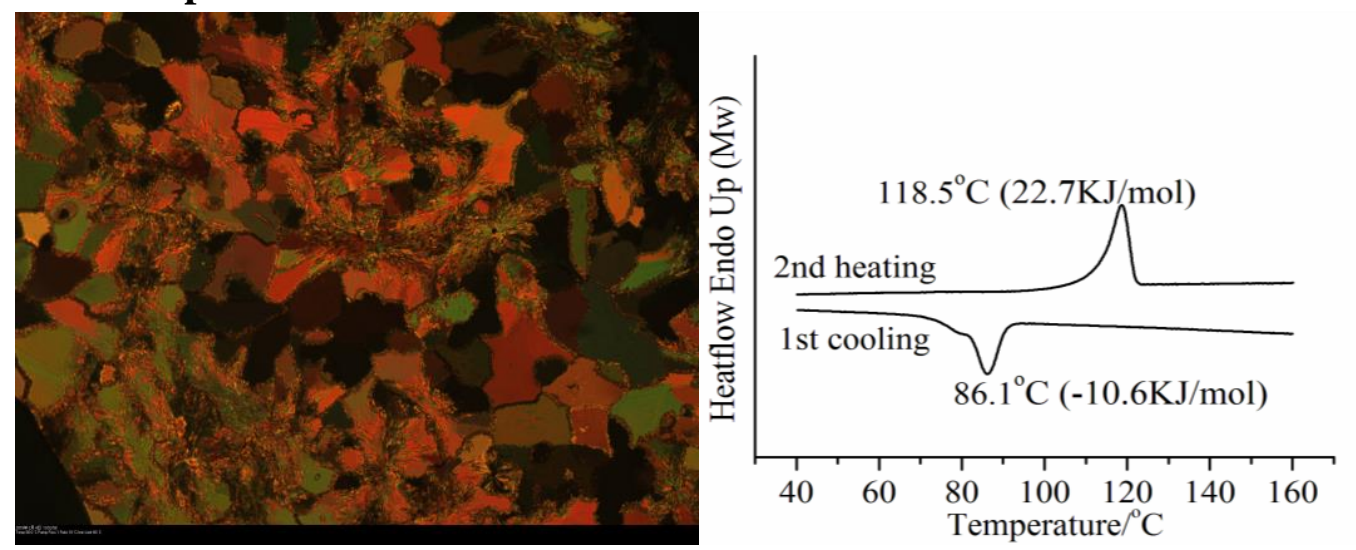

Fig. 56S Mosaic texture observed by POM with $90^{\circ}$ angle of compound T3D12 sandwiched between clean glass slides on cooling from isotropic phase at $80^{\circ} \mathrm{C}(\mathrm{left})$; DSC trace of compound T3D12run at $10^{\circ} \mathrm{Cmin}^{-1}$ under $\mathrm{N}^{2}$ (right).

\section{Mesomorphism of T5D3}
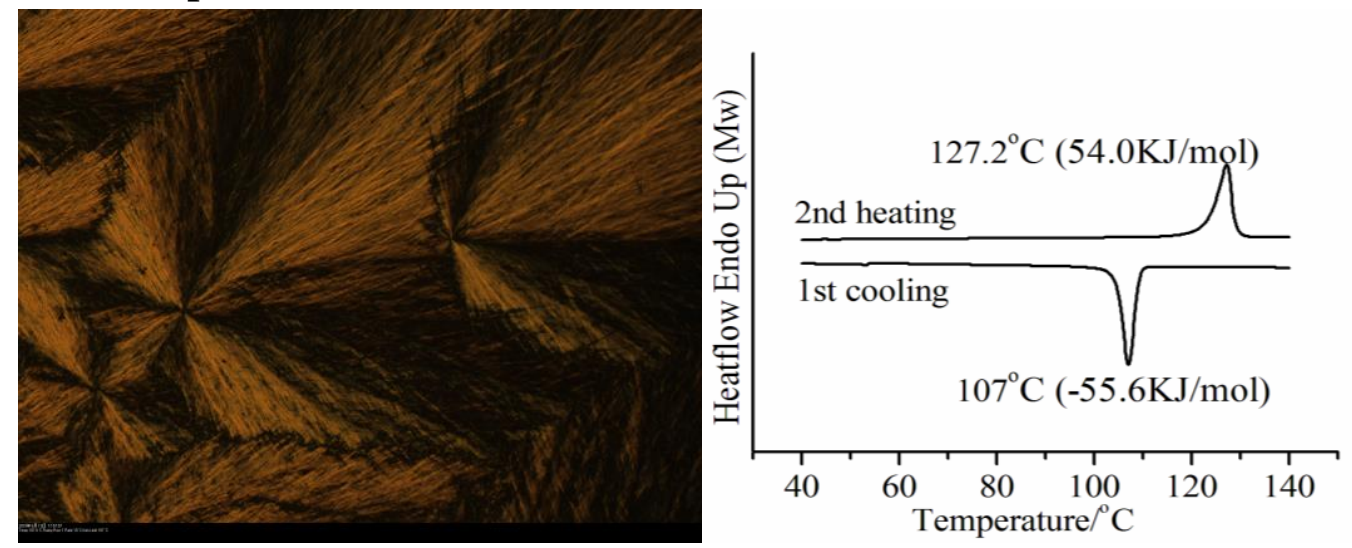

Fig. 57S Crystalline texture observed by POM with $90^{\circ}$ angle of compound T5D3 sandwiched between clean glass slides on cooling from isotropic phase at $107^{\circ} \mathrm{C}$ (left); DSC trace of compound T5D3 run at $10^{\circ} \mathrm{Cmin}^{-1}$ under $\mathrm{N}^{2}$ (right).

\section{Mesomorphism of T5D4}


Fig. 58S Crystalline texture observed by POM with $90^{\circ}$ angle of compound T5D4 sandwiched between clean glass slides on cooling from isotropic phase at $102^{\circ} \mathrm{C}(\mathrm{left})$; DSC trace of compound T5D4 run at $10^{\circ} \mathrm{Cmin}^{-1}$ under $\mathrm{N}^{2}$ (right). 


\section{Mesomorphism of T5D5}
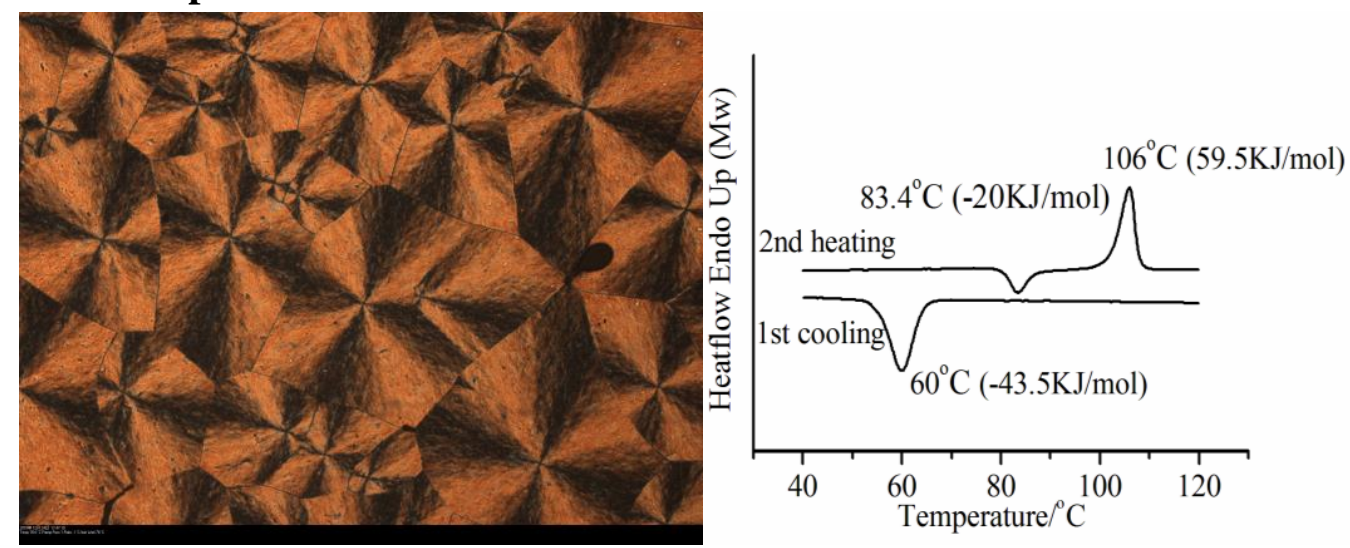

Fig. 59S Crystalline texture observed by POM with $90^{\circ}$ angle of compound T5D5 sandwiched between clean glass slides on cooling from isotropic phase at $40^{\circ} \mathrm{C}$ (left); DSC trace of compound T5D5 run at $10^{\circ} \mathrm{Cmin}^{-1}$ under $\mathrm{N}^{2}$ (right).

\section{Mesomorphism of T5D6}


Fig. 60S Fan-shaped texture observed by POM with $90^{\circ}$ angle of compound T5D6 sandwiched between clean glass slides on cooling from isotropic phase at $85^{\circ} \mathrm{C}(\mathrm{left})$; DSC trace of compound T5D6 run at $10^{\circ} \mathrm{Cmin}^{-1}$ under $\mathrm{N}^{2}$ (right).

\section{Mesomorphism of T5D7}
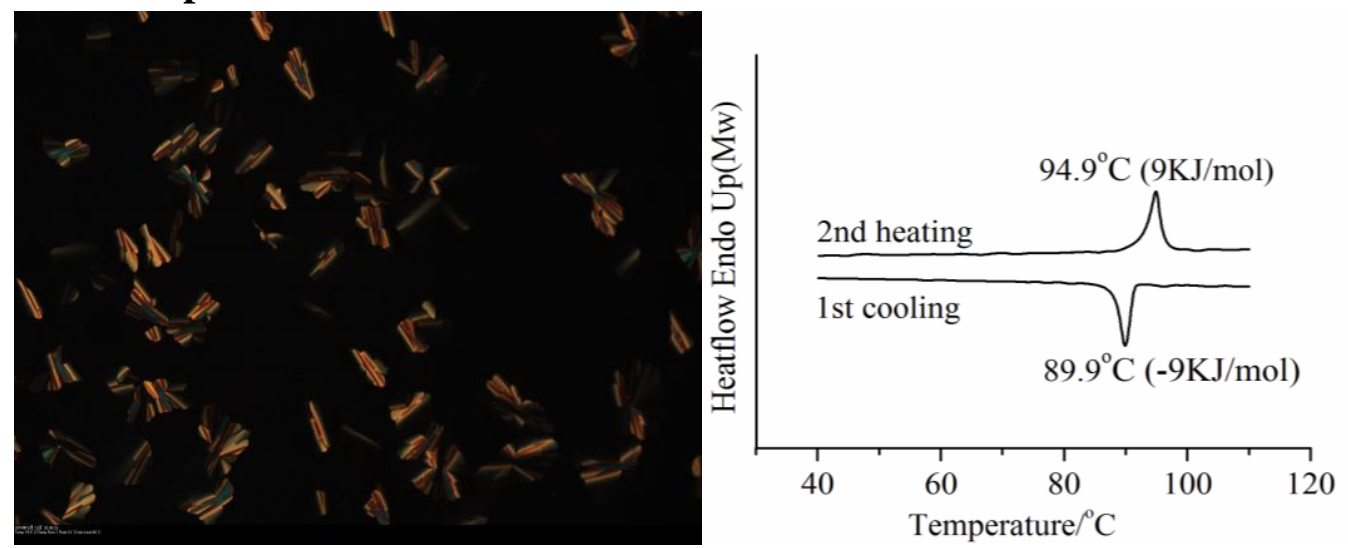

Fig. 61S Fan-shaped texture observed by POM with $90^{\circ}$ angle of compound T5D7 sandwiched between clean glass slides on cooling from isotropic phase at $85^{\circ} \mathrm{C}(\mathrm{left})$; 
DSC trace of compound T5D7 run at $10^{\circ} \mathrm{Cmin}^{-1}$ under $\mathrm{N}^{2}$ (right).

\section{Mesomorphism of T5D8}
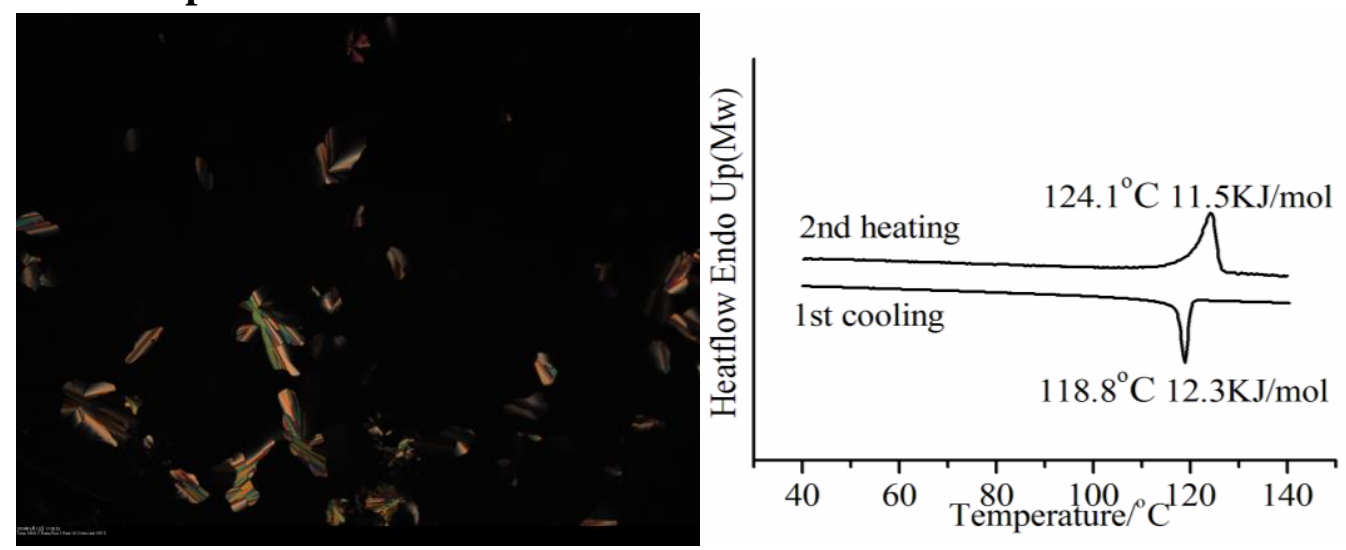

Fig. 62S Fan-shaped texture observed by POM with $90^{\circ}$ angle of compound T5D8 sandwiched between clean glass slides on cooling from isotropic phase at $114^{\circ} \mathrm{C}(\mathrm{left})$; DSC trace of compound T5D8 run at $10^{\circ} \mathrm{Cmin}^{-1}$ under $\mathrm{N}^{2}$ (right).

\section{Mesomorphism of T5D9}
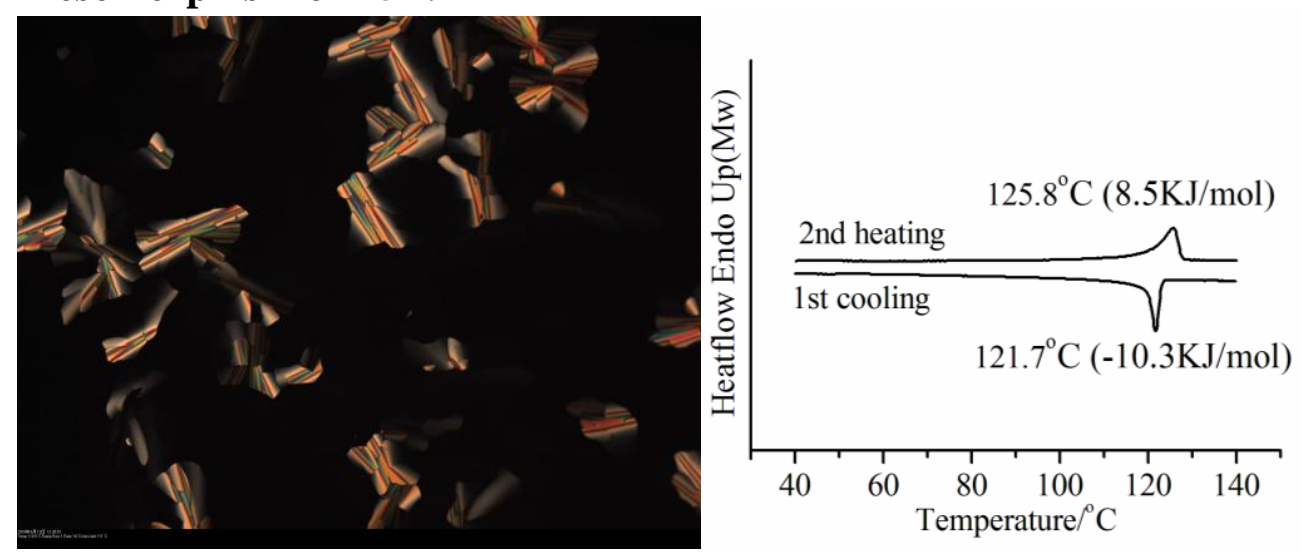

Fig. 63S Fan-shaped texture observed by POM with $90^{\circ}$ angle of compound T5D9 sandwiched between clean glass slides on cooling from isotropic phase at $116^{\circ} \mathrm{C}(\mathrm{left})$; DSC trace of compound T5D9 run at $10^{\circ} \mathrm{Cmin}^{-1}$ under $\mathrm{N}^{2}$ (right).

\section{Mesomorphism of T5D10}


Fig. 64S Fan-shaped texture observed by POM with $90^{\circ}$ angle of compound T5D10 
sandwiched between clean glass slides on cooling from isotropic phase at $126^{\circ} \mathrm{C}(\mathrm{left})$; DSC trace of compound T5D10 run at $10^{\circ} \mathrm{Cmin}^{-1}$ under $\mathrm{N}^{2}$ (right).

\section{Moesomorphism of T5D11}

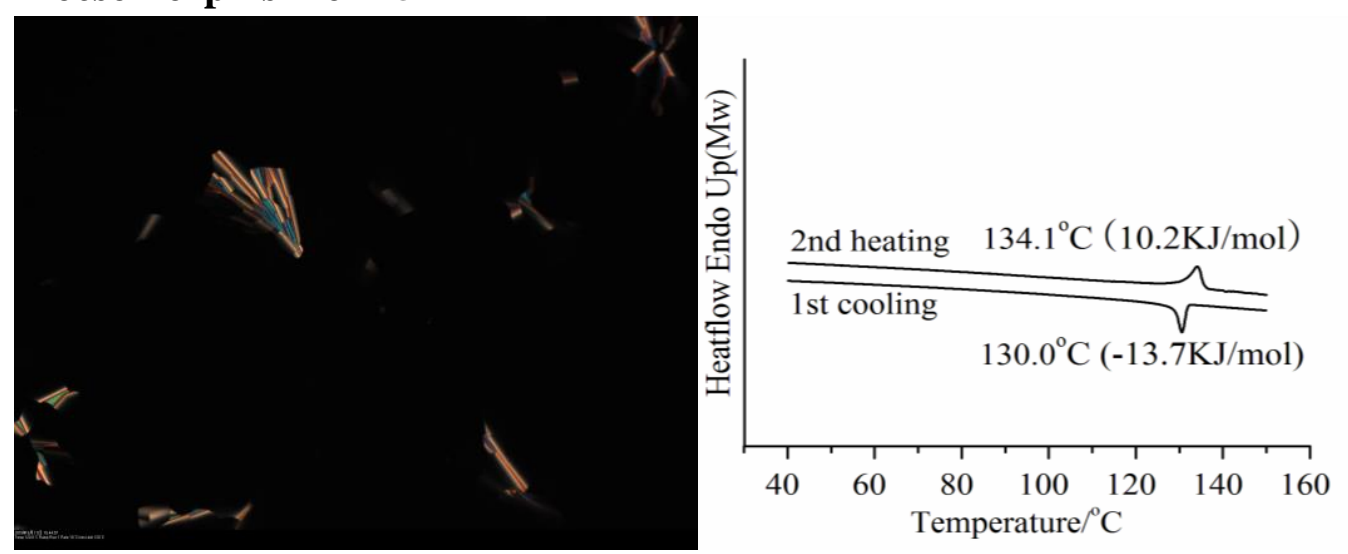

Fig. 65S Fan-shaped texture observed by POM with $90^{\circ}$ angle of compound T5D11 sandwiched between clean glass slides on cooling from isotropic phase at $124^{\circ} \mathrm{C}(\mathrm{left})$; DSC trace of compound T5D11 run at $10^{\circ} \mathrm{Cmin}^{-1}$ under $\mathrm{N}^{2}$ (right).

\section{Mesomorphism of T5D12}

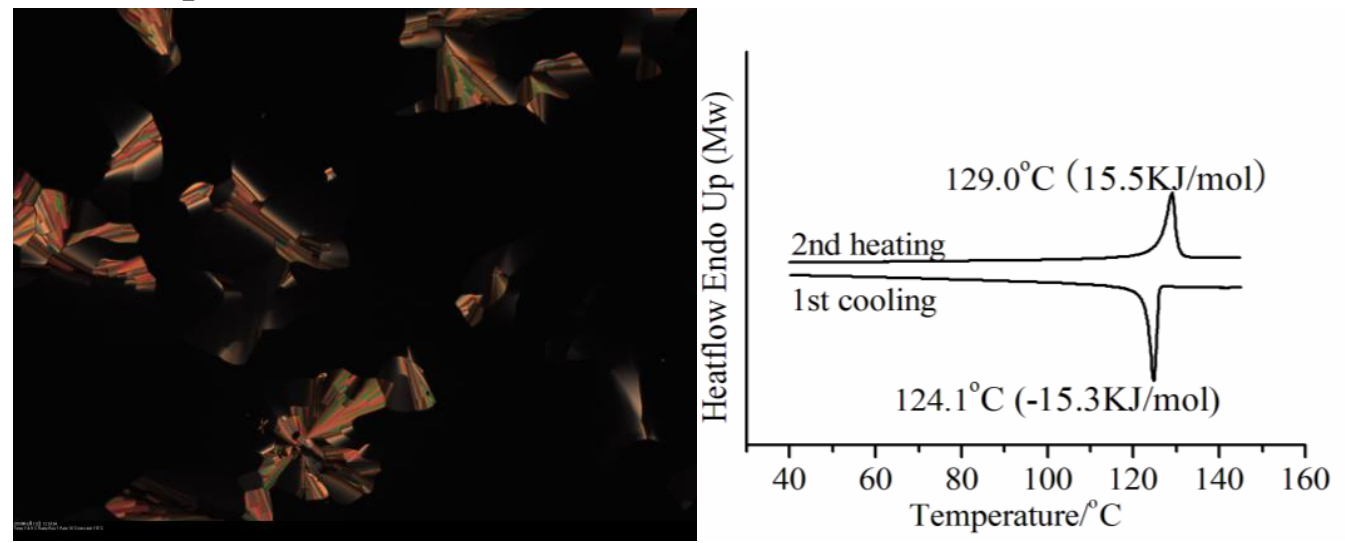

Fig. 66S Fan-shaped texture observed by POM with $90^{\circ}$ angle of compound T5D12 sandwiched between clean glass slides on cooling from isotropic phase at $115^{\circ} \mathrm{C}(\mathrm{left})$; DSC trace of compound T5D12 run at $10^{\circ} \mathrm{Cmin}^{-1}$ under $\mathrm{N}^{2}$ (right). 